\title{
Controversies and pitfalls in diagnosing Huntington's Disease
}

Citation for published version (APA):

Oosterloo, M. (2020). Controversies and pitfalls in diagnosing Huntington's Disease. [Doctoral Thesis, Maastricht University]. ProefschriftMaken. https://doi.org/10.26481/dis.20201106mo

Document status and date:

Published: 01/01/2020

DOI:

10.26481/dis.20201106mo

Document Version:

Publisher's PDF, also known as Version of record

\section{Please check the document version of this publication:}

- A submitted manuscript is the version of the article upon submission and before peer-review. There can be important differences between the submitted version and the official published version of record.

People interested in the research are advised to contact the author for the final version of the publication, or visit the DOI to the publisher's website.

- The final author version and the galley proof are versions of the publication after peer review.

- The final published version features the final layout of the paper including the volume, issue and page numbers.

Link to publication

\footnotetext{
General rights rights.

- You may freely distribute the URL identifying the publication in the public portal. please follow below link for the End User Agreement:

www.umlib.nl/taverne-license

Take down policy

If you believe that this document breaches copyright please contact us at:

repository@maastrichtuniversity.nl

providing details and we will investigate your claim.
}

Copyright and moral rights for the publications made accessible in the public portal are retained by the authors and/or other copyright owners and it is a condition of accessing publications that users recognise and abide by the legal requirements associated with these

- Users may download and print one copy of any publication from the public portal for the purpose of private study or research.

- You may not further distribute the material or use it for any profit-making activity or commercial gain

If the publication is distributed under the terms of Article $25 \mathrm{fa}$ of the Dutch Copyright Act, indicated by the "Taverne" license above, 


\section{CONTROVERSIES AND PITFALLS IN DIAGNOSING HUNTINGTON'S DISEASE}

MAYKE OOSTERLOO 
(C) copyright Mayke Oosterloo, 2020

Cover: Maurits Karstkarel

Printing: ProefschriftMaken || www.proefschriftmaken.nl

ISBN 978-94-6380-904-7

All rights reserved. No part of this publication may be reproduced, stored in a retrieval system or transmitted, in any form or by any means, electronic, mechanical, photocopying, recording or otherwise, without prior permission of the author or the copyright-owning journals for previous published chapters. 


\title{
CONTROVERSIES AND PITFALLS IN DIAGNOSING HUNTINGTON'S DISEASE
}

\begin{abstract}
PROEFSCHRIFT
Ter verkrijging van de graad van doctor aan de Universiteit van Maastricht, op gezag van de Rector Magnificus, Prof. Dr. Rianne M. Letschert volgens het besluit van het College van Decanen, in het openbaar te verdedigen op vrijdag 6 november om 10.00 uur.
\end{abstract}

Door

Mayke Oosterloo 


\section{Promotores}

Prof. dr. R.A.C. Roos (LUMC, Leiden)

Prof. dr. C.E.M. de Die-Smulders

\section{Co-promotor}

Dr. E.K. Bijlsma (LUMC, Leiden)

\section{Beoordelingscommissie}

Prof. dr. J.M.G.A Schols (Voorzitter)

Prof. dr. R.J. van Oostenbrugge

Prof. dr. F.R.J. Verhey

Mw. dr. J.A. Kievit (Erasmus MC, Rotterdam)

Dr. R. Reilmann (George Huntington Institut, Münster, Duitsland) 


\section{Table of contents}

$\begin{array}{lll}\text { CHAPTER } 1 \text { General introduction } & 7\end{array}$

CHAPTER 2 Disease onset in Huntington's disease: when is the conversion?

CHAPTER 3 Is there convincing evidence that intermediate repeats in the HTT gene cause Huntington's disease?

CHAPTER 4 Clinical and genetic characteristics of late-onset Huntington's disease

CHAPTER 5 Predictive genetic testing in Huntington's disease: should a neurologist be involved?

CHAPTER 6 Diagnosing juvenile Huntington's disease: an explorative study among caregivers of affected children

CHAPTER 7 General discussion

Summary

Samenvatting

Valorisation

Publications

Dankwoord 


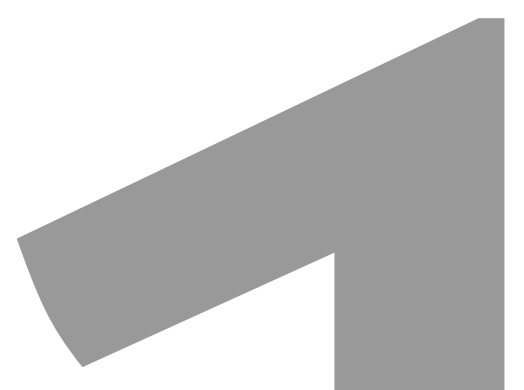

CHAPTER 1 


\section{General introduction}





\section{History}

Huntington's disease (HD) is an autosomal dominant inherited disease characterized by unwanted movements, psychiatric disorders, and cognitive deterioration. It is a rare disorder with a prevalence of 5-10 per 100,000 in the Caucasian population. Patients typically display the first symptoms between the age of 30 and 50 years, with a range of 2 to 85 years. The mean duration of the disease is $17-20$ years (1).

The disease was first described by Waters in 1842. But it was not until 1872, after the paper 'On Chorea' by George Huntington, that it became known as Huntington's chorea. He described a form of chorea in some families living on Long Island, USA, now known as Huntington's Disease (2).

The term chorea originates from the Greek word ' $\chi 0 \rho \varepsilon i \alpha^{\prime}$ ' meaning 'dance'. In the middle ages chorea was known as the dancing mania or the St. Vitus dance, because individuals with this chorea believed they were cured if they touched churches storing the relics of St Vitus. Philippus Aureolus Theophrastus Paracelsus Bombastus von Hohenheim (1493-1541) further differentiated various forms of dancing mania and called them 'choreas'. Thomas Sydenham described an acute form of chorea in children known as Sydenham's chorea. We now know this form of chorea is associated with juvenile rheumatic fever and myocarditis caused by a group A streptococcus pharyngitis (3).

In 1955 the physician Americo Negrette described a large isolated community with HD near lake Maracaibo, Venezuela (4). Nancy Wexler started the Venezuelan Project in 1979 and described the genealogy of this community. The Venezuela project played a crucial role in locating the HD gene. The data of this kindred led to the establishment of linkage with a locus on chromosome 4 in 1983 by Gusella et al. (5). In 1993 the Huntington's disease collaboration research group discovered that HD results from an abnormal and unstable expansion of a Cytosine Adenine Guanine (CAG) trinucleotide repeat in the Huntingtin (HTT) gene on chromosome 4 (6). The size of the CAG repeat is determined by Polymerase Chain Reaction (PCR), with primers that amplify the CAG repeat. The discovery of the HTT gene had tremendous consequences. DNA testing can definitely confirm a suspected clinical diagnosis. Although premanifest diagnosis of at risk person and prenatal diagnosis were already possible due to genetic linkage, it became possible to directly test individuals for carrier status of the HTT gene.

\section{Etiology and pathogenesis}

HD is caused by an abnormal expansion of the CAG repeat in het HTT gene on the short arm of chromosome 4 (6). The HTT gene produces a protein called Huntingtin with a polyglutamine (polyQ) stretch. The cellular function of HTT is still not completely understood (7). The normal Huntingtin protein plays a role in synaptic function and is necessary in the post-embryonic period. Although the function of the protein is not completely clear, there is evidence that the mutant form leads to a gain of function as well as to a loss of function (8). The mutant Huntingtin protein has a misfolded structure and interferes with 
cellular trafficking. The polyQ stretch located at the $\mathrm{N}$ terminus of the protein is cleaved by caspase 6 and forms toxic $\mathrm{N}$-terminal fragments. Toxic effects in the cytoplasm cause aggregation of these fragments. Within the brain inclusion bodies are found in the nucleus and to a lesser extend in the cytoplasm, which are not the primary cause of pathogenesis (7). The aggregation of the mutant protein is believed to play a role in the disease process leading to neuronal dysfunction and finally to loss, mainly of striatal GABAergic medium spiny projection neurons in the striatum (caudate nucleus and putamen). Neuronal loss with their connections leads to cerebral atrophy (9). A CAG repeat size of 40 or more is invariably associated with HD. A CAG repeat of 36 to 39, in the reduced penetrance range, might be associated with a later onset in life and sometimes milder clinical symptoms. CAG repeat lengths between 6 to 27 are not considered associated with HD. A trinucleotide size between 27 and 35 is considered 'intermediate'. The CAG repeats in this range sporadically show instability and have the potential to expand into the disease range within one or more generations, mainly through the paternal line. It was believed that a trinucleotide repeat in the intermediate range cannot cause symptoms of $\operatorname{HD}(25,26)$. However, over the years several case reports have described an HD phenotype with an intermediate CAG repeat, but population-based data are lacking. Intermediate alleles in the HTT gene are relatively common in the general population, with frequency estimates between 1 and $7 \%$ (27-31).

The length of the CAG repeat determines about $70 \%$ of the variance in age at onset and gives no indication about the initial symptom, the course, or the duration of illness. The only correlation now described is the faster weight loss associated with a longer CAG repeat (15). Anticipation is seen in Huntington families in the paternal line of inheritance. This means that the disease has an earlier onset in the next generation due to a longer repeat size, which may eventually lead to pediatric onset HD.

\section{Clinical description, diagnosis and course of the disease}

The course of HD can be divided into a 'premanifest', 'prodromal' and 'manifest' period. In the 'premanifest' period individuals show no symptoms or clinical signs of HD. Individuals may then enter the 'prodromal' period, during which the gradual appearance of subtle motor, cognitive, and or behavioral changes occurs $(10,11)$. However, these changes do not meet the current criteria for a formal diagnosis of HD based on motor onset (12).

The clinical diagnosis of 'manifest' HD is generally based on the appearance of unequivocal motor signs with or without psychiatric or cognitive changes, a positive family history and/ or DNA confirmation. In most cases a combination of the three main signs is present.

The most prominent motor abnormality is chorea. Therefore, for a long-time HD was called Huntington's chorea. However, patients can display all sorts of movement disorders, such as rigidity, dystonia, bradykinesia and tics. Bradykinesia and rigidity often dominate the late stages of the disease and are the most prominent features in pediatric HD (PHD).

A variety of neuropsychiatric symptoms are highly prevalent in HD, including depression, irritability, apathy, perseverations, obsessions, and occasionally psychosis (13). These 
behavioral symptoms have a huge impact in daily life for both patients and caregivers. Retrospectively, irritablity is frequently the first sign of disease (14). On the other hand, apathy is the most prevalent behavioral problem and increases with disease stage.

Cognitive decline is the third core feature of HD. Cognitive problems might be mild even in the very late stage. Slowness of thinking (bradyphrenia) is usually the first sign of cognitive decline. Especially loss of executive functions is striking. Patients lose the ability to plan and therefore organising their lifes becomes very problematic. Furthermore, they develop mental inflexibility and might easily misjudge situations, leading to social problems (1).

Last but not least weight loss, disturbance of sleep and circadian rythm are symptoms of the disease. Unintended weight loss appears in all patients, especially in late stages of the disease. Decrease in caloric intake due to swallowing problems might play a role, but hypermetabolic state is the main cause of weight loss (15). Furthermore, disturbance of sleep and circadian rhythm is present in $90 \%$ of HD patients. This often causes a major problem in daily life and reduces quality of life. The probable cause is atrophy of the hypothalamic area (16). Although there are no evidence based treatments, HD experts recommend to treat sleep disorders with melatonine, sedating antidepressants and/or neuroleptics (17).

$\mathrm{HD}$ is a relentlessly progressive disorder with a mean disease duration of 17-20 years. The disease course can be divided in three clinical stages of functional decline. In stage 1 the patient presents with his/her first clinical symptoms and is still independent in Activities of Daily Living (ADL). In stage 2 the patient starts to become more dependent on others, not only physical but also psychological. In the third and last stage, patients are completely dependent on others and may become bed bound. The most common cause of death in HD patients is pneumonia due to swallowing problems. Also suicide and euthanasia are frequent causes of death in HD.

\section{Age of onset}

The common age of onset in HD is in the range of 30-50 years. It is known that there is a significant inverse correlation between the size of the CAG repeat and the age of onset. The higher the CAG repeat is the earlier disease associated symptoms start.

A small group of patients develop HD in their childhood or adolescence, which is defined as HD with an onset < 21 years of age (18). This was until 2019 called juvenile onset of Huntington's Disease (JHD), but is extremely rare and contributes about 5-6\% of all HD cases, with the percentage ranging from 1-15\% in individual series $(19,20)$. In 2018 the European Huntington's Disease Network (EHDN) juvenile HD working group introduced the term pediatric HD (PHD) which includes young people affected by HD who are currently $<18$ years (21). Clinical presentation in children varies from that in adults. Chorea is uncommon in children with HD especially within the first decade. Most prevalent clinical features at presentation in PHD are cognitive impairment and behavioral changes. Common presenting motor features are rigidity, gait disorder, and oral motor dysfunction (20). The variable and nonspecific clinical presentation, such as declining school performances and behavioral 
disturbance may be confused with disorders such as autism disorders or attention deficit hyperactivity disorder (ADHD). Thus, misdiagnosis and/or diagnostic delay is often occurring.

For a substantial part symptoms and signs start after 60 years of age, so called late-onset HD (LoHD). LoHD is defined as Huntington's Disease Gene Expansion Carriers (HDGECs) displaying their first symptoms and signs after 59 years of age. It is believed that LoHD is not very common, although frequencies in literature vary between $4.4 \%$ and $25 \%$ in small cohorts $(22,23)$. Diagnosing LoHD might be challenging, especially when the family history is negative and chorea is the only feature.

\section{Diagnosis}

The clinical diagnosis of 'manifest' HD is generally based on the appearance of unequivocal motor signs with or without psychiatric or cognitive changes, a positive family history and DNA confirmation. However, estimation of disease onset is challenging. Early motor symptoms are variable in presentation and occurrence. Subtle motor changes may easily be missed or misinterpreted during neurological examination (24) and are dependent on the experience of the person who performs the clinical examination. Furthermore, motor symptoms vary from day to day, hour to hour and are very sensitive to stress. All this makes it difficult to determine the exact moment of motor onset of HD. Although the motor onset is believed to confirm the clinical diagnosis of $\mathrm{HD}$, cognitive and behavioral changes can be seen in premanifest HDGECs up to more than 10 years before estimated HD diagnosis (10). Last but not least, motor manifest patients as well as spouses often find it difficult to remember when the abnormal movements started, as the changes are very gradually appearing. Another reason can be that due to unawareness of illness and/or denial, the first manifestation is not noted. This makes it very complex, almost impossible, to adequately estimate onset of disease.

\section{Differential Diagnosis}

$\mathrm{HD}$ is the commonest inherited cause of chorea. However, $1 \%$ of the patients have the cardinal features of HD, but do not have the HD mutation. Another (not HD) diagnosis is made in only $2 \%$ of these patients (25). The differential diagnosis of HD phenocopies is long with Spinocerebellar Ataxia 17 (SCA17) being the most common phenocopy. In 2018 frontotemporal dementia caused by a mutation in the C9orf72 gene was found to be the second most important HD phenocopy in the Caucasian population (26). Other HD phenocopies are Dentatorubral-palliodluysian atrophy (DRPLA) which is common in Japan, Huntington's Disease-Like 1 (HDL-1) an inherited prion disorder described in a Swedish and French population (27) and Huntington's Disease-Like 2 (HDL-2) which is generally rare, except in individuals of African ancestry (28). Apart from genetic causes, structural lesions, autoimmune disorders, infections, metabolic disturbances and toxins and drugs (especially antipsychotics) can cause chorea. 


\section{Genetic counseling and reproductive options}

Before the discovery of the HTT gene in 1993, predictive DNA testing was possible on the basis of genetic linkage analysis since 1983 . This was only possible in persons with a positive family history for HD. Nowadays direct molecular testing of the HTT gene is possible. The children of an HD patient have a $50 \%$ chance of risk to inherit the disease. Despite the high level of interest amongst HD family members at risk, predictive testing rates remain low. The decision to take the test is the sole choice of the person at risk. Psychosocial support and counseling is available before and after the test procedure. This means that the patient is appropriately counseled about the implications of genetic testing and possible test outcomes. An abnormal (predictive) DNA test result may have important emotional sequelae for the patients and his or her family members. Also, social-economic consequences, such as employment, social security and insurance and other problems may occur as a consequence of disclosing the test result. In some clinics across the world the predictive testing team consists of not only the clinical geneticist, genetic counselor and/ or social worker or psychologist, but also a neurologist or psychiatrist. These specialists will see the person at risk before predictive testing, according the guidelines of the Huntington Association and the World Federation of Neurology Research Group on Huntington's chorea (29). This is not always a standard part of predictive counseling as participants are believed to be without symptoms yet.

HDGECs have a few reproductive options to prevent transmitting HD to their offspring. They can decide not to have children, opt for adoption or use donor gametes. If they prefer genetically related offspring, they can opt for prenatal diagnosis or preimplantation genetic testing (PGT). In prenatal diagnosis, placental DNA material representing the fetal DNA is tested for HD. The foetal DNA is obtained by a chorionic villus (placental) biopsy, at around 11-12 weeks of gestational age or by amniocentesis, from 16 weeks on PGT uses in vitro fertilization (IVF) followed by selection of embryos without an abnormal repeat expansion (30). PGT is prohibited in some countries, mainly because of the late onset of disease and the sensitive nature of testing embryo's. Furthermore, for at-risk individuals who do not want to be informed about their status, exclusion testing may be an option. Marker testing using DNA of the at-risk individual and his/her spouse is used to distinguish the HD alleles derived from different grandparents, without information being disclosed about the CAG repeats of the at-risk individual.

\section{Treatment}

Motor symptoms can be treated with medication such as tetrabenazine or neuroleptic drugs (31). Behavioral and psychiatric symptoms can be treated by SSRI and or neuroleptic drugs (17). Furthermore, non-pharmatherapeutical treatments, such as physiotherapy, psychological support and speech and language therapy may attribute to sustain quality of life (32). During the course of disease, patients require more care and become more and more dependent on others for daily life activities. In many cases this results in day-care and finally nursing home admission. In the Netherlands, specialized care homes provide custom made care for HD patients for those still living at home and those who reside in a nursing home. 
Up till now there is no causal or disease modifying treatment. A reduction of the mutant HTT levels is supposed to alleviate disease onset or progression. The first international disease slowing drug trial ever using intrathecal injected antisense oligonucleotides in 46 early manifest patients showed a lowering of the overall amount of the Huntingtin protein and no severe side effects (33). However, these are preliminary data and it is unknown what the long-term effects of these treatments will be. Furthermore, long-term intrathecal administration is not desirable from patient perspective. Therefore, future development of other disease modifying treatments and other ways to administrate such treatments is important.

\section{Aim of this thesis}

The general aim of this thesis was to investigate the controversies and pitfalls in diagnosing HD. Diagnosing HD in general and in several sub-groups in particular may be challenging and asks a lot of clinical experience. An untimely diagnosis or misdiagnosis is not without harm and may cause a lot of distress in these HD families. Providing more and better insight in diagnosing and the diagnostic process in HD, might benefit the HD population in general.

\section{The specific aims were:}

1. to study the natural course of premanifest participants in the Enroll HD study, to determine the accuracy of estimating disease onset when using the international diagnostic criteria and Unified Huntington's Disease Rating Scale (UHDRS). Disease onset and diagnosis of the disease may not always correspond with one another and depend on what symptoms are marked as disease onset. We investigated patients who converted from premanifest to manifest on clinical symptoms and diagnostic confidence levels and compared them with those who are still premanifest (chapter $\mathbf{2}$ ).

2. to study and review the clinical manifestations of persons with intermediate repeat size. It is sometimes believed that this group will never develop symptoms and signs of HD, however case reports claim otherwise. Therefore, we investigated whether it is realistic to presume that intermediate repeat alleles may exceptionally give a clinical picture of HD (chapter 3).

3. to study the clinical and genetic characteristics of late-onset HD ( $>59$ years). Late-onset $\mathrm{HD}$ is believed to be uncommon and different from common onset HD. However, we relatively frequently observed patients with a presumed late-onset in our outpatient clinics. Therefore, we investigated if late-onset HD differs from common onset in a large European cohort (Registry) (chapter 4).

4. to formulate recommendations for HD clinics at which moment in the predictive testing trajectory a neurologists' judgment is desirable. To do so, we investigated the experience and wishes of HD risk carriers who opt for predictive testing (chapter 5).

5. to study the experience of parents regarding the diagnostic process of pediatric onset of $\mathrm{HD}$ in the Netherlands. The variable and nonspecific clinical presentation and confusion 
with other disorders leads to the chance of misdiagnosis and/or diagnostic delay. We provide an overview if and how we can optimize the diagnostic process in children with PHD (chapter 6). 


\section{Reference List}

1. Roos RA. Huntington's disease: a clinical review. Orphanet journal of rare diseases. 2010;5(1):40.

2. Huntington G. On chorea. George Huntington, M.D. The Journal of neuropsychiatry and clinical neurosciences. 2003;15(1):109-12.

3. Vale TC, Cardoso F. Chorea: A Journey through History. Tremor Other Hyperkinet Mov (N Y). $2015 ; 5$.

4. Okun MS, Thommi N. Americo Negrette (1924 to 2003): diagnosing Huntington disease in Venezuela. Neurology. 2004;63(2):340-3.

5. Gusella JF, Wexler NS, Conneally PM, Naylor SL, Anderson MA, Tanzi RE, et al. A polymorphic DNA marker genetically linked to Huntington's disease. Nature. 1983;306(5940):234-8.

6. A novel gene containing a trinucleotide repeat that is expanded and unstable on Huntington's disease chromosomes. The Huntington's Disease Collaborative Research Group. Cell. 1993;72(6):971-83.

7. Ross CA, Tabrizi SJ. Huntington's disease: from molecular pathogenesis to clinical treatment. Lancet Neurol. 2011;10(1):83-98.

8. Rubinsztein DC. Lessons from animal models of Huntington's disease. Trends Genet. 2002;18(4):202-9.

9. Vonsattel JP, DiFiglia M. Huntington disease. J Neuropathol Exp Neurol. 1998;57(5):369-84.

10. Tabrizi SJ, Langbehn DR, Leavitt BR, Roos RA, Durr A, Craufurd D, et al. Biological and clinical manifestations of Huntington's disease in the longitudinal TRACK-HD study: cross-sectional analysis of baseline data. Lancet Neurol. 2009;8(9):791-801.

11. Tabrizi SJ, Scahill RI, Owen G, Durr A, Leavitt BR, Roos RA, et al. Predictors of phenotypic progression and disease onset in premanifest and early-stage Huntington's disease in the TRACKHD study: analysis of 36-month observational data. Lancet neurology. 2013;12(7):637-49.

12. Reilmann R, Leavitt BR, Ross CA. Diagnostic criteria for Huntington's disease based on natural history. Movement disorders : official journal of the Movement Disorder Society. 2014;29(11):1335-41.

13. van Duijn E, Craufurd D, Hubers AA, Giltay EJ, Bonelli R, Rickards H, et al. Neuropsychiatric symptoms in a European Huntington's disease cohort (REGISTRY). Journal of neurology, neurosurgery, and psychiatry. 2014;85(12):1411-8.

14. van Duijn E, Kingma EM, van der Mast RC. Psychopathology in verified Huntington's disease gene carriers. The Journal of neuropsychiatry and clinical neurosciences. 2007;19(4):441-8. 
15. Aziz NA, van der Burg JM, Landwehrmeyer GB, Brundin P, Stijnen T, Group ES, et al. Weight loss in Huntington disease increases with higher CAG repeat number. Neurology. 2008;71(19):1506-13.

16. van Wamelen DJ, Roos RA, Aziz NA. Therapeutic strategies for circadian rhythm and sleep disturbances in Huntington disease. Neurodegenerative disease management. 2015;5(6):549-59.

17. Anderson KE, van Duijn E, Craufurd D, Drazinic C, Edmondson M, Goodman N, et al. Clinical Management of Neuropsychiatric Symptoms of Huntington Disease: Expert-Based Consensus Guidelines on Agitation, Anxiety, Apathy, Psychosis and Sleep Disorders. Journal of Huntington's disease. 2018;7(3):355-66.

18. Bruyn GW. In: Handbook of Clinical Neurology. Huntington's chorea. Historical, clinical and laboratory synopsis. PJ Vinken GB, editor. Amsterdam: Elsevier; 1968.

19. Koutsis $G$, Karadima G, Kladi A, Panas M. The challenge of juvenile Huntington disease: to test or not to test. Neurology. 2013;80(11):990-6.

20. Nance MA, Myers RH. Juvenile onset Huntington's disease--clinical and research perspectives. Mental retardation and developmental disabilities research reviews. 2001;7(3):153-7.

21. Quarrell OWJ, Nance MA, Nopoulos P, Reilmann R, Oosterloo M, Tabrizi SJ, et al. Defining pediatric huntington disease: Time to abandon the term Juvenile Huntington Disease? Movement disorders : official journal of the Movement Disorder Society. 2019.

22. Cornejo-Olivas MR, Inca-Martinez MA, Espinoza-Huertas K, Veliz-Otani D, Velit-Salazar MR, Marca $\mathrm{V}$, et al. Clinical and Molecular Features of Late Onset Huntington Disease in a Peruvian Cohort. Journal of Huntington's disease. 2015;4(1):99-105.

23. Sipila JOT, Kauko T, Paivarinta M, Majamaa K. Comparison of mid-age-onset and late-onset Huntington's disease in Finnish patients. Journal of neurology. 2017.

24. de Boo G, Tibben A, Hermans J, Maat A, Roos RA. Subtle involuntary movements are not reliable indicators of incipient Huntington's disease. Movement disorders : official journal of the Movement Disorder Society. 1998;13(1):96-9.

25. Wild EJ, Tabrizi SJ. The differential diagnosis of chorea. Practical neurology. 2007;7(6):360-73.

26. Martins J, Damasio J, Mendes A, Vila-Cha N, Alves JE, Ramos C, et al. Clinical spectrum of C9orf72 expansion in a cohort of Huntington's disease phenocopies. Neurological sciences : official journal of the Italian Neurological Society and of the Italian Society of Clinical Neurophysiology. 2018;39(4):741-4.

27. Stevanin G, Fujigasaki H, Lebre AS, Camuzat A, Jeannequin C, Dode C, et al. Huntington's diseaselike phenotype due to trinucleotide repeat expansions in the TBP and JPH3 genes. Brain : a journal of neurology. 2003;126(Pt 7):1599-603. 
28. Margolis RL, Holmes SE, Rosenblatt A, Gourley L, O'Hearn E, Ross CA, et al. Huntington's Diseaselike 2 (HDL2) in North America and Japan. Annals of neurology. 2004;56(5):670-4.

29. MacLeod R, Tibben A, Frontali M, Evers-Kiebooms G, Jones A, Martinez-Descales A, et al. Recommendations for the predictive genetic test in Huntington's disease. Clin Genet. 2013;83(3):221-31.

30. de Die-Smulders CE, de Wert GM, Liebaers I, Tibben A, Evers-Kiebooms G. Reproductive options for prospective parents in families with Huntington's disease: clinical, psychological and ethical reflections. Human reproduction update. 2013;19(3):304-15.

31. Huntington Study G. Tetrabenazine as antichorea therapy in Huntington disease: a randomized controlled trial. Neurology. 2006;66(3):366-72.

32. Veenhuizen R, Nijsten $H$, van Roosmalen $P$, Lammertsen $K$, Stor $T$, de Jager $L$, et al. Huntington's Disease Outpatient Clinic for Functional Diagnosis and Treatment: Coming to Consensus: How Long Term Care Facility Procedures Complement Specialist Diagnosis and Treatment. Journal of Huntington's disease. 2018;7(2):189-91.

33. Tabrizi SJ, Leavitt BR, Landwehrmeyer GB, Wild EJ, Saft C, Barker RA, et al. Targeting Huntingtin Expression in Patients with Huntington's Disease. The New England journal of medicine. 2019;380(24):2307-16. 



\section{CHAPTER 2}




\section{Disease onset in Huntington's disease: when is the conversion?}

Mayke Oosterloo, Bianca TA de Greef, Emilia K Bijlsma, Alexandra Durr, Sarah J Tabrizi, Carlos Estevez-Fraga, Christine EM de Die-Smulders, and Raymund AC Roos. 


\section{Abstract}

Background: Determination of disease onset in Huntington's Disease is made by clinical experience. The Diagnostic Confidence Level is an assessment regarding the certainty about the clinical diagnosis based on motor signs. A level of 4 means the rater has $\geq 99 \%$ confidence motor abnormalities are unequivocal signs of disease. However, it does not state which motor abnormalities are signs of disease and how many must be present.

Objective: our aim is to explore how accurate the Diagnostic Confidence Level is in estimating disease onset using the Enroll-HD dataset. For clinical disease onset we use a cut-off total motor score $>5$ of the Unified Huntington Disease Rating Scale. This score is used in the TRACK-HD study, with $\leq 5$ indicating no substantial motor signs in premanifests.

Methods: At baseline premanifest participants who converted to manifest (converters) and non-converters were compared for clinical symptoms and diagnostic confidence level. Clinical symptoms and diagnostic confidence levels were longitudinally displayed in converters.

Results: Of 3,731 eligible participants, 455 were converters and 3,276 non-converters. Baseline Diagnostic Confidence Levels were significantly higher in converters compared to non-converters ( $p<.001) .232(51 \%)$ converters displayed a baseline motor score $>5$ (mean 6.7). Converters had significantly more baseline clinical symptoms, and higher disease burden compared to non-converters $(p<.001)$. Diagnostic Confidence Level before disease onset ranged between 2 and 3 in converters.

Conclusions: According to this data the Diagnostic Confidence Level is not an accurate instrument to determine phenoconversion. With trials evaluating disease modifying therapies it is important to develop more reliable diagnostic criteria. 


\section{Introduction}

Huntington's disease (HD) is an autosomal dominant neurodegenerative disease characterized by involuntary movements, psychiatric disorders, and cognitive deterioration. HD results from an unstable and expanded CAG trinucleotide repeat in the Huntingtin (HTT) gene on chromosome 4 (1). A CAG repeat size of 36 or more is associated with HD. The age that symptoms and signs become manifest is called the age at onset (AO). The AO has a mean of 40 years with a tremendous spread from 2-80 years (2). The importance of a precise determination of the AO plays at several levels. Firstly, one wants to make an accurate clinical diagnosis in patient care; secondly a precise $A O$ is needed for participation in clinical trials, and thirdly the moment disease inhibiting drugs become available one needs to estimate when to start medication.

The clinical diagnosis of HD is predominantly made on the basis of characteristic motor signs often with a positive family history and/or confirmed by DNA analysis. For clinical follow-up and research purposes the Unified Huntington's Disease Rating Scale (UHDRS) was designed (3). The UHDRS contains a motor (Total Motor Score (TMS)), psychiatric, psychological and functional part. Based on the motor signs a four item assessment regarding the certainty about the clinical diagnosis was added: the Diagnostic Confidence Level (DCL). By definition in this scale only a person with a DCL of 4 receives the formal diagnosis of manifest HD, meaning that the $A O$ is determined at that time point. $A D C L$ of 4 means that the motor abnormalities are unequivocal signs of $\mathrm{HD}(\geq 99 \%$ confidence of the rater) and not otherwise explained by another movement disorder. However, several remarks can be made: 1) the DCL does not state which motor abnormalities are unequivocal signs of HD and 2) does not mention how many motor signs must be present. In other words, there is no cut-off point on the TMS (range 0-124). An operational definition that guides the clinician is lacking. The TMS rates movement disorder motor abnormalities. This suggests that healthy persons, including premanifest persons are supposed to have a TMS of 0 . Otherwise, this person should have a movement disorder other than HD. In the TRACK-HD study a defined cut-off total motor score of 5 or less in the UHDRS, was chosen, indicating no substantial motor signs in premanifest gene carriers (11). This allows Huntington's Disease Gene Expansion Carriers (HDGECs) to have some motor abnormalities without being called manifest yet. However, this cut-off is not used in the current diagnostic criteria.

Early motor symptoms are variable in presentation and occurrence. Subtle motor changes may easily be missed during neurological examination (4) and recognition is dependent on the experience of the person who performs the clinical examination. All this makes it difficult to determine the exact moment of motor onset of HD. 
Illustration: A now 67-year-old female noticed at the age of 28 years incidental finger twitches on her left hand. She was aware of her $50 \%$ genetic risk for HD, but denied and forgot the movements. In her mid-forties she noticed a little instability in her left leg. Over the years these movements remained present. Her spouse noticed a slow increase of unwanted movements over the last five years without influencing her daily life activities. Neurological examination revealed generalized choreatic movements and a slowness in thinking. There were no other signs of Huntington's disease. DNA analysis confirmed the diagnosis. Should we conclude that her disease age at onset is $28,45,62$, or 67 years?

Furthermore, cognitive and behavioral changes are frequently mentioned by HDGECS before the start of motor symptoms and signs $(5,6)$. The PREDICT-HD and TRACK-HD data show that not only subtle motor, but also cognitive and behavioral changes as well as brain atrophy on MRI are present in premanifest HDGECs up to more than 10 years from estimated HD diagnosis (7-13). However, the findings of PREDICT-HD are compromised by subjects in the premanifest cohort exhibiting UHDRS-TMS scores ranging up to above 20. Significant cognitive changes in premanifest participants $>10$ years form predicted onset in TRACKHD were seen on the Stroop Word Reading test compared to controls. However, during 36-month follow up no cognitive changes were seen in this group of participants. These early neuropsychiatric symptoms contribute to a decline in daily functioning and are often the most distressing aspects of HD for patients, families as well as their caregivers $(13,14)$. The current version of the UHDRS does not ask for a DCL rating that expands to non-motor features $(3,15,16)$. This means the investigator is not able to rate the $D C L$ as 4 based on all elements of the UHDRS and scoring is restricted to the motor part.

And last but not least, motor manifest patients often find it difficult to remember, due to a lack of disease insight or denial, when the first motor symptoms started. Sometimes they and their spouse do not recognize the movements or deny symptoms and signs of the disease. This makes it almost impossible to adequately estimate onset of disease.

Therefore, our aim is to find out how consistent the TMS $>5$ and DCL of 4 relate to one another in estimating disease onset using the Enroll-HD dataset. For clinical disease onset we use the TRACK-HD cut-off score of TMS $>5$. Furthermore, we compare Enroll-HD participants who converted from premanifest to manifest (converters) with those who are still premanifest (non-converters) and show a follow-up of DCL, behavioral, cognitive and motor symptoms in the converters group.

\section{Methods}

The data were extracted from the 'live' Enroll-HD database on October 31, 2018 (Periodic Dataset 4 (PDS4). Enroll-HD is a global clinical research platform designed to facilitate clinical research in Huntington's disease (19). Core data sets are collected annually on all research participants as part of this multi-center longitudinal observational study of Huntington's disease. Data are monitored for quality and accuracy using a risk-based monitoring approach. All sites are required to obtain and maintain local Ethics Committee approvals. This dataset 
not only includes data gathered from the Enroll-HD study, but also integrates data from REGISTRY 2 and 3, as well as Ad Hoc data (data, drawn from a variety of different sources, gathered prior to a participant's enrollment into Enroll-HD) $(20,21)$. All participants provided written informed consent for this observational study. The HTT CAG genotyping was carried out at the local genetic laboratories of the sites as well as at a central biorepository facility (Biorep). Data collection adhered to a standard protocol including electronic case report forms and used identical study protocols for the assessment and sampling of biomaterials. At baseline, HD mutation carriers are classified as manifest/motor-manifest HD (carriers with clinical features that are regarded in the opinion of the investigator as diagnostic of HD) or premanifest/premotor-manifest HD (carriers without clinical features regarded as diagnostic of HD). Participants were evaluated by a specialist with experience in HD. The study site raters are trained, evaluated, and certified annually to minimize inter-rater and intra-rater variability (https://hdtraining.enroll-hd.org/).

\section{Participants and clinical assessments}

Only participants who entered the database as premanifest were included in this study. The PDS4 dataset contains participants aged $\geq 18$ years with CAG information. Clinical characteristics (motor, behavior and cognitive) and age of onset were documented.

The time of diagnosis was documented by the clinician converting the participant from premanifest to manifest in the database. Participants with unknown category (manifest or premanifest) were excluded. The disease-burden score is calculated from a formula (age $x$ [CAG - 35.5]). This score gives an a posteriori estimate of an individual's lifetime exposure to mutant huntingtin, at any age, before and after motor onset (22). To provide insight in which symptoms of the disease are most frequently reported at the onset of disease, motor and cognitive signs were scored using the UHDRS (3). A UHDRS TMS $>5$ was used for clinical disease onset (maximum score 124). For cognition, we used the cognitive UHDRS composite score (UHDRS total corrected for letter fluency, symbol digit modalities test, trail making test, and Stroop sub-scores for word reading, color naming, and interference), with lower scores indicating lower performance. For behavior, we used the problem behavior assessment short form (PBAs) (23) or the behavior section of the UHDRS which consists of items evaluating several behavioral signs and symptoms (depressed mood, anxiety, suicidal ideation, irritability, aggressive behavior, apathy, perseverative/obsessive-compulsive behavior, delusions and hallucinations). In both assessments participants are ranked on severity (0-4) with higher scores indicating higher degree of behavioral impairment. The item of 'disoriented behavior' in the PBAs is not used in the behavior section of the UHDRS, whereas the item 'low self-esteem/guilt' is only used in the UHDRS. Therefore, these two items are not used for analysis. Perseverative behavior and obsessive-compulsive behavior were combined because the PBAs and the UHDRS use different sub-items. The disease stage was obtained using the $D C L$ which ranges from 0 to $4: 0=$ normal; $1=$ nonspecific motor abnormalities (less than $50 \%$ confidence); $2=$ motor abnormalities that may be signs of HD (50 - $89 \%$ confidence); $3=$ motor abnormalities that are likely signs of HD (90 - $98 \%$ confidence); and $4=$ motor abnormalities that are unequivocal signs of $\mathrm{HD}(\geq 99$ \% confidence). Participants with an unknown DCL at baseline were excluded. If the rater changed the $\mathrm{DCL}$ of a participant to 4 during follow up, the database does not automatically 
changes the participant from premanifest to manifest. This means the rater has to do this manually.

Functionality was documented using the total functional capacity (TFC) scores with a maximum score of 13 , with lower scores indicating a lower functional status. Comorbidities were documented according to the ICD-10 code. Participants were followed up on a yearly basis according to the Enroll-HD protocol.

\section{Statistical analysis}

Baseline characteristics such as age of onset, gender, and CAG repeat size (both alleles) were recorded/counted and the frequency of symptoms and signs in each group, converters and non-converters, were calculated. Differences between the two groups were tested with the t-test for continuous variables and the chi-square or Fisher exact test (if necessary) for the categorical variables.

For the natural course of symptoms (including cognition, behavior, and motor signs and symptoms), data were gathered and visualized by plotting all data separately as well as looking at a trend. All available measurements of all participants were analyzed. All analyses were carried out using R. P-values of $<0.05$ were considered as statistically significant.

\section{Results}

\section{Baseline analysis}

The PDS4 consisted of 15,301 participants generating a total of 50,452 visits. Categorization of the participant (premanifest or manifest) was not available for Ad Hoc and Registry 2. Therefore, these data were not used for analysis. Of all 15,301 participants 3,528 also participated in Registry 3.

A total of 3,775 participants were premanifest at enrollment. Participants with unknown category (manifest or still premanifest) $(n=13)$ and unknown $D C L$ at baseline $(n=9)$ were excluded. Twenty-two participants who were categorized as premanifest with a DCL of 4 (motor abnormalities that are unequivocal signs of HD) at presentation were excluded from analysis. Of the remaining 3,731 premanifest participants $455(12.2 \%)$ became manifest (converters) during follow up and 3,276 remained premanifest (non-converters) (Figure 1). 


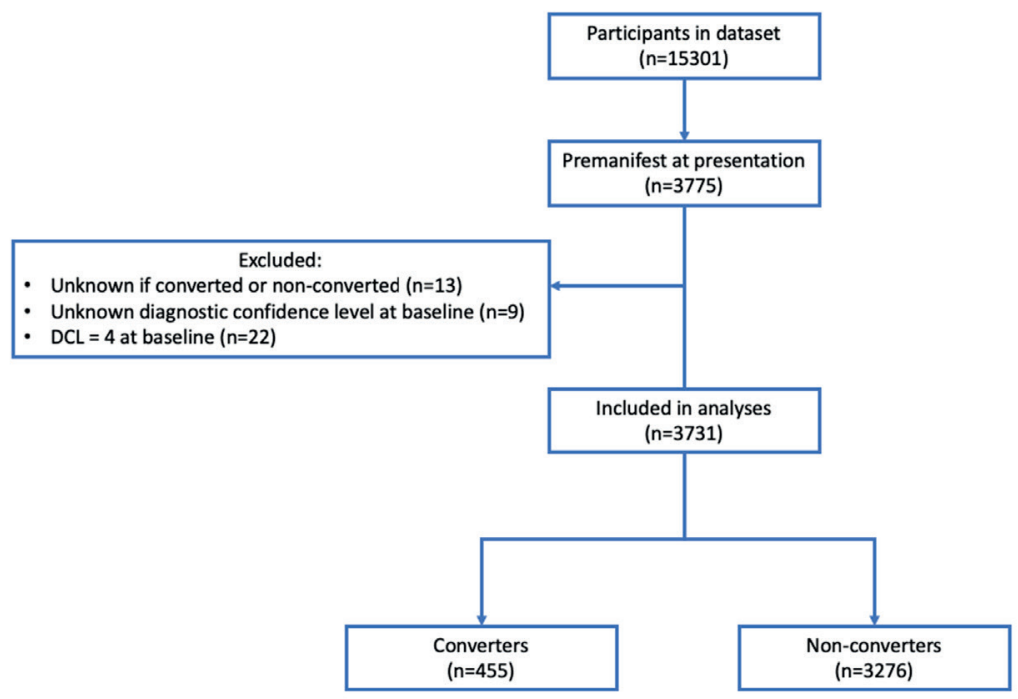

Figure 1. Flow Chart of inclusion

$\mathrm{DCL}=$ Diagnostic Confidence Interval

The baseline characteristics of all participants, stratified by disease category are given in Table 1. 232 (51\%) converters displayed a baseline TMS $>5$ (mean 6.7). The number of participants with a baseline TMS $\leq 5$ in the converters ( $n=223,49,1 \%$ ) was significantly lower than in the non-converters $(n=2,732,83.7 \%)(p<0.001)$. The baseline disease burden score was significantly higher in the converters (mean 326.4; SD 80.8) compared to the nonconverters (mean 246.9; SD 80.6) $(p<0.001)$. The mean number of visits was significantly higher in the converters (mean 3.31; SD 1.31) compared to non-converters (mean 2.4; SD 1.3) $(p<0.001)$. The years of visits in the converters ranged from a maximum of 12 years before and a maximum of 4 years after becoming manifest. The DCL (range $0-4$ ) at baseline was significantly higher in the converters compared to the non-converters $(p<0.001)$ (Table 1 and Figure 2). 
Table 1. Baseline characteristics participants stratified by non-converters and converters

\begin{tabular}{|c|c|c|c|c|}
\hline & $\begin{array}{c}\text { Non-converters } \\
\mathrm{n}=3276 \\
\end{array}$ & $\begin{array}{c}\text { Converters } \\
n=455\end{array}$ & p-value & Missing \\
\hline Age at first visit, mean (SD) & $38.8(11.9)$ & $44.0(12.1)$ & $<0.001$ & $2 / 0$ \\
\hline Sex, male (\%) & $1334(40.7)$ & $189(41.5)$ & 0.7394 & $0 / 0$ \\
\hline CAG repeats size high, mean (SD) & $42.3(2.7)$ & $43.6(3.3)$ & $<0.001$ & $0 / 0$ \\
\hline CAG repeats size low, mean (SD) & $18.3(2.9)$ & $18.2(2.8)$ & 0.5375 & $45 / 11$ \\
\hline Baseline Disease burden score, mean (SD) & $246.93(80.6)$ & $326.37(80.8)$ & $<0.001$ & $2 / 0$ \\
\hline Number of visits, mean (SD) & $2.41(1.3)$ & $3.31(1.3)$ & $<0.001$ & $0 / 0$ \\
\hline Baseline motor score, mean (SD) & $2.6(3.7)$ & $6.7(6.6)$ & $<0.001$ & $11 / 1$ \\
\hline Baseline total motor score $\leq 5(\%)$ & $2732(83.7)$ & $223(49.1)$ & $<0.001$ & $11 / 1$ \\
\hline DCL at baseline, yes (\%) & & & $<0.001$ & $0 / 0$ \\
\hline $0=$ Normal & $2069(63.2)$ & $120(26.4)$ & & \\
\hline $\begin{array}{l}\text { 1=Non-specific motor abnormalities ( }<50 \% \\
\text { confidence) }\end{array}$ & $787(24.0)$ & $151(33.2)$ & & \\
\hline $\begin{array}{l}2=\text { Motor abnormalities that may be signs of HD } \\
\text { (50-89\% confidence) }\end{array}$ & $282(8.6)$ & $93(20.4)$ & & \\
\hline $\begin{array}{l}\text { 3=Motor abnormalities that are likely signs of HD } \\
\text { (90-98\% confidence) }\end{array}$ & $138(4.2)$ & $91(20.0)$ & & \\
\hline $\begin{array}{l}4=\text { Motor abnormalities that are unequivocal } \\
\text { signs of HD ( } \geq 99 \% \text { confidence) }\end{array}$ & - & - & & \\
\hline $\begin{array}{l}\text { Baseline UHDRS Total functional Capacity, } \\
\text { mean (SD) }\end{array}$ & $12.8(0.9)$ & $12.4(1.3)$ & $<0.001$ & $8 / 1$ \\
\hline $\begin{array}{l}\text { Baseline UHDRS Functional Assessment, } \\
\text { mean (SD) }\end{array}$ & $24.7(1.3)$ & $24.3(2.0)$ & $<0.001$ & $65 / 8$ \\
\hline \multicolumn{5}{|l|}{ Cognitive assessments } \\
\hline SDMT total correct, mean (SD) & $50.3(11.9)$ & $41.6(12.4)$ & $<0.001$ & $197 / 44$ \\
\hline Verbal Fluency Test (Category) total correct & $21.4(5.7)$ & $19.1(6.2)$ & $<0.001$ & $226 / 61$ \\
\hline Verbal Fluency Test (Letters) total correct & $39.5(12.7)$ & $34.0(13.1)$ & $<0.001$ & $643 / 82$ \\
\hline Stroop colour naming total correct & $73.1(14.6)$ & $65.2(15.3)$ & $<0.001$ & $213 / 48$ \\
\hline Stroop reading test total correct & $94.0(17.9)$ & $84.0(19.8)$ & $<0.001$ & $210 / 49$ \\
\hline Stroop interference test total correct & $43.6(11.1)$ & $38.0(11.3)$ & $<0.001$ & $372 / 61$ \\
\hline Trailmaking Test Part A total correct & $24.7(2.7)$ & $25.0(0.1)$ & $<0.001$ & $934 / 158$ \\
\hline Trailmaking Test Part B total correct & $24.5(3.8)$ & $24.6(2.3)$ & 0.8344 & $936 / 163$ \\
\hline \multicolumn{5}{|l|}{ PBA-s (or UHDRS-B*) } \\
\hline \multicolumn{5}{|l|}{ Depression } \\
\hline Depressed mood (3120/290) & 1309 (43.5) & $214(53.2)$ & $<0.001$ & $268 / 53$ \\
\hline Suicidal ideation (3120/290) & $190(6.3)$ & $40(10.0)$ & 0.0064 & $268 / 53$ \\
\hline Anxiety (3119/290) & $1557(51.8)$ & $208(51.7)$ & 0.9886 & $269 / 53$ \\
\hline \multicolumn{5}{|l|}{ Irritability/Agression } \\
\hline Irritability (3118/290) & $1276(42.4)$ & $194(48.4)$ & 0.0240 & $269 / 54$ \\
\hline Angry/aggressive (3118/290) & $570(19.0)$ & $89(22.2)$ & 0.1229 & $269 / 54$ \\
\hline \multicolumn{5}{|l|}{ Psychosis } \\
\hline Delusions (3118/290) & $70(2.3)$ & $13(3.2)$ & 0.2688 & $270 / 53$ \\
\hline Hallucinations $(3118 / 290)$ & $20(0.7)$ & $4(1.0)$ & 0.5175 & $269 / 54$ \\
\hline \multicolumn{5}{|l|}{ Apathy } \\
\hline Apathy $(3116 / 290)$ & $697(23.2)$ & $149(37.2)$ & $<0.001$ & $271 / 54$ \\
\hline \multicolumn{5}{|l|}{ Executive function } \\
\hline Perseverative thinking/OCB $(3116 / 290)$ & $422(14.0)$ & $76(18.9)$ & $<0.001$ & $271 / 54$ \\
\hline \multicolumn{5}{|l|}{ Comorbid conditions, yes (\%) } \\
\hline Neurologic & $443(13.5)$ & $81(17.8)$ & 0.0138 & \\
\hline Psychiatric & $917(28.0)$ & $155(34.1)$ & 0.0073 & \\
\hline
\end{tabular}

Data are mean (SD) or $\mathrm{n}(\%)$. * PBA-s data were complemented with UHDRS-B in case PBA-s data were not available. The numbers of PBA-s or UHDRS-B are given (PBA-s + UHDRS-B). Abbreviations: UHDRS= Unified Huntington Disease Rating Scale; UHDRS-B= Unified Huntington Disease Rating Scale Behavioral part; $\mathrm{OCB}=$ Obsessive Compulsive Behavior 


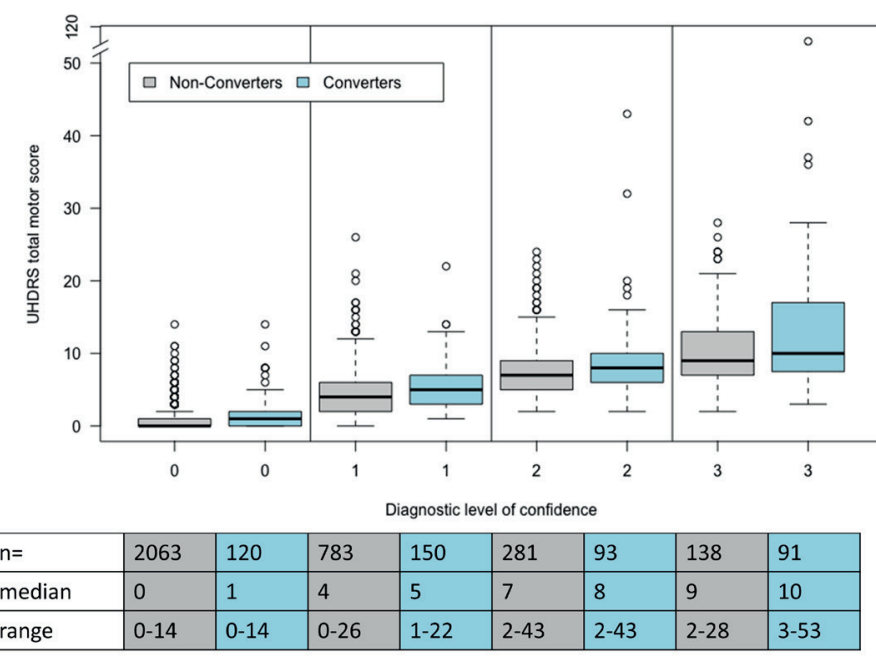

Figure 2. Unified Huntington Disease Rating Scale - Total Motor Score compared to Diagnostic Level of Confidence at baseline in Premanifest and Converted HD patients Abbrevations: UHDRS = Unified Huntington's Disease Rating Scale

The converters had significantly more neurological $(p=0.014)$ and psychiatric $(p=0.007)$ comorbid conditions compared to non-converters. Two converters had movement disorders compared to twenty-six non-converters. The two converters had an essential tremor and a unspecified dystonia. Of the non-converters three had essential tremor, one Parkinson's Disease, two myoclonus, two other chorea, one blepharospasms, and 17 had an unspecified movement disorder. In both groups, 5-6\% of the participants received physical therapy (prior to or) at baseline, around 4.5\% received psychotherapy, 4-6\% psychological counseling, and $5-7 \%$ relaxation therapy.

\section{Longitudinal analysis}

The TMS varied before disease onset, with a majority of the participants displaying a score of $>5$ (Figure $3 \mathrm{~A}$ ). After disease onset the TMS gradually increased per visit. The TFC score respectively remained 13 or just below until the participants became manifest and then slowly decreased. The severity of behavioral symptoms gradually increased in time and was always present before disease onset. Especially apathy and perseverative/obsessivecompulsive behavior increased respectively six and four years before disease-onset (Figure $3 B$ and $C$ ). The $D C L$ in the years previous to disease-onset never scored 0 , but was between 2 and 3 (Figure 3D). Figure $4 A$ and $B$ show slight decrease in the total correct answers on the Stroop Interference Test and Symbol Digit Modality Test over time, but no significant decrease before disease onset. 


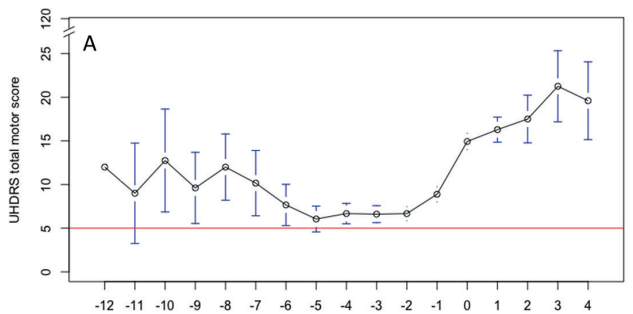

Years from disease onset

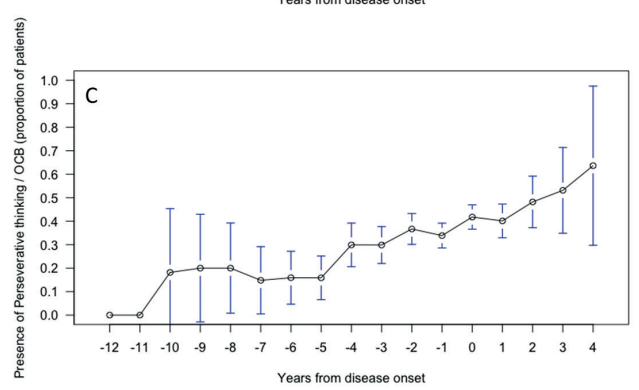

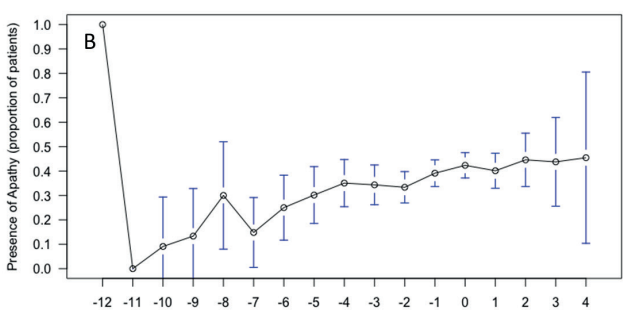

Years from disease onset

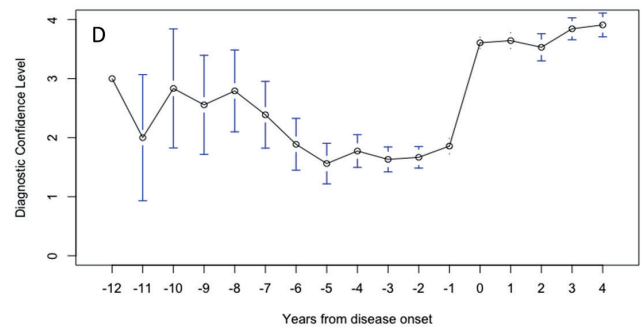

Figure 3. Unified Huntington Disease Rating Scale - Total Motor Score (A), apathy (B), perseverative/ obsessive-compulsive behavior (C) and Diagnostic Confidence Level (D) in time in Converted group Abbrevations: UHDRS = Unified Huntington's Disease Rating Scale; OCB= Obsessive Compulsive Behavior
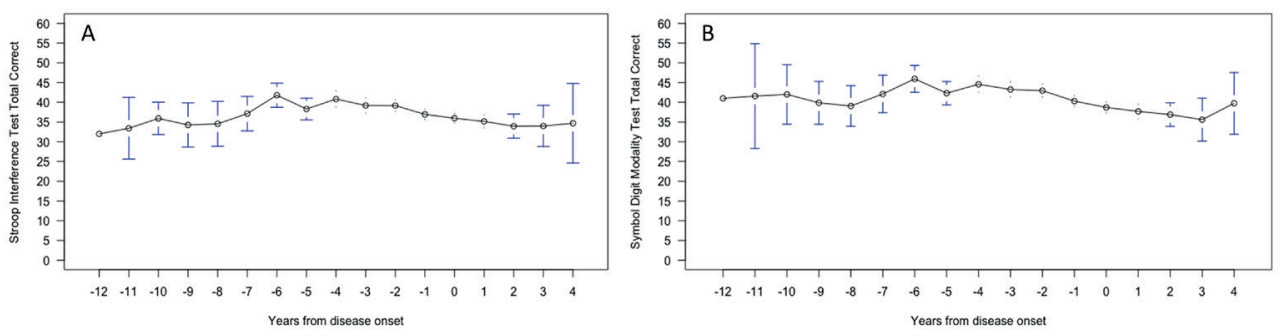

Figure 4. Stroop Interference Test Total Correct (A), Symbol Digit Modality Test Total Correct (B) in time in the Converted group

\section{Discussion}

We are the first to analyze how consistent a TMS cut-off score of 5 and the DCL of 4 relate to one another in estimating disease onset in Enroll-HD participants. As expected and in concordance with the results of the TRACK-HD and PREDICT-HD studies (7-13), we found that HDGEC's closer to disease onset show more motor and psychiatric symptoms compared to those further away from onset. However, the data revealed that $232(51 \%)$ converters had a mean TMS $>5$ at baseline. Although, longitudinally the TMS fluctuated, it still remained $>5$ before disease onset. This means that at that point participants already had clear motor 
abnormalities. We found that 2 converters had a movement disorder; one had an essential tremor and the other a dystonia. This might partially explain the fact that the participants were not scored as manifest at that point in time despite a TMS $>5$. However, the TMS $>5$ of the other 230 participants can not otherwise be explained than motor abnormalities matching HD. Furthermore, our results show that the TMS strongly fluctuates before disease onset. One explanation could be that motor symptoms vary, are very sensitive for stress and may be influenced by medication. Another explanation could be the fact that the dataset contains more participants closer to disease onset and therefore statistical analysis of the TMS becomes more precise.

In converters the DCL in the years previous to disease-onset did not score 0 , but remained between 2 and 3. A DCL of 2 or 3 already gives a $50-98 \%$ confidence that abnormalities are likely signs of HD. This means the raters had $50-98 \%$ confidence the participant had signs and symptoms of HD up to 12 years before they rated the participant to be manifest. It is very unlikely that all participants remained premanifest for such a long time.

Perhaps the raters struggle with the fact they observe motor abnormalities but do not want to distress the participants with their findings. From the clinician's point of view this seems understandable, as these abnormalities do not interfere with daily life functioning and there are currently no disease progression stabilizing treatments. However, from a scientific point of view this is worrisome.

There are some limitations to this study. Unfortunately, the Enroll-HD and REGISTRY data contain multiple instances of missing data, so we had to modify our statistical model accordingly. Ideally, all participants would have been tracked from the same moment in time from estimated disease onset, but this is not feasible. As a result, some participants were already closer to their disease onset than others when they were enrolled in this database. Furthermore, the dataset contains fewer participants further from disease onset. Also, medication use might induce or suppress motor abnormalities. Unfortunately, the EnrollHD data are registered in a way that makes it impossible to analyze the effect of medication use on motor scores.

Another limitation is that in the Registry data the behavior section of the UHDRS is used, whereas Enroll-HD uses the PBAs. Although both assessments use the same ranking scale on both severity and frequency, they differ on two items. These two items 'disoriented behavior' and 'low self-esteem/guilt', were omitted according to the advice of the Behavioral Working Group of the European Huntington's Disease Network (EHDN). Furthermore, sub-items on perseverative and obsessive-compulsive behavior differ between the two questionnaires and were therefore combined to one.

Unfortunately, it seems that even with premanifest follow up it is impossible to estimate an accurate time of motor disease onset, let alone non-motor onset. Despite cognitive and behavioral symptoms and signs frequently preceding motor symptoms, motor changes are still the landmark for clinical research on age of onset (15). The Movement Disorder Society Task Force on Huntington's Disease diagnostic categories suggested to redefine the diagnostic criteria of genetically confirmed HD into pre-symptomatic (no significant motor 
signs; DCL of 0 or 1 and no cognitive change); prodromal (DCL of 2 plus clear cognitive changes) and manifest HD (DCL of 3 plus minor neurocognitive disorder or DCL of 4) $(17,18)$. This classification will make it possible to categorize HDGECs as prodromal. The prodromal stage is not used in Enroll-HD. However, in our opinion, with these suggested diagnostic criteria actual clinical disease onset remains unclear in many participants. What is meant with 'no significant motor signs'? The new criteria still don't use cut-off scores for motor symptoms (TMS).

In addition, biomarkers, such as brain MRI and spinal fluid examination might be helpful to support early diagnosis. However, Van der Plas et al. recently showed that asymptomatic child and adolescent mutant HTT carriers already have abnormal brain development (24), possibly making this less useful.

We conclude that estimating disease onset in HD remains very difficult even in premanifest participants who are followed annually by trained and skilled HD physicians. The current diagnostic criteria give no guidance when an HDGECs has unequivocal signs of HD. The diagnosis is made by clinical experience and, currently there is no operational definition that guides the clinician. It also remains unclear when behavioral, cognitive and functional changes may be attributed to manifest HD as there are no clear cutoff points of the used scales. We conclude that the $\mathrm{DCL}$ is not an accurate and reliable instrument to determine $\mathrm{HD}$ disease onset. With numerous trials evaluating disease modifying therapies it is extremely important to develop more adequate diagnostic criteria, including non-motor symptoms. With this in mind, it is also important to become upfront with our patients. If we want them to benefit from future therapies, we need to confront them regarding symptoms and signs. We believe it is time to define motor and non-motor disease onset more clearly. First of all, we should use cut-off scores for the TMS. Here we used a cut-off score of 5 . Although this cut-off score has been used in an important and leading HD study (TRACK-HD), there is no scientific background why this value should be the cut-off score. Therefore, further investigation on what cut-off score is reliable and justifies motor disease onset is necessary. Perhaps the DCL could be categorized by using separate cut-off points for the prodromal and manifest stages. Furthermore, we need cut-off points in the PBA and cognitive tests used in Enroll-HD to diagnose non-motor disease onset. After all, there is clear evidence that cognitive and behavioral changes may start several decades before motor-onset and cannot be attributed to other causes.

\section{Acknowledgment}

Enroll-HD is a longitudinal observational study for Huntington's disease families intended to accelerate progress towards therapeutics; it is sponsored by CHDI Foundation, a nonprofit biomedical research organization exclusively dedicated to developing therapeutics for HD. Enroll-HD would not be possible without the vital contribution of the research participants and their families. https://www.enroll-hd.org/acknowledgments/ 


\section{Reference List}

1. A novel gene containing a trinucleotide repeat that is expanded and unstable on Huntington's disease chromosomes. The Huntington's Disease Collaborative Research Group. Cell. 1993;72(6):971-83.

2. Bruyn GW. In: Handbook of Clinical Neurology. Huntington's chorea. Historical, clinical and laboratory synopsis. PJ Vinken GB, editor. Amsterdam: Elsevier; 1968.

3. Unified Huntington's Disease Rating Scale: reliability and consistency. Huntington Study Group. Movement disorders : official journal of the Movement Disorder Society. 1996;11(2):136-42.

4. de Boo G, Tibben A, Hermans J, Maat A, Roos RA. Subtle involuntary movements are not reliable indicators of incipient Huntington's disease. Movement disorders : official journal of the Movement Disorder Society. 1998;13(1):96-9.

5. Witjes-Ane MN, Vegter-van der Vlis M, van Vugt JP, Lanser JB, Hermans J, Zwinderman AH, et al. Cognitive and motor functioning in gene carriers for Huntington's disease: a baseline study. The Journal of neuropsychiatry and clinical neurosciences. 2003;15(1):7-16.

6. Witjes-Ane MN, Zwinderman AH, Tibben A, van Ommen GJ, Roos RA. Behavioural complaints in participants who underwent predictive testing for Huntington's disease. J Med Genet. 2002;39(11):857-62.

7. Paulsen JS, Langbehn DR, Stout JC, Aylward E, Ross CA, Nance M, et al. Detection of Huntington's disease decades before diagnosis: the Predict-HD study. Journal of neurology, neurosurgery, and psychiatry. 2008;79(8):874-80.

8. Biglan KM, Ross CA, Langbehn DR, Aylward EH, Stout JC, Queller S, et al. Motor abnormalities in premanifest persons with Huntington's disease: the PREDICT-HD study. Movement disorders : official journal of the Movement Disorder Society. 2009;24(12):1763-72.

9. Paulsen JS, Long JD, Johnson HJ, Aylward EH, Ross CA, Williams JK, et al. Clinical and Biomarker Changes in Premanifest Huntington Disease Show Trial Feasibility: A Decade of the PREDICT-HD Study. Front Aging Neurosci. 2014;6:78.

10. Duff K, Paulsen JS, Beglinger L, Langbehn DR, Stout JC, Predict HDlotHSG. Psychiatric symptoms in Huntington's disease before diagnosis: the predict-HD study. Biol Psychiatry. 2007;62(12):1341-6.

11. Tabrizi SJ, Langbehn DR, Leavitt BR, Roos RA, Durr A, Craufurd D, et al. Biological and clinical manifestations of Huntington's disease in the longitudinal TRACK-HD study: cross-sectional analysis of baseline data. Lancet Neurol. 2009;8(9):791-801.

12. Tabrizi SJ, Scahill RI, Durr A, Roos RA, Leavitt BR, Jones R, et al. Biological and clinical changes in premanifest and early stage Huntington's disease in the TRACK-HD study: the 12-month longitudinal analysis. Lancet Neurol. 2011;10(1):31-42. 
13. Tabrizi SJ, Scahill RI, Owen G, Durr A, Leavitt BR, Roos RA, et al. Predictors of phenotypic progression and disease onset in premanifest and early-stage Huntington's disease in the TRACKHD study: analysis of 36-month observational data. Lancet Neurol. 2013;12(7):637-49.

14. Hamilton JM, Salmon DP, Corey-Bloom J, Gamst A, Paulsen JS, Jerkins S, et al. Behavioural abnormalities contribute to functional decline in Huntington's disease. Journal of neurology, neurosurgery, and psychiatry. 2003;74(1):120-2.

15. Biglan KM, Zhang $Y$, Long JD, Geschwind M, Kang GA, Killoran A, et al. Refining the diagnosis of Huntington disease: the PREDICT-HD study. Frontiers in aging neuroscience. 2013;5:12.

16. Huntington Study Group. Unified Huntington's Disease Rating Scale(UHDRS). Available from: http://huntingtonstudygroup.org/tools-resources/uhdrs/.

17. Reilmann R, Leavitt BR, Ross CA. Diagnostic criteria for Huntington's disease based on natural history. Movement disorders : official journal of the Movement Disorder Society. 2014;29(11):1335-41.

18. Ross CA, Reilmann R, Cardoso F, McCusker EA, Testa CM, Stout JC, et al. Movement Disorder Society Task Force Viewpoint: Huntington's Disease Diagnostic Categories. Mov Disord Clin Pract. 2019;6(7):541-6.

19. Landwehrmeyer GB, Fitzer-Attas CJ, Giuliano JD, Goncalves N, Anderson KE, Cardoso F, et al. Data Analytics from Enroll-HD, a Global Clinical Research Platform for Huntington's Disease. Mov Disord Clin Pract. 2017;4(2):212-24.

20. Orth M, Handley OJ, Schwenke C, Dunnett SB, Craufurd D, Ho AK, et al. Observing Huntington's Disease: the European Huntington's Disease Network's REGISTRY. PLoS Curr. 2010;2:RRN1184.

21. Orth M, European Huntington's Disease N, Handley OJ, Schwenke C, Dunnett S, Wild EJ, et al. Observing Huntington's disease: the European Huntington's Disease Network's REGISTRY. Journal of neurology, neurosurgery, and psychiatry. 2011;82(12):1409-12.

22. Penney JB, Jr., Vonsattel JP, MacDonald ME, Gusella JF, Myers RH. CAG repeat number governs the development rate of pathology in Huntington's disease. Annals of neurology. 1997;41(5):689-92.

23. Craufurd D, Thompson JC, Snowden JS. Behavioral changes in Huntington Disease. Neuropsychiatry Neuropsychol Behav Neurol. 2001;14(4):219-26.

23. van der Plas E, Langbehn DR, Conrad AL, Koscik TR, Tereshchenko A, Epping EA, et al. Abnormal brain development in child and adolescent carriers of mutant huntingtin. Neurology. 2019. 



\section{CHAPTER 3}




\section{Is there convincing evidence that intermediate repeats in the HTT gene cause Huntington's disease?}

Mayke Oosterloo, Martine J Van Belzen, Emilia K Bijlsma, and Raymund AC Roos 


\begin{abstract}
Background: Huntington's disease is a neurodegenerative disease associated with a CAG repeat expansion in the Huntingtin (HTT) gene. A trinucleotide size between 27 and 35 is considered 'intermediate' and not to cause symptoms and signs of Huntington's disease. There are articles claiming otherwise, however publishing only the cases that have a HD phenotype introduces a significant publication bias. Our objective is to determine if there is convincing evidence that intermediate repeats cause Huntington's disease.
\end{abstract}

Methods: Previously published case reports on HTT intermediate repeat sizes and all cases from the Netherlands with an intermediate repeat were reviewed for clinical symptoms and signs.

Results: Four patients had a clinical presentation of Huntington's disease and an intermediate repeat out of ten reported cases in literature. Between 2001 and 2012, 1,690 patients were tested for Huntington's Disease in the Netherlands. One case out of 60 with an intermediate allele had a phenotype resembling Huntington's disease, but had already been published in a case report.

Conclusion: Given the high background frequency of intermediate alleles in several populations, the possibility of developing Huntington's disease would have huge implications for $1-7 \%$ of the normal population. It is possible that intermediate alleles present as an endo-phenotype with the potential of subsequent clinical manifestations. However, given the scarcity of convincing cases, the lack of convincing biological evidence for pathogenicity of intermediate alleles, and many genes still to be discovered for HD mimics, we find that it is premature to claim that intermediate alleles can cause Huntington's disease. We recommend systematic follow up of this group of individuals and if possible brain pathology for confirmation or exclusion of Huntington's disease. 


\section{Introduction}

Huntington's disease (HD) is an autosomal dominant neurodegenerative disease characterized by unwanted movements, psychiatric disorders, and cognitive deterioration. $H D$ results from an unstable and expanded CAG trinucleotide repeat in the Huntingtin (HTT) gene on chromosome 4 (1). A CAG repeat size of 40 or more is invariably associated with HD. A CAG repeat of 36 to 39 might give reduced penetrance, which means that the clinical symptoms might be milder and/or symptoms start later in life. CAG repeat lengths between 6 to 35 are not considered associated with HD. A trinucleotide size between 27 and 35 is considered 'intermediate' (2). The CAG repeats in this range sporadically show instability and have the potential to expand into the disease range within one or more generations, mainly through the paternal line $(3,4)$. The limits of the CAG size range on normal and HD associated chromosomes cannot be reliably determined from the literature, since the exact amount of CAG repeats may differ one or two repeats depending on the laboratory (5). It was believed that a trinucleotide repeat in the intermediate range cannot cause symptoms of $\operatorname{HD}(5,6)$. However, over the years several case reports have described an HD phenotype with an intermediate CAG repeat, but population-based data are lacking (7-12). Publishing only the cases that have a (more or less convincing) HD phenotype however, introduces a significant publication bias.

In this paper, we review all published cases and cases with clinical symptoms and signs resembling HD combined with intermediate repeat size from our nationwide database, and investigate whether intermediate repeat alleles may give a clinical picture of HD.

\section{Material and methods}

A literature search of published cases of patients with intermediate repeat size and HD phenotype was performed. All records were identified by an online Pubmed search, or by snow ball sampling from references. Search terms using Pubmed were 'Huntington's disease', 'intermediate CAG repeats' and 'intermediate CAG alleles'.

Furthermore, all cases with an intermediate sized CAG repeat (27-35 repeats) were searched from 1,690 patients who had undergone diagnostic DNA analysis for HD between January 2001 and December 2012 in the Laboratory for Diagnostic Genome Analysis (LDGA), department of Clinical Genetics (Leiden Medical University Center, the Netherlands). DNA analysis for $\mathrm{HD}$ in the Netherlands is centralized in Leiden. The number of CAG repeats was determined by Polymerase Chain Reaction (PCR) analysis of the region encompassing the CAG repeat with primers HD1 and HD3 followed by fragment sizing through capillary electrophoresis at sufficient resolution to allow separation of alleles with one repeat difference (13). Medical information from all these patients was inquired by a letter to their treating physician (neurologist/psychiatrist). From these patients clinical, neuropsychological and laboratory findings, if available, were reviewed by a neurologist who was not acquainted with the patients. Because clinical records were reviewed retrospectively, the Unified Huntington's disease Rating Scale (UHDRS) was not available in most cases. 
The following inclusion and exclusion criteria were applied: those with hyperkinesia in combination with cognitive decline that might be highly probable signs of HD and could not be explained by other known factors were included. Excluded were all cases with a nonprogressive chorea, structural basal ganglia lesions on MRI other than atrophy, a persistent focal or hemichorea, and all cases without cognitive deterioration as well as all cases using drugs known to induce chorea. Hemichorea or a focal chorea may be the first symptom of HD but a persistent focal or hemichorea is in most cases associated with underlying structural basal ganglia lesions or autoimmune choreas (14).

\section{Results}

The literature search identified six articles containing case reports of 10 patients with a clinical performance presuming Huntington's disease and a trinucleotide length between 27 and 35 (7-12). All clinical characteristics of these 10 patients with various motor, behavioral and cognitive abnormalities suggestive for HD are shown in Table 1 . In all cases additional laboratory tests were performed to rule out diseases that mimic HD (Table 2). Wilson's disease and neuroacanthocytosis were excluded by respectively testing copper, ceruloplasmin, and performing a peripheral blood smear. Brain imaging was performed in all cases except in case 9 (10). CT scan or MRI showed generalized atrophy of the brain in 5 of the 9 cases (Table 2). In case 10 a Fluorodeoxyglucose (FDG) positron emission tomography (PET) scan was performed, which showed a caudate glucose hypometabolism (12).

Most of the case reports mentioned in table 1 do not completely fulfill the phenotype of HD using the inclusion and exclusion criteria mentioned above. Cases $2,6,8$ and $9(7,8,10)$ are the four completely fitting the rigorous criteria of clinical symptoms and signs seen in HD. All case reports are described in short.

Table 1. Clinical features of patients with IA from case reports in literature

\begin{tabular}{|c|c|c|c|c|c|c|c|}
\hline Case & Reference & Gender & $\begin{array}{c}\text { Age of } \\
\text { onset } \\
(y)\end{array}$ & $\begin{array}{l}\text { CAG } \\
\text { repeats }\end{array}$ & $\begin{array}{c}\text { History of } \\
\text { neuroleptics }\end{array}$ & $\begin{array}{l}\text { Affected } \\
\text { family } \\
\text { members }\end{array}$ & $\begin{array}{l}\text { Independent } \\
\text { sample } \\
\text { confirmation }\end{array}$ \\
\hline 1 & [9] & $M$ & 60 & $20 / 29$ & $?$ & Father? & no \\
\hline 2 & [8] & $F$ & 60 & $17 / 34$ & no & 0 & yes \\
\hline 3 & [11] & $M$ & 44 & $16 / 34$ & $?$ & 2 & $?$ \\
\hline 4 & [11] & $\mathrm{F}$ & $\sim 40$ & $16 / 34$ & $?$ & 2 & $?$ \\
\hline 5 & [7] & $\mathrm{F}$ & 65 & $17 / 30$ & no & 0 & $?$ \\
\hline 6 & [7] & $\mathrm{M}$ & 68 & $18 / 31$ & no & 4 & yes \\
\hline 7 & [10] & $\mathrm{F}$ & 45 & $17 / 29$ & yes & $\begin{array}{l}\text { Mother and } \\
\text { sister? }\end{array}$ & yes \\
\hline 8 & [10] & $M$ & 78 & $29 / 32$ & no & ? & ? \\
\hline 9 & [10] & $M$ & $\sim 37$ & $19 / 27$ & no & $?$ & $?$ \\
\hline 10 & [12] & $M$ & 68 & $? / 33$ & $?$ & 1 at least & $?$ \\
\hline
\end{tabular}

$?=$ unknown 
Table 2. Excluded HD mimics of patients with IA from case reports in literature

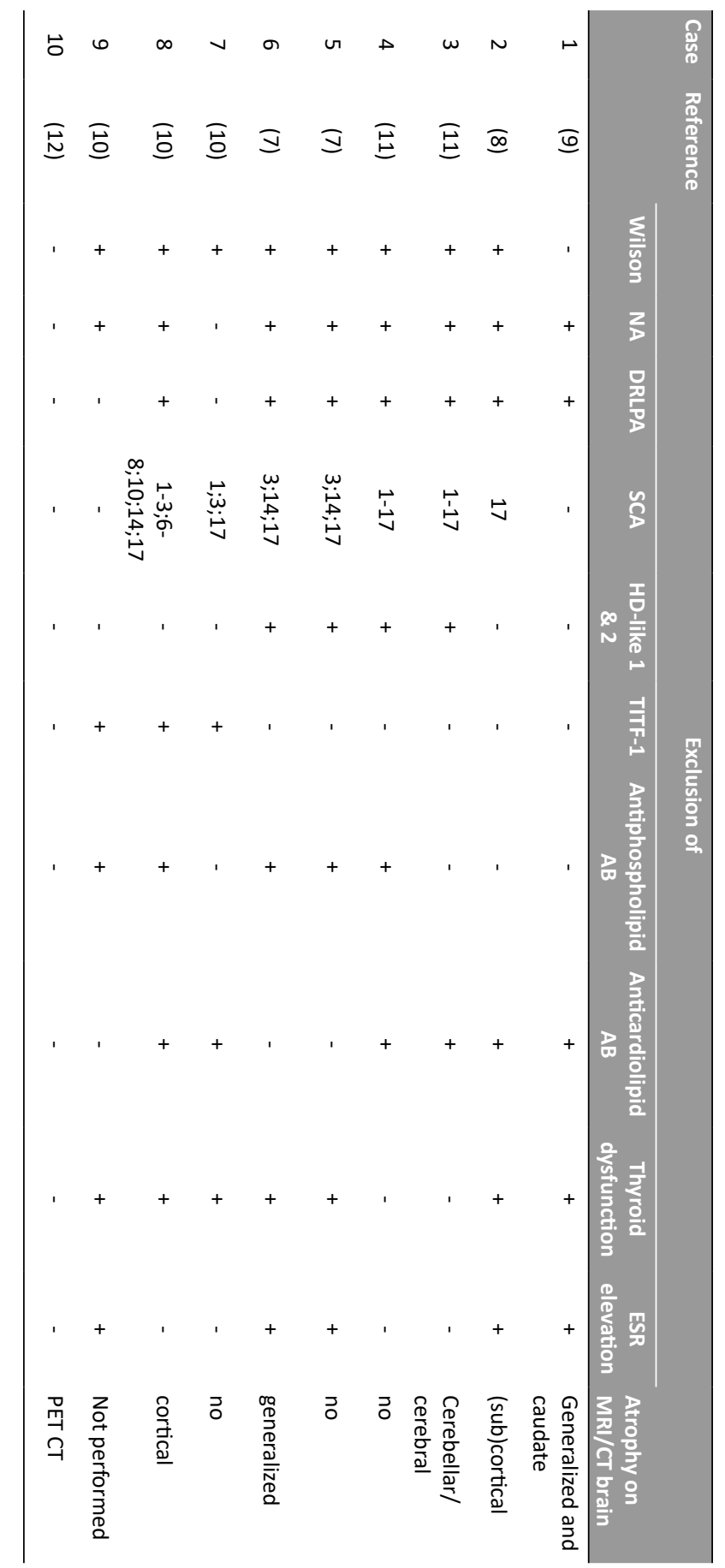

Abbrevations: NA: neuroacanthocytosis. DRPLA: Dentatorubral Pallidoluysian Atrophy. SCA: Spinocerebellar Ataxia. HD-like 1 \& 2: Huntington Disease- like 1 \& 2. TITF-1: Benign Hereditary Chorea. $A B$ : antibodies. ESR: Erythrocyte Sedimentation Rate 


\section{Case report 1}

Kenney et al. (table 1) described a patient with chorea and depression with a CAG repeat size of 29 , claiming the first report of an intermediate allele resulting in HD. Both Reynolds and Semaka et al. showed their concerns towards the reliability of this case $(15,16)$. First of all there is no cognitive deterioration 5 years after onset of disease despite a severe chorea. Also the patient was not tested for Spinocerebellar ataxia 17 (SCA17), a common cause of a HD phenocopy in European populations (17).

Brain autopsy was performed after the patient had died in an accident. Histological examination revealed a thinning of the cortical ribbon along with moderate gliosis and neuronal loss of the caudate and putamen (9). Nothing was reported about Vonsattel's grading classification (18). Additional immunohistochemical staining to detect HD inclusions was performed afterwards in our center (Dr. Maat-Schieman; Department of Neurology and Pathology, LUMC, The Netherlands). Tissue sections, including cerebral cortex and pons, were stained with antibodies against ubiquitin (monoclonal DAKO) and to the N-terminus of Huntingtin. Ubiquitine immunohistochemistry revealed the presence of neuronal intranuclear inclusions (NII) in the cerebral cortex and the pons of this case and a control case. The cerebral cortex of the age and gender matched HD control case showed ubiquitinpositive structures with the morphology of neuropil inclusions (NI) (19). Similar inclusions were occasionally observed in the cerebral cortex of the case Kenney et al. described. Both $\mathrm{NII}$ and $\mathrm{NI}$ inclusions were detected in the control HD case. Immunoreactivity for $\mathrm{N}$-terminal Huntingtin was entirely absent in the sections of the index case while present in the HD control. In our opinion the conclusion that this patient has HD, is not justified by immunohistochemical and clinical findings (20).

\section{Case report 2}

Andrich et al. mentioned a 75-year-old Caucasian man with a progressive generalized chorea and cognitive impairment since 15 years. He had severe dysarthria, dysphagia as well as saccadic eye movements. HD mimics like SCA 17, Wilson's disease and acanthocytosis were excluded. However, HD-like 1 and 2 were not ruled out.

\section{Case report 3 and 4}

Herishanu et al. described 2 patients (siblings) within an Israeli Karaite community. Case 3 had a fairly stable cognitive state after 5 years follow up and was able to maintain working as a clerk. Case 4, however showed marked mental deterioration, but was prior known with a psychosis and diagnosed with schizophrenia. The use of antipsychotic drugs in the past or present is not described, but highly likely. Therefore, both cases did not meet our inclusion criteria. Furthermore both individuals are part of a community with a high consanguinity rate which favors genetic disease clustering, and of a family known with HD as well as a myopathy.

\section{Case report 5 and 6}

Groen et al. also described 2 patients. Both of these patients are part of the group with IAs found in our nationwide database of the LDGA of which the results will be described below. Case 5 presented with a generalized chorea, dystonia of the upper limbs and cervical dystonia existing for 3 years. There was a loss of interest, but no cognitive decline. The 
patient remained stable during 6 years follow up. An MRI brain showed no abnormalities. The fact that the patient showed no cognitive deterioration or psychiatric symptoms after 6 years of disease, makes the diagnosis of HD less likely but not impossible.

Case 6, on the other hand, presented with a generalized chorea, cognitive impairment and irritability for 4 years. He slowly deteriorated over a course of 4 years. His sister died with the clinical diagnosis of olive-ponto-cerebellar atrophy. Her three children, however, had genetically confirmed HD (43 repeats), and it is therefore likely she suffered from HD too.

\section{Case report 7, 8 and 9}

Ha et al. described 3 patients with symptoms resembling HD. Case 7 presented with a 10year history of chorea in facial muscles progressing to her limbs. She had been exposed to neuroleptics and had an acute dystonic reaction to prochlorperazine as well as akathisia following intravenous promethazine. Neuropsychological examination showed impairment on executive behavior which were attributed to bipolar disorder. Because neuroleptics can induce chorea, this case does not meet our inclusion criteria. However the cognitive decline in combination with chorea suggests another disorder than bipolar disorder.

Case 8 developed a progressive generalized chorea with motor impersistency and unspecified functional decline. However, it is unknown how long the patient suffered from these symptoms or for how long he was followed. Despite the minimal clinical information, the patient meets our inclusion criteria.

Case 9 had a history of a progressive, generalized chorea since 12 years. His short term memory was impaired and there was severe anxiety. The patient had been treated with paroxetine, a selective serotonin reuptake inhibitor which is associated with chorea (14). The percentages of paroxetine causing extrapyramidal signs are less than $0.01 \%$ and less likely to be the cause of the chorea. Therefore the patient was included.

\section{Case report 10}

Squitieri et al. described a patient with jerky ocular persuit, increased latency saccade initiation, a Minimal Mental State Examination (MMSE) of 28 out of 30 and a slight arm incoordination. These clinical symptoms are not enough to meet criteria of clinical HD as there is no chorea. However, a PET CT showed glucose hypometabolism which is seen in HD.

\section{Database search}

Of a total of 1,690 patients tested between January 2001 and December 2012, 793 (46,9\%) had a repeat size of $\leq 26,60$ (3.6\%) had a CAG repeat size 27-35 (Fig. 1), 40 (2.4\%) a repeat size between 36 and 39 and $798(47.2 \%)$ a repeat size of $\geq 40$ in the larger allele (Fig. 2).

From two patients with an IA clinical data could not be obtained. Of the remaining 58 patients 31 had no family history concerning HD and 10 had one or more relatives suffering from HD. From 17 patients is was not possible to retrieve the family history from the medical information. Of the 58 patients carrying an intermediate repeat we found 1 patient who had clinical features suggesting Huntington's Disease (1.7\%). This patient (case 6 ) has already been published by Groen et al. (7). The other 57 patients had movement disorders by 
different causes such as the use of antipsychotics, stroke, conversion, or did not meet our inclusion criteria otherwise. Four patients suffered from dementia without chorea. One of them is described by Semaka et al. as her daughter was diagnosed with HD, after which the patient was tested post mortem (33 repeats) (21). It might be that she suffered from an endophenotype of HD, although chorea was never described. Many requests were due to exclude rather than to prove HD. There was one application error: a patient with spinal muscle atrophy (SMA) had been tested for HD. There were no clinical symptoms suggesting HD.

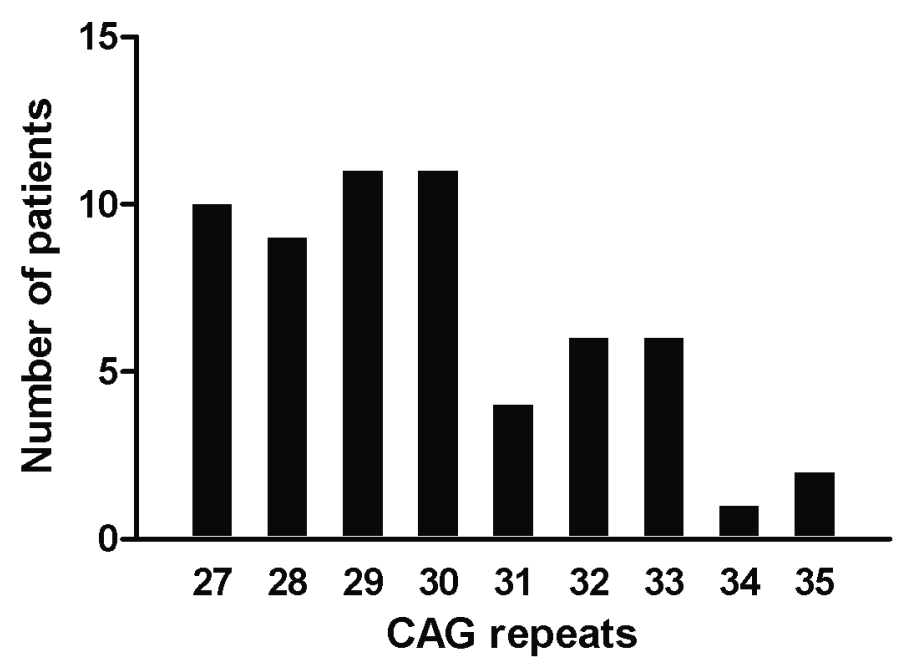

Figure 1. CAG repeat frequency in intermediate range

Schematic view of 60 patients with an IA from the LDGA database (Leiden University Medical Centre, The Netherlands).

\section{Discussion}

Intermediate alleles in the HTT gene are relatively common in the general population, with frequency estimates between 1 and $7 \%(2,10,22-24)$. Recent publications claim that intermediate alleles in the HTT gene can cause HD symptoms, and several cases are reported. However, publishing only the cases with an intermediate allele that have an HD(-like) phenotype, introduces a significant publication bias. With this paper we present an unbiased series and illustrate that in most patients with symptoms and signs that may indicate HD, or need exclusion of HD, the finding of an intermediate allele is likely coincidental. All in all, combining cases from the literature and a database search, we found four individuals with an intermediate repeat size and symptoms and signs comparable with those seen in HD. Still, we are reluctant to conclude to a causal relationship, as there are several factors that have to be taken into account before a definite conclusion can be reached. 


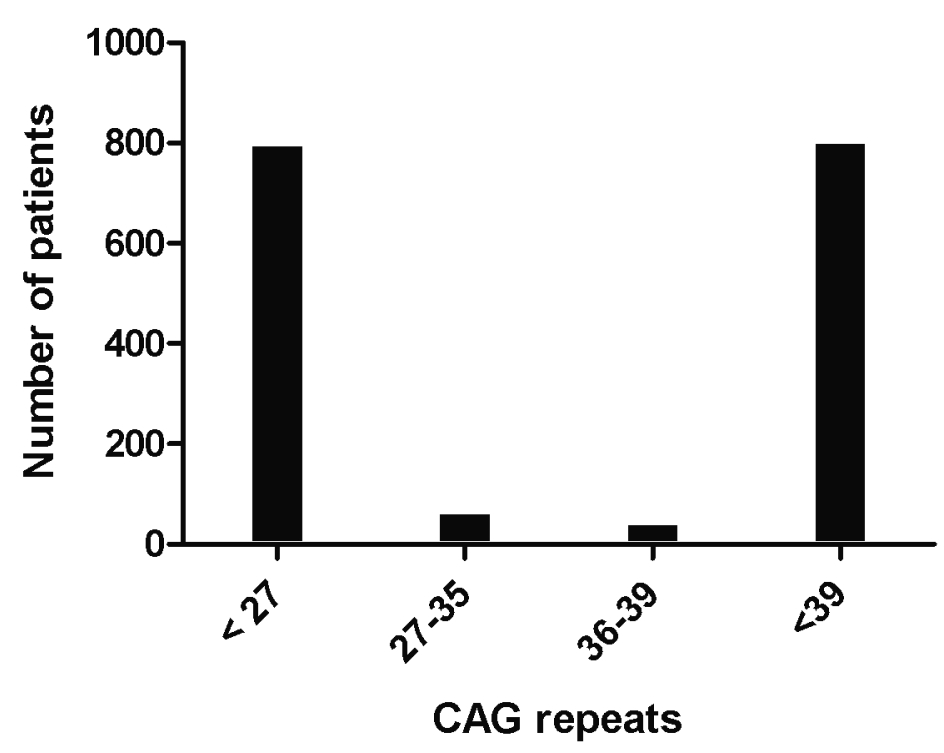

Figure 2. Summary of CAG frequency in ranges.

A total of 1,690 patients was tested for confirmation or exclusion of a clinical diagnosis of HD at the LDGA (Leiden University Medical Centre, The Netherlands). 793 had a normal repeat size, 60 a repeat size in the intermediate range, 40 between 36 and 39 and 798 a repeat size of 40 or more in the larger allele.

Firstly, the finding of a patient with clinical features of HD without a repeat size in the disease range ( $\geq 36$ repeats) rises the possibility of misdiagnosis. Huntington's disease is by far the most common genetic cause of chorea, only $1 \%$ of suspected Huntington's disease cases have no expanded CAG repeat and these are known as Huntington's disease phenocopies (17). Only $2 \%$ of these Huntington's disease phenocopy patients are diagnosed otherwise (17). Another pitfall is the use of antipsychotics, which might cause chorea and/or dystonia. Other reasons for errors are sample mix up or clerical errors.

Secondly, the question is whether there is biological proof for pathogenicity of intermediate alleles. From the literature focused on research on intermediate alleles in HD, there is as yet no convincing evidence, measured by the performance of intermediate alleles compared to 37 CAGs and above $(25,26)$. However, as those studies point to a continuous process rather than a threshold for a certain number of CAG repeats, a pathogenic effect of intermediate alleles cannot be excluded.

Moreover, there is emerging evidence that carriers of an intermediate allele are at risk to develop behavioral problems. The Prospective Huntington At Risk Observational Study (PHAROS) enrolled 1,001 participants at risk for HD of whom 50 had an intermediate repeat 
size (27). Compared to non-expanded controls, the IA group had significantly worse apathy score and suicidal ideation (27).

Another explanation for IAs causing HD symptoms and signs might be the existence of somatic mosaicism (heterogeneity of repeat length in tissue). Therefore, postmortem neuropathological evaluation might be valuable to verify the diagnosis as well as in search for somatic mosaicism. The CAG repeat displays different levels of mosaicism. Severely affected regions of the brain in HD (caudate nucleus and putamen) have been shown to have an increased CAG repeat compared with PCR products of peripheral blood $(3,28)$. Mouse model studies confirm this phenomenon (29). Transgenic HD mice have CAG repeats $>100$ and the longer the repeat size the more instable it becomes. If peripheral blood DNA analysis in case of IA, combined with clinical features of HD, shows an intermediate CAG repeat size, one could hypothesize CAG repeat analysis in brain tissue most affected in HD shows a larger CAG repeat size. Especially if the repeat size approaches the upper limits of the intermediate range, it may be speculated that the repeat size in these parts of the brain has expanded into the disease range.

Taken all biological information together, it is possible that IAs present as a behavioral phenotype with the potential of subsequent clinical manifestations (27).

Thirdly, with evolving genetic insight and the finding of new genetic causes for HD like syndromes, one has to take into account that the symptoms of reported patients may be caused by yet unknown HD mimics. For example, Hensman Moss et al. (30) recently described C9orf72 expansion as the most common genetic cause of HD phenotype presentations in a UK cohort, with a prevalence of $1.95 \%$. Until recently SCA17 used to be the most common HD mimic, and none of the reported patients is tested for C9orf72. With emerging data resulting from new diagnostic methods using next generation sequencing, a series of new genes for HD mimics can be anticipated. Stopping the diagnostic process and closing the file after finding an IA allele in HTT, assuming that the cause has been found, may therefore result in a misdiagnosis. This would imply that the correct diagnosis is withheld from the patient and his family.

With our database series, we intended to balance the publicly available information regarding intermediate alleles in symptomatic patients. Our series is one of the few unbiased series on cases with a reason to exclude HD. Besides Ha et al. (9) who described 2 cohorts of IA recorded in a period of respectively 14 years and 12 years, there are no other publications in which the number of cases with HD phenotype together with IA have been assessed.

Our study, however, has some limitations. Evaluation and judgment had to be done retrospectively on clinical notes. Most of the cases have not been seen by a movement disorder specialist. It is possible that some cases are judged incorrectly due to missing information. Another limitation is the fact that most of the 58 cases had a short follow up, therefore it is still possible that symptoms turn into classic HD over time.

Summarizing, four cases with IA from the literature, among them one of 60 patients from our own database, evolved into a clinical spectrum mimicking HD. The other cases did not 
meet the full clinical spectrum of HD. But are we able to confirm that IA can cause HD, based on these four cases?

We certainly will keep an open mind of the possibility that intermediate alleles may occasionally cause HD. However, as long as other explanations have not been excluded, we are reluctant to accept an intermediate repeat as the cause for $\mathrm{HD}$ (-like) symptoms. Not only for the patient, but also from a family point of view, the diagnosis HD means an enormous burden. Given the high background frequency of intermediate alleles in several populations, the possibility of developing HD would have huge implications for $1-7 \%$ of the normal population. The question is whether there is enough evidence yet to incorporate this possibility in the information that is shared with the patient once an intermediate allele has been found. Given the scarcity of convincing cases, the lack of convincing biological evidence and many genes still to be discovered, we find that it is not yet time to do so. Given the high frequency of IAs in the general population, the combination of an IA and symptoms resembling HD may well be a coincidental finding (22).

We recommend follow up of this group of individuals for complaints resembling HD. Other Huntington-like diseases should be ruled out and patients should be re-evaluated whenever a new gene for HD mimics is found. In the long term, brain pathology may give a better insight in this category of patients (20). Further exploration of mosaicism as well as neuropathological analysis in IA patients is therefore recommended. 


\section{Reference List}

1. A novel gene containing a trinucleotide repeat that is expanded and unstable on Huntington's disease chromosomes. The Huntington's Disease Collaborative Research Group. Cell 1993: 72: 971-983.

2. Semaka A, Creighton S, Warby $S$ et al. Predictive testing for Huntington disease: interpretation and significance of intermediate alleles. Clinical genetics 2006: 70: 283-294.

3. Telenius $H$, Kremer B, Goldberg YP et al. Somatic and gonadal mosaicism of the Huntington disease gene CAG repeat in brain and sperm. Nature genetics 1994: 6: 409-414.

4. Semaka A, Kay C, Doty $C$ et al. CAG size-specific risk estimates for intermediate allele repeat instability in Huntington disease. Journal of medical genetics 2013: 50: 696-703.

5. Rubinsztein DC, Leggo J, Coles R et al. Phenotypic characterization of individuals with 30-40 CAG repeats in the Huntington disease (HD) gene reveals HD cases with 36 repeats and apparently normal elderly individuals with 36-39 repeats. American journal of human genetics 1996: 59: 16-22.

6. Kremer B, Goldberg P, Andrew SE et al. A worldwide study of the Huntington's disease mutation. The sensitivity and specificity of measuring CAG repeats. The New England journal of medicine 1994: 330: 1401-1406.

7. Groen JL, de Bie RM, Foncke EM et al. Late-onset Huntington disease with intermediate CAG repeats: true or false? Journal of neurology, neurosurgery, and psychiatry 2010: 81: 228-230.

8. Andrich J, Arning L, Wieczorek $S$ et al. Huntington's disease as caused by 34 CAG repeats. Movement Disord 2008: 23: 879-881.

9. Kenney C, Powell S, Jankovic J. Autopsy-proven Huntington's disease with 29 trinucleotide repeats. Movement disorders : official journal of the Movement Disorder Society 2007: 22: 127-130.

10. Ha AD, Jankovic J. Exploring the correlates of intermediate CAG repeats in Huntington disease. Postgraduate medicine 2011: 123: 116-121.

11. Herishanu YO, Parvari R, Pollack $Y$ et al. Huntington disease in subjects from an Israeli Karaite community carrying alleles of intermediate and expanded CAG repeats in the HTT gene: Huntington disease or phenocopy? Journal of the neurological sciences 2009: 277: 143-146.

12. Squitieri F, Esmaeilzadeh $M$, Ciarmiello $A$ et al. Caudate glucose hypometabolism in a subject carrying an unstable allele of intermediate CAG(33) repeat length in the Huntington's disease gene. Movement disorders : official journal of the Movement Disorder Society 2011: 26: 925-927.

13. Losekoot M, van Belzen MJ, Seneca S et al. EMQN/CMGS best practice guidelines for the molecular genetic testing of Huntington disease. European journal of human genetics : EJHG 2013: 21: 480486. 
14. Cardoso F, Seppi K, Mair KJ et al. Seminar on choreas. Lancet neurology 2006: 5: 589-602.

15. Reynolds N. Re: Autopsy-proven Huntington's disease with 29 trinucleotide repeats. Movement disorders : official journal of the Movement Disorder Society 2008: 23: 1795-1796; author reply 1793.

16. Semaka A, Warby S, Leavitt BR et al. Re: Autopsy-proven Huntington's disease with 29 trinucleotide repeats. Movement disorders : official journal of the Movement Disorder Society 2008: 23: 17941795; author reply 1793.

17. Wild EJ, Tabrizi SJ. The differential diagnosis of chorea. Practical neurology 2007: 7: 360-373.

18. Vonsattel JP, Myers RH, Stevens TJ et al. Neuropathological classification of Huntington's disease. Journal of neuropathology and experimental neurology 1985: 44: 559-577.

19. Dickson DW, Wertkin A, Kress $Y$ et al. Ubiquitin immunoreactive structures in normal human brains. Distribution and developmental aspects. Laboratory investigation; a journal of technical methods and pathology 1990: 63: 87-99.

20. Maat-Schieman $M$, Roos $R$, Losekoot $M$ et al. Neuronal intranuclear and neuropil inclusions for pathological assessment of Huntington's disease. Brain pathology 2007: 17: 31-37.

21. Semaka A, Kay C, Belfroid RD et al. A new mutation for Huntington disease following maternal transmission of an intermediate allele. European journal of medical genetics 2015: 58: 28-30.

22. Sequeiros J, Ramos EM, Cerqueira J et al. Large normal and reduced penetrance alleles in Huntington disease: instability in families and frequency at the laboratory, at the clinic and in the population. Clinical genetics 2010: 78: 381-387.

23. Maat-Kievit A, Losekoot $\mathrm{M}$, Van Den Boer-Van Den Berg $\mathrm{H}$ et al. New problems in testing for Huntington's disease: the issue of intermediate and reduced penetrance alleles. Journal of medical genetics 2001: 38: E12.

24. Semaka A, Kay C, Doty CN et al. High frequency of intermediate alleles on huntington diseaseassociated haplotypes in British Columbia's general population. American journal of medical genetics Part B, Neuropsychiatric genetics : the official publication of the International Society of Psychiatric Genetics 2013.

25. Seong IS, Ivanova E, Lee JM et al. HD CAG repeat implicates a dominant property of huntingtin in mitochondrial energy metabolism. Human molecular genetics 2005: 14: 2871-2880.

26. Scherzinger $E$, Sittler A, Schweiger $K$ et al. Self-assembly of polyglutamine-containing huntingtin fragments into amyloid-like fibrils: implications for Huntington's disease pathology. Proceedings of the National Academy of Sciences of the United States of America 1999: 96: 4604-4609. 
27. Killoran A, Biglan KM, Jankovic J et al. Characterization of the Huntington intermediate CAG repeat expansion phenotype in PHAROS. Neurology 2013: 80: 2022-2027.

28. De Rooij KE, De Koning Gans PA, Roos RA et al. Somatic expansion of the (CAG)n repeat in Huntington disease brains. Human genetics 1995: 95: 270-274.

29. Gonitel $\mathrm{R}$, Moffitt $\mathrm{H}$, Sathasivam $\mathrm{K}$ et al. DNA instability in postmitotic neurons. Proceedings of the National Academy of Sciences of the United States of America 2008: 105: 3467-3472.

30. Hensman Moss DJ, Poulter M, Beck J et al. C9orf72 expansions are the most common genetic cause of Huntington disease phenocopies. Neurology 2014: 82: 292-299. 



\section{CHAPTER 4}

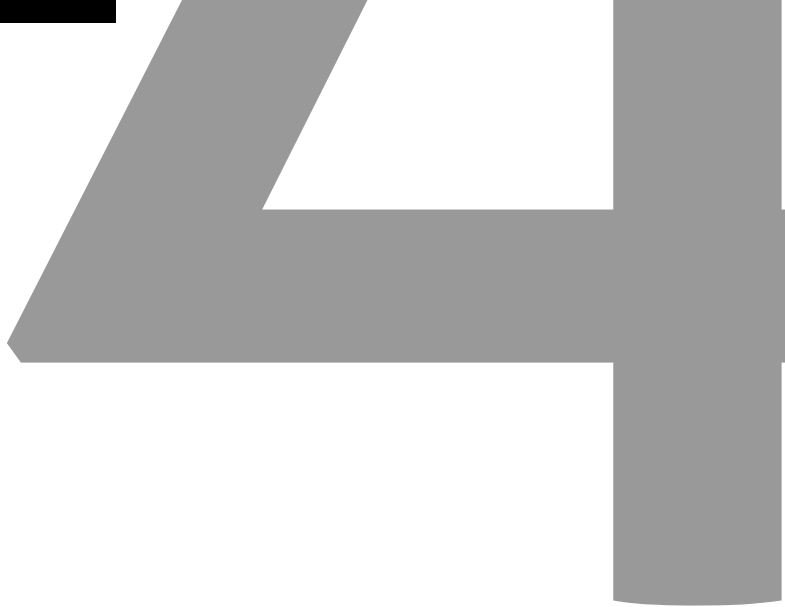




\section{Clinical and genetic characteristics of late-onset Huntington's disease}

Mayke Oosterloo, Emilia K Bijlsma, Sander MJ van Kuijk, Floor Minkels, Christine EM de Die-Smulders, for the REGISTRY Investigators of the European Huntington's Disease Network, Raymund AC Roos 


\section{Abstract}

Background: The frequency of late-onset Huntington's disease ( $>59$ years) is assumed to be low and the clinical course milder. However, previous literature on late-onset disease is scarce and inconclusive.

Objective: Our aim is to study clinical characteristics of late-onset compared to commononset HD patients in a large cohort of HD patients from the Registry database.

Methods: Participants with late- and common-onset (30-50 years) were compared for first clinical symptoms, disease progression, CAG repeat size and family history. Participants with a missing CAG repeat size, a repeat size of $\leq 35$ or a UHDRS motor score of $\leq 5$ were excluded.

Results: Of 6,007 eligible participants, 687 had late-onset (11.4\%) and 3,216 (53.5\%) common-onset HD. Late-onset $(n=577)$ had significantly more gait and balance problems as first symptom compared to common-onset $(n=2408)(P<.001)$. Overall motor and cognitive performance $(P<.001)$ were worse, however only disease motor progression was slower (coefficient, -0.58; SE 0.16; $\mathrm{P}<.001$ ) compared to the common-onset group. Repeat size was significantly lower in the late-onset $(n=40.8 ; S D 1.6)$ compared to common-onset $(n=44.4$; SD 2.8) $(P<.001)$. Fewer late-onset patients $(n=451)$ had a positive family history compared to common-onset $(n=2940)(P<.001)$.

Conclusions: Late-onset patients present more frequently with gait and balance problems as first symptom, and disease progression is not milder compared to common-onset HD patients apart from motor progression. The family history is likely to be negative, which might make diagnosing HD more difficult in this population. However, the balance and gait problems might be helpful in diagnosing HD in elderly patients. 


\section{Introduction}

Huntington's disease (HD) is an autosomal dominant neurodegenerative disease characterized by unwanted movements, psychiatric disorders, and cognitive deterioration (1). HD results from an expanded CAG trinucleotide repeat in the Huntingtin (HTT) gene on chromosome 4 (2). A CAG repeat size of 36 or more is invariably associated with HD. The common age of onset in HD is in the range of 30-50 years (1). However, for a substantial part of HD patients symptoms and signs start after 59 years of age. It is believed that late-onset HD (LoHD) is not very common and usually very mild, although frequencies in literature vary between $4.4 \%$ and $25 \%$ in small cohorts (3-8). These studies are not conclusive regards clinical presentation of LoHD or disease progression $(3,6,9-11)$. The proportion of LoHD patients in literature with a negative family history of HD ranges from 3-68\% (5). As lateonset chorea falls outside the common-age spectrum for HD, diagnosis might be more challenging (12). Therefore, our aim is to provide an overview of this group of patients compared to HD patients with a common age of onset (30-50 years) in a large cohort of HD patients from the Registry database $(13,14)$.

\section{Patients and methods}

Data were obtained from patients enrolled in the European Huntington's Disease Registry Database of the European Huntington's Disease Network (EHDN-Registry). This is a prospective monitored study recording the natural course, clinical spectrum, and management of HD in 140 centers in 17 European and 3 non-European countries $(13,14)$. Participants provided written informed consent for this observational study. Ethical approval was collected from the local ethics committee for each study site contributing to the EHDN Registry.

\section{Participants and clinical assessments.}

Data from the EHDN-Registry database from 2004 to 2016 were used to compare participants with an age of onset of HD $>59$ years (LoHD) with participants with an age of onset of 30-50 years (common-onset HD). Years of follow up varied between one and 11 years. The database includes repeated measurements of all HD patients that were seen in that period, but may have received their diagnosis well before being enrolled in the database. Patients who have a Unified Huntington's Disease Rating Scale (UHDRS) motor score of $\leq 5$ do not meet the criteria of manifest HD and were therefore excluded $(15,16)$. Participants with a missing CAG repeat size or a repeat size of $\leq 35$ were also excluded. Data collection adhered to a standard protocol including electronic case report forms and used identical study protocols for the assessment and sampling of biomaterials. At each center, participants were evaluated by specialists with experience in HD. Study site raters were trained, evaluated, and certified annually to minimize inter-rater and intra-rater variability. Data entry was reviewed online and on-site by monitors fluent in the language of the study site. The HTT CAG genotyping was carried out at each local genetic laboratory.

The onset of disease was estimated by the clinician, family members and participants themselves. The documented time of clinical diagnosis was available as well. When clinical 
information was lacking, the family's estimated time of onset was used, then the patient's estimation and finally the date of clinical diagnosis.

Motor and psychiatric signs were scored using the UHDRS (17). Higher UHDRS motor scores indicated a higher degree of motor impairment (maximum score 124). For cognition, we used the cognitive UHDRS composite score (UHDRS total corrected for letter fluency, symbol digit modalities test, and Stroop sub-scores for word reading, colour naming, and interference), with lower scores indicating lower performance. The disease stage was obtained from total functional capacity (TFC) scores with a maximum score of 13, with lower scores indicating a lower functional status. HADS-SIS sub-scores were obtained for depression, anxiety and irritability combined. A sub-score $\geq 11$ meant the participant had an anxiety or depression disorder. Patients were followed up on a yearly basis according to the EHDN Registry protocol.

Family history and estimated age of onset in parents were obtained from the participants and/or family members. Comorbidities were documented according to the ICD-10 code.

\section{Statistical analysis}

Baseline patient characteristics stratified by onset category were described using mean and standard deviation, or absolute number and percentage. Where continuous variables were highly skewed, their location and spread were described using median and interquartile range (IQR).

Baseline differences between age of onset, gender, CAG repeat size (both alleles), family history, parental inheritance, age of onset in parents, first clinical symptom according to patient and family (motor, cognitive, psychiatric, mixed, other), total motor scores on UHDRS, and first symptoms (chorea, dystonia, rigidity, gait and balance problems) were tested using the independent t-test or the Mann-Whitney U-test for normally and non-normally distributed continuous variables, respectively, or the Chi-squared test for categorical variables. In case of expected cell counts of 5 or lower, we used Fisher's exact test.

Longitudinal differences between the groups regarding the total motor score, total function capacity scale (TFC) score, total of neuropsychological test scores (verbal fluency letter test, verbal fluency category test, Stroop colour naming test, Stroop word reading, Stroop interference test, symbol digit modality test) and HADS-SIS sub- scores were compared using linear mixed-effects regression. The mixed-effects regression models included age group, centered time since diagnosis and an interaction term between both as fixed effects, and an intercept and slope as random effects using an unstructured variance-covariance matrix. Covariances between within-patient measurements over time were modelled using an autoregressive covariance structure. Where the model with the autoregressive covariance structure did not lead to a decrease in the Akaike Information Criterion (AIC), this covariance structure was subsequently omitted from the model, and only variances were estimated. In cases of a violation of heteroscedasticity, a variance function was added to the model.

For statistical analysis we used R, version 3.3.3. 


\section{Results}

\section{Baseline analysis}

9,970 participants were included in the EHDN Registry, of which a total of 3,069 participants without a clinical diagnosis of HD or a UHDRS motor score $\leq 5$ were identified. Participants with a missing CAG repeat size $(n=792)$ and a repeat size of $d 35(n=102)$ were excluded. Of the remaining 6,007 participants, 687 patients had an estimated age of onset $>59$ years $(11.4 \%)$ and 3,216 (53.5\%) an onset of age between 30 and 50 years (Figure1). Retrieving an estimation of the age of onset by rater was possible for 3,020 (93.9\%) participants with common-onset HD and for 630 (91.7\%) participants with LoHD. The age of onset for the remaining part was retrieved from family members, the participant or time of diagnosis. Table 1 shows the baseline characteristics of all patients, stratified by age-of-onset group. The number of patients with motor symptoms as the first symptom was significantly higher in the LoHD group $(n=446)$ compared to the common-onset group $(n=1574)(p<0.001)$, whereas the number of patients with behavioral symptoms was significantly higher in the common-onset group $(n=262)$ compared to the LoHD group $(n=49)(P<.001)$. Gait and balance problems were significantly higher as first symptom in LoHD $(n=577)$ compared to common-onset HD $(n=2408)(P<.001)$.

CAG repeat size in the affected allele was lower in the LoHD group (mean 40.8; SD 1.6) compared to the common-onset group (mean 44.4; SD 2.8) $(P<.001)$. Also the number of patients with a CAG repeat in the reduced penetrance range in the LoHD group $(n=95)$ was significant higher in comparison with the common-onset group $(n=75)(P<.001)$. Fewer LoHD patients had a positive family history $(n=451)$ compared to common-onset patients $(n=2940)$ $(P<.001)$. In case of a positive family history, the age of onset in parents was significantly higher in LoHD patients, with a mean age of onset of 59.1 (SD 11.1) in affected mothers and 58.2 (SD 10.8) in affected fathers, compared to a mean age of onset of in common-onset patient parents of respectively 43.9 (SD 9.2) and 47.2 (SD 10.4) $(P<.001)$.

\section{Longitudinal analyses}

On average, patients with LoHD scored worse from the start as well as over the course of time compared to patients with common-onset HD (Table 2). There was a significant interaction (regression coefficient -0.58 ; SE 0.16; $\mathrm{P}<.001$ ) between age of onset and the effect of time since diagnosis, showing a decrease in progression of the motor score for the LoHD group compared to common-onset group (Figure 2A). We observed statistically significant lower scores in the LoHD group compared to the common-onset group regarding the total function capacity scale (regression coefficient -1.06; SE 0.22; P<.001), but no significant interaction between age group and time (regression coefficient -0.01; SE 0.03; $\mathrm{P}=$.795) (Figure $2 \mathrm{~B}$ ). In addition, all neuropsychological tests (i.e. the verbal fluency tests, both Stroop tests, and the symbol digit modalities test) yielded significantly worse results for the LoHD group (Table 2). The two HADS sub-scores for anxiety and depression did not differ significantly between both age of onset groups (regression coefficient -0.19; SE 0.22; $\mathrm{P}=.049$ and $0.50 ; \mathrm{SE} 0.26 ; \mathrm{P}=.049$ respectively). The anxiety score in the late-onset group decreased over time, whereas for the common-onset group anxiety increased over time. However, there is no significant interaction (regression coefficient 0.03; SE 0.05; P=.543). 
The irritability sub-score, on the other hand, was significantly worse for LoHD patients (regression coefficient -1.17; SE 0.49; $\mathrm{P}=.017$ ).

Compared to LoHD patients (10.5\%), common-onset HD patients (14.4\%) were found to be significant more prone to other neurological and/or musculoskeletal disorders $(P=.012)$.

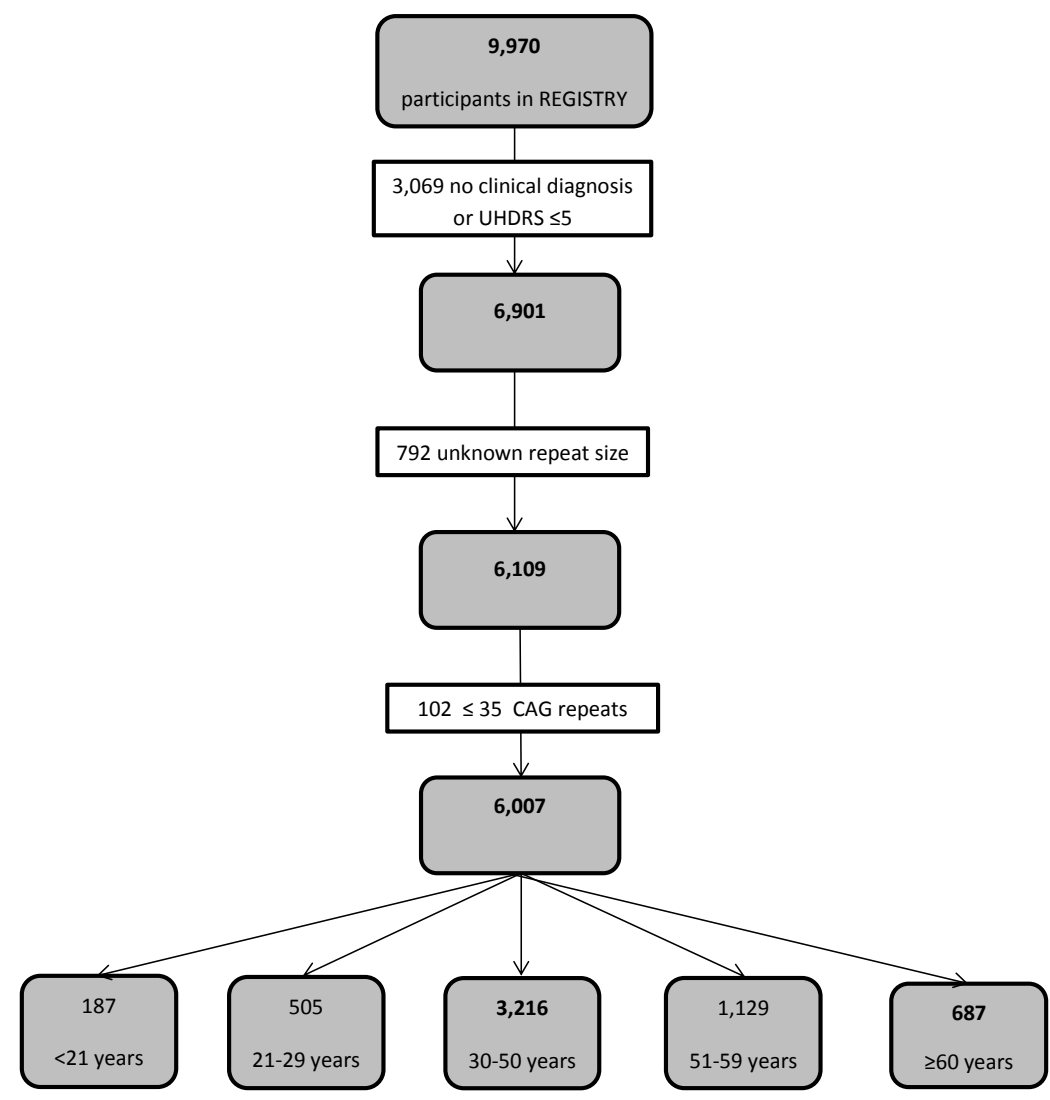

Figure 1. Flowchart of inclusion by clinical diagnosis and repeat size. UHDRS presents for Unified Huntington Disease Rating Scale 
A

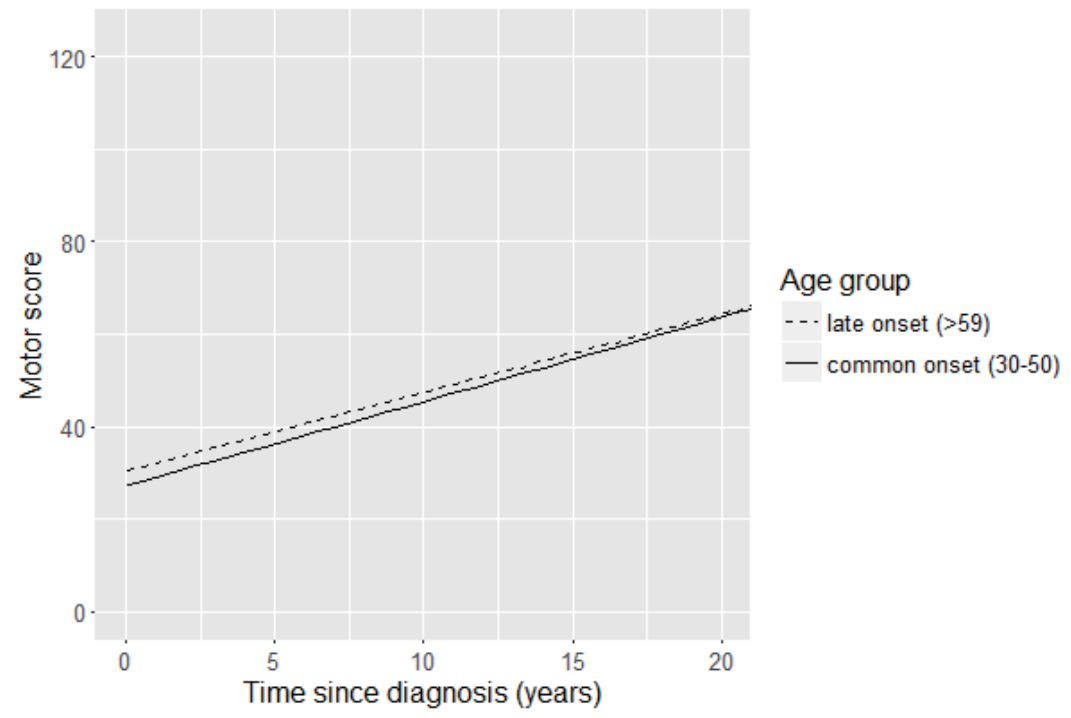

B

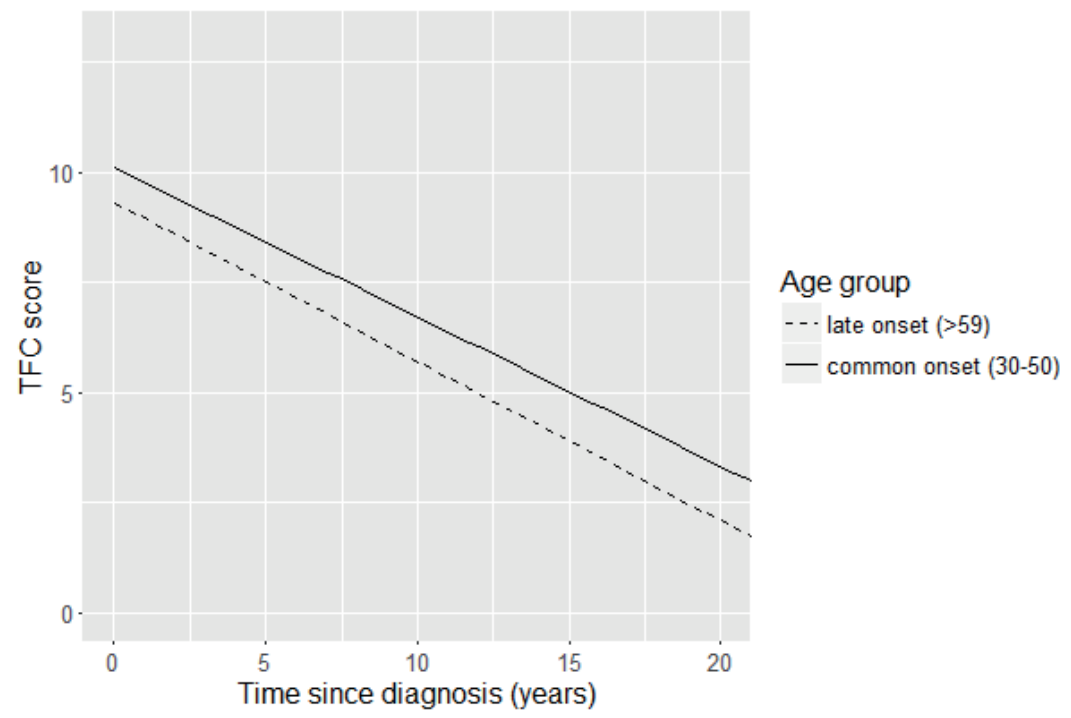

Figure 2. Unified Huntington Disease Rating Scale - motor score (A) and Total Function Capacity (B) in time UHDRS = Unified Huntington's Disease Rating Scale 
Table 1. Baseline characteristics of patients stratified by age of onset group.

\begin{tabular}{|c|c|c|c|}
\hline Characteristics & $\begin{array}{l}\text { Late-onset } \\
\qquad(n=687)\end{array}$ & $\begin{array}{l}\text { Normal-onset } \\
(\mathrm{n}=3216)\end{array}$ & $\begin{array}{l}\text { P-value for } \\
\text { difference }\end{array}$ \\
\hline Age of onset & $68.2(5.6)$ & $44.7(7.5)$ & - \\
\hline Female & $364(53.0 \%)$ & $1683(52.3 \%)$ & 0.788 \\
\hline \multicolumn{4}{|l|}{ CAG repeat size } \\
\hline Allele 1 & $18.3(3.6)$ & $18.6(3.5)$ & 0.115 \\
\hline Allele 2 & $40.8(1.6)$ & $44.4(2.8)$ & $<0.001$ \\
\hline CAG repeat size 36 - 39 & 95 (13.8\%) & $75(0.02 \%)$ & $<0.001$ \\
\hline Family history & 451 (76.1\%) & 2940 (94.6\%) & $<0.001$ \\
\hline Mother affected & $263(43.6 \%)$ & 1467 (46.6\%) & 0.190 \\
\hline Age onset mother & $59.1(11.1)$ & $43.9(9.2)$ & $<0.001$ \\
\hline Father affected & $192(32.2 \%)$ & 1477 (47.4\%) & $<0.001$ \\
\hline Age onset father & $58.2(10.8)$ & $47.2(10.4)$ & $<0.001$ \\
\hline \multicolumn{4}{|l|}{ First clinical symptom } \\
\hline Motor & $446(65.5 \%)$ & $1574(49.1 \%)$ & $<0.001$ \\
\hline Cognitive & $49(7.2 \%)$ & $262(8.2 \%)$ & 0.434 \\
\hline Behavior & $94(13.8 \%)$ & $760(23.7 \%)$ & $<0.001$ \\
\hline Oculomotor & $0(0.0 \%)$ & $6(0.2 \%)$ & 0.599 \\
\hline Mixed & $88(12.9 \%)$ & $562(17.5 \%)$ & 0.004 \\
\hline Other & $4(0.6 \%)$ & 39 (1.2\%) & 0.220 \\
\hline \multicolumn{4}{|l|}{ UHDRS } \\
\hline Chorea & 652 (94.9\%) & 3054 (95.0\%) & 1.000 \\
\hline Dystonia & $415(60.4 \%)$ & 2052 (63.8\%) & 0.102 \\
\hline Rigidity & 409 (59.5\%) & $1940(60.3 \%)$ & 0.733 \\
\hline Gait and balance problems & $577(84.0 \%)$ & 2408 (74.9\%) & $<0.001$ \\
\hline
\end{tabular}

Data are mean (SD) or $\mathrm{n}(\%)$. Abbreviations: UHDRS = Unified Huntington's Disease Rating Scale. 


\section{Discussion}

We analyzed characteristics of LoHD patients in a large European HD cohort. The proportion of LoHD patients in the REGISTRY database is $11.4 \%$. Previous studies that used small cohorts (all fewer than 50 patients) reported estimations of LoHD between 4.4-25\% (3, 4, 6, $7,18,19)$. This study, however, represents the largest cohort study in literature describing the pheno- and genotype of LoHD patients and is therefore statistically more reliable. LoHD was thought to be rare for a long time. Possible explanations for the increase in prevalence include more accurate diagnostics, genetic testing, and better and more readily available symptomatic therapies, certainly in combination with an overall longer life expectancy (20).

In concordance with Koutsis and Lipe, we found that LoHD patients had significantly more balance and gait problems as a first clinical symptom compared to common-onset patients $(6,10)$. Gait and balance disturbances may be caused by other age related diseases, such as arthritis or polyneuropathy. However, the number of patients who suffered from neurological and/or musculoskeletal disease was significantly lower in the LoHD group compared to the common-onset group, so this provided no explanation for the gait and balance disturbances.

Entering the database, LoHD patients scored worse on motor, cognitive and behavioral domains and through-out the course of the disease, although differences in the behavioral symptoms of depression and anxiety did not reach statistical significance. Only progression of the motor score tended to be significantly slower compared to common-onset.

Furthermore, there was a significant difference in family history between the two groups: the LoHD group more frequently had a negative family history. Previous articles already mentioned this $(5,10)$. There are some hypotheses that might explain this phenomenon. First, one might consider that for those who had parents with a late onset of symptoms were more likely to have a negative family history as well and (prior to genetic testing) were misdiagnosed or not diagnosed at all. The fact that the parents of LoHD patients with a positive family history in this study also had a higher age of onset (average 58-59 years), supports this hypothesis. A second explanation might be that parents had an intermediate allele (27-35 CAG repeats). Intermediate alleles are not considered to cause HD, but have the potential to expand into the disease range within one or more generations. Another explanation is that parents had a reduced penetrance repeat length (36-39 CAG repeats). A CAG repeat of 36 to 39 might lead to reduced penetrance, which means that the clinical symptoms are milder and/or symptoms start later in life. Parents of $1-3 \%$ of HD patients are reported to have a repeat size $<36$ (21). Ramos-Arroyo et al. found this to be the case for four LoHD patients in Spain with a negative family history (18). The fact that we found that reduced penetrance alleles were more frequent in the LoHD group supports this idea. Their ancestors might have had a reduced penetrance allele as well, or an intermediate repeat. Unfortunately, we do not have data for the participants' parents.

The CAG repeat length for LoHD was significantly lower than for common-onset HD. This is not a surprise, as we already know that CAG repeat length negatively correlates with age of onset and accounts for almost $50-70 \%$ of the variation in age of onset (22). 
There are some limitations to this study. The REGISTRY data, unfortunately, contains multiple instances of missing data, which made it necessary to modify our statistical model accordingly. For many participants, age of onset is a crude estimation. The estimation of age of onset by the rater is likely to be the most reliable estimation. This was available for $92-$ $94 \%$ of participants in both groups. Since there is no marker to establish the date of disease onset, this is the most accurate method currently available. By choosing two well-defined age groups we hoped to avoid any overlap in age of onset. Furthermore, the common age of onset for $\mathrm{HD}$ is in the range of 30-50 years. We chose to compare the common age of onset with an age of onset $>59$. Ideally, all patients would have been tracked from the moment their first symptoms started, but this was not possible. As a result, some patients were already more affected than others when they were enrolled in this database.

Furthermore, the REGISTRY data provide no information on diagnostic delay in LoHD patients. This means that, especially, for those with a negative family history the estimated time of onset of disease remains a crude estimation, as mentioned above. It is likely, that disease onset might have been earlier, but not recognized as such by patient, family and/or healthcare professionals, because of a negative family history.

We conclude that LoHD patients present more frequently with motor symptoms and less frequently with behavioral problems compared to common-onset HD patients. They have significantly more balance and gait problems as first symptom compared to common-onset patients. In contrast to previous studies, we found that disease progression is not milder in LoHD as has been suggested before, however motor progression tends to be slower (5). The family history is likely to be negative, which might make diagnosing HD more difficult in this population. However, the balance and gait problems as first symptom might be helpful in diagnosing HD in elderly patients with a clear chorea, mild or no behavioral problems and a negative family history. 


\section{Reference List}

1. Roos RA. Huntington's disease: a clinical review. Orphanet journal of rare diseases. 2010;5(1):40.

2. A novel gene containing a trinucleotide repeat that is expanded and unstable on Huntington's disease chromosomes. The Huntington's Disease Collaborative Research Group. Cell. 1993;72(6):971-83.

3. Cornejo-Olivas MR, Inca-Martinez MA, Espinoza-Huertas K, Veliz-Otani D, Velit-Salazar MR, Marca $\mathrm{V}$, et al. Clinical and Molecular Features of Late Onset Huntington Disease in a Peruvian Cohort. Journal of Huntington's disease. 2015;4(1):99-105.

4. Sipila JOT, Kauko T, Paivarinta M, Majamaa K. Comparison of mid-age-onset and late-onset Huntington's disease in Finnish patients. Journal of neurology. 2017.

5. Chaganti SS, McCusker EA, Loy CT. What do we know about Late Onset Huntington's Disease? Journal of Huntington's disease. 2017;6(2):95-103.

6. Koutsis G, Karadima G, Kladi A, Panas M. Late-onset Huntington's disease: diagnostic and prognostic considerations. Parkinsonism \& related disorders. 2014;20(7):726-30.

7. Alonso ME, Ochoa A, Boll MC, Sosa AL, Yescas P, Lopez M, et al. Clinical and genetic characteristics of Mexican Huntington's disease patients. Movement disorders : official journal of the Movement Disorder Society. 2009;24(13):2012-5.

8. Roos RA, Vegter-van der Vlis M, Hermans J, Elshove HM, Moll AC, van de Kamp JJ, et al. Age at onset in Huntington's disease: effect of line of inheritance and patient's sex. Journal of medical genetics. 1991;28(8):515-9.

9. James CM, Houlihan GD, Snell RG, Cheadle JP, Harper PS. Late-onset Huntington's disease: a clinical and molecular study. Age and ageing. 1994;23(6):445-8.

10. Lipe $\mathrm{H}$, Bird T. Late onset Huntington Disease: clinical and genetic characteristics of 34 cases. Journal of the neurological sciences. 2009;276(1-2):159-62.

11. Roos RA, Hermans J, Vegter-van der Vlis M, van Ommen GJ, Bruyn GW. Duration of illness in Huntington's disease is not related to age at onset. Journal of neurology, neurosurgery, and psychiatry. 1993;56(1):98-100.

12. Appollonio I, Frisoni GB, Curto N, Trabucchi M, Frattola L. Which diagnostic procedures in the elderly? The case of late-onset Huntington's disease. J Geriatr Psychiatry Neurol. 1997;10(1):39-46.

13. Orth M, European Huntington's Disease N, Handley OJ, Schwenke C, Dunnett S, Wild EJ, et al. Observing Huntington's disease: the European Huntington's Disease Network's REGISTRY. Journal of neurology, neurosurgery, and psychiatry. 2011;82(12):1409-12. 
14. Orth M, Handley OJ, Schwenke C, Dunnett SB, Craufurd D, Ho AK, et al. Observing Huntington's Disease: the European Huntington's Disease Network's REGISTRY. PLoS currents. 2010;2:RRN1184.

15. Reilmann R, Leavitt BR, Ross CA. Diagnostic criteria for Huntington's disease based on natural history. Movement disorders : official journal of the Movement Disorder Society. 2014;29(11):1335-41.

16. Tabrizi SJ, Scahill RI, Durr A, Roos RA, Leavitt BR, Jones R, et al. Biological and clinical changes in premanifest and early stage Huntington's disease in the TRACK-HD study: the 12-month longitudinal analysis. Lancet neurology. 2011;10(1):31-42.

17. Unified Huntington's Disease Rating Scale: reliability and consistency. Huntington Study Group. Movement disorders : official journal of the Movement Disorder Society. 1996;11(2):136-42.

18. Ramos-Arroyo MA, Moreno S, Valiente A. Incidence and mutation rates of Huntington's disease in Spain: experience of 9 years of direct genetic testing. Journal of neurology, neurosurgery, and psychiatry. 2005;76(3):337-42.

19. Almqvist EW, Elterman DS, MacLeod PM, Hayden MR. High incidence rate and absent family histories in one quarter of patients newly diagnosed with Huntington disease in British Columbia. Clinical genetics. 2001;60(3):198-205.

20. Evans SJ, Douglas I, Rawlins MD, Wexler NS, Tabrizi SJ, Smeeth L. Prevalence of adult Huntington's disease in the UK based on diagnoses recorded in general practice records. Journal of neurology, neurosurgery, and psychiatry. 2013.

21. Andrew SE, Goldberg YP, Hayden MR. Rethinking genotype and phenotype correlations in polyglutamine expansion disorders. Human molecular genetics. 1997;6(12):2005-10.

22. Andrew SE, Goldberg YP, Kremer B, Telenius H, Theilmann J, Adam S, et al. The relationship between trinucleotide (CAG) repeat length and clinical features of Huntington's disease. Nature genetics. 1993;4(4):398-403 

CHAPTER 5 


\section{Predictive genetic testing in Huntington's disease: should a neurologist be involved?}

Mayke Oosterloo, Emilia K Bijlsma, Corien C Verschuuren-Bemelmans, Meyke I Schouten, Christine EM de Die-Smulders and Raymund AC Roos 


\section{Abstract}

Background: International guidelines on Huntington's Disease recommend neurological examination in the predictive testing trajectory. Experiences and personal wishes of persons at-risk of Huntington's Disease regarding this topic have never been evaluated.

Objective: The objective was to provide an overview of the experiences of Dutch at-risk persons, opting for predictive testing, in consulting a neurologist before and after DNAanalysis.

Method: Persons who were counseled in four Dutch clinics between 2017 and 2019 were retrospectively or prospectively approached for a questionnaire which listed topics as experiences with consultation and personal wishes.

Results: From 71 participants, 44 participants visited a neurologist. 41 participants indicated their visit to a neurologist as positive (93.2\%). The majority of participants $(n=59)$ desired consulting a neurologist. 32 participants indicated consultation shortly after (Desired After Group) and twenty-seven before DNA-analysis (Desired Before Group) as personal wish. The Desired Before Group consisted of a significantly higher number of participants who actually consulted a neurologist before predictive testing $(n=26)$ compared to the number of participants who actually consulted a neurologist after DNA-analysis in the Desired After Group $(n=11)(p<0.001)$. The Desired After Group $(n=19)$ had a significantly higher number of Huntington's Disease Gene Expansion Carriers compared to the Desired Before Group $(n=5)(p 0.003)$.

Conclusion: Participants are content with consultation. However, persons without the gene expansion still feel the need to get in touch with an neurologist. Therefore, offering a consultation with a neurologist before DNA-analysis might be beneficial for all. 


\section{Introduction}

Huntington's disease (HD) is an autosomal dominant neurodegenerative disease characterized by involuntary movements, psychiatric disorders, and cognitive deterioration. $H D$ results from an unstable and expanded CAG trinucleotide repeat in the Huntingtin (HTT) gene on chromosome 4 (1). A CAG repeat size of 36 or more is associated with HD (2). Most patients develop symptoms and signs in adulthood with a mean onset of 40 years of age.

Persons at risk are those from an HD family who do not know their genetic status. They have the availability to opt for predictive DNA testing. If predictive testing shows an expanded CAG repeat (>39), this person will develop HD in time (HD gene expansion carrier, HDGEC). A CAG repeat of 36 to 39 gives reduced penetrance which means that the clinical symptoms might not appear. The main reasons for persons at risk to get predictive testing are: prepare for the future, wanting to inform their children and family planning (3-8).

There are several departments of Clinical Genetics offering predictive testing in the Netherlands. Four of these, Leiden University Medical Center (LUMC), Maastricht University Medical Center (MUMC+), Radboud University Medical Center (Radboudumc) and University Medical Center Groningen (UMCG) participated in the study. A person at risk for HD who visits one of these four clinics is informed by a clinical geneticist about the possibilities of predictive testing. In LUMC persons at risk are also assessed by a neurologist with HD expertise. The neurologist takes the medical history and performs a neurological examination. In MUMC+, Radboudumc and UMCG persons at risk are as a routine not assessed by a neurologist in the counseling phase. They are offered to consult a neurologist with HD expertise, appointments are made at patient's request before or after the predictive testing trajectory.

The international guidelines of the Huntington Association and the World Federation of Neurology Research Group on Huntington's chorea of 1994 and the revised version of 2013 posits that neurological examinations (if possible) are considered important to establish a baseline evaluation of each person (paragraph REC 6.2). This however is not a requirement for participation in predictive testing $(9,10)$. At the moment there is a diverse use of neurological examination around predictive testing: some persons at risk are assessed by a neurologist before their predictive test as a part of the procedure while others are only offered a neurologic examination before or after the test procedure $(4,7,11)$.

No data are available if a neurological consultation contributes to the psychological wellbeing of persons at risk for HD or HDGECs. The results of PREDICT-HD and TRACK-HD showed that even in premanifest HDGECs subtle motor, cognitive and behavioral changes can be observed, before clinical diagnosis according to the current criteria of HD-onset (12-19). If fear for the disease onset is the reason for predictive testing, consulting a neurologist might have a positive contribution and even be stress reducing if there are no signs of the disease. On the other hand, a neurological examination might also arouse fear of finding signs of the disease. 
The experiences of persons at risk of HD in consulting a neurologist in the predictive testing phase have never been systematically evaluated. The guidelines advise a neurological examination, during the preliminary investigation phase of predictive testing. It is our aim to provide an overview of the experiences of Dutch persons at risk of HD in consulting a neurologist before or after DNA analysis. Furthermore, we would like to be able to make a recommendation if and at what moment in the testing procedure the judgment of a neurologist is desirable.

\section{Subjects and methods}

This is a partially retrospective and prospective cohort study in at-risk persons who visited one of four genetic counseling clinics in the Netherlands. Ethical approval was collected from the local ethics committee of each of the four university hospitals.

At risk persons who visited the genetic counseling clinics of LUMC, MUMC+, Radboudumc and UMCG between 1st January 2017 and 31st July 2019 were approached by mail to participate in this study and fill in an online questionnaire. They received a code to login online. Informed consent was also given online. Both HDGECs and participants with a normal DNA test result were included, as well as those who finally decided not to undergo the predictive test. Those who were legal incapable or under 18 years of age were excluded from participation.

There are no validated questionnaires regarding this subject. Therefore, a list of emerging topics was made: current age, gender, reason for predictive testing, consultation of neurologist, stage of the predictive process, personal experiences with consultation and personal wishes.

Data were analyzed using Pearson chi-square test, Fisher's exact test, T-test, Mann-Whitney $\mathrm{U}$ test or Pearson correlation, whichever is appropriate. Statistical analysis was performed using SPSS version 23. P-values of $<0.05$ were considered as statistically significant.

\section{Results}

245 patients received an invitation to participate (Figure 1). 71 participants, of which $87.3 \%$ retrospectively, completed the questionnaire. The response rate was $29 \%$. All, but three participants underwent predictive testing. 31 participants had a repeat size $>35(43.7 \%)$. The main reasons for counseling are given in Table 1.44 (62\%) participants visited a neurologist before or after DNA-analysis and $27(38 \%)$ did not visit a neurologist. The majority of the participants indicated their visit to a neurologist as positive $(n=41 ; 93.2 \%)$. Whilst more than one reason was given for being positive visiting a neurologist, 24 (58.5\%) gave meeting the future treating neurologist as one of these, followed by the possibility to get informed about HD ( $n=20$; 48.9\%). 32 participants visited a neurologist before molecular testing $(72.7 \%)$ (Table 1). 
All participants $(n=71)$ were asked at what moment in the predictive testing phase they would have preferred to consult a neurologist. 67 participants answered the question. The majority ( $n=59 ; 88 \%$ ) opted for consulting a neurologist before or shortly after DNA analysis. Twenty-seven participants (45.8\%) would prefer consulting a neurologist before DNA-analysis ( Desired Before Group). 26 participants (96.3\%) in the Desired Before Group actually consulted a neurologist before DNA-analysis (Actual Before Group) and one did not (0.3\%) (Actual After Group) (Table 2). The group ( $n=32 ; 54,2 \%)$ who would prefer a consultation shortly after DNA-analysis (Desired After Group), was more varied (Figure 2).

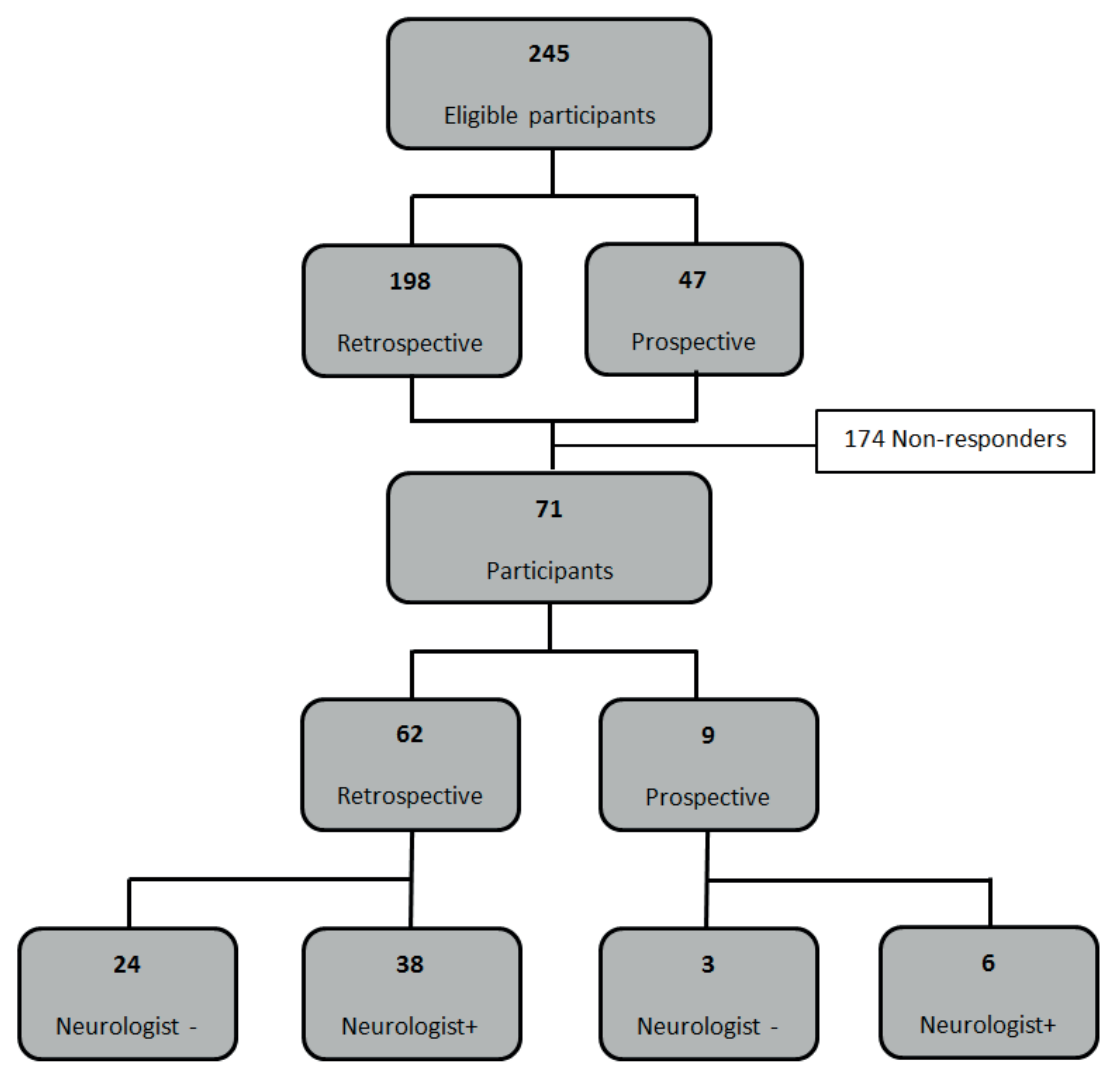

Figure 1. Flowchart of inclusion

Neurologist $=$ no consult by a neurologist in predictive trajectory; neurologist $+=$ consult by neurologist in the predictive trajectory 
Table 1 Baseline characteristics of patients

\begin{tabular}{|c|c|}
\hline Number of participants & 71 \\
\hline Age (SD) (years) & $47.8(15.4)$ \\
\hline Female/male & $38 / 33$ \\
\hline Retrospective & $62(87.3)$ \\
\hline Repeat $>35$ & $30(42.3)$ \\
\hline \multicolumn{2}{|l|}{ Main reason for counseling } \\
\hline Family planning & $8(11.3)$ \\
\hline Fear of developing disease & $24(33.8)$ \\
\hline Future planning & $9(12.7)$ \\
\hline For the next generation & $22(31)$ \\
\hline Fear of having $\mathrm{HD}$ & $7(9.9)$ \\
\hline Missing & $1(1.4)$ \\
\hline \multicolumn{2}{|l|}{ Consultation neurologist } \\
\hline Yes & $44(62)$ \\
\hline No & $27(38)$ \\
\hline \multicolumn{2}{|l|}{ Time of consultation } \\
\hline Before DNA test & $32(72.7)$ \\
\hline After DNA test & $12(27.3)$ \\
\hline \multicolumn{2}{|l|}{ Consultation neurologist } \\
\hline Symptoms HD discussed & $35(79.5)$ \\
\hline Neurological examination showed & $28(63.6)$ \\
\hline No abnormalities & $19(67.9)$ \\
\hline Non-specific abnormalities & $3(10.7)$ \\
\hline HD symptoms & $6(21.4)$ \\
\hline \multicolumn{2}{|l|}{ Experience consultation neurologist } \\
\hline Positive & $41(93.2)$ \\
\hline Neutral & $3(6.8)$ \\
\hline Negative & 0 \\
\hline \multicolumn{2}{|c|}{ Reasons positive experience visit neurologist* } \\
\hline Information about $\mathrm{HD} /$ ask questions & $20(29.4)$ \\
\hline Information about research & $9(13.2)$ \\
\hline Relief there were no signs of HD & $15(22.0)$ \\
\hline Get acquainted with neurologist & $24(35.3)$ \\
\hline
\end{tabular}

Data are $\mathrm{n}(\%)$ or $\mathrm{n}(\mathrm{SD}) .{ }^{*}$ more than one reason was given in some cases Abbreviations: $\mathrm{HD}=$ Huntington's Disease 
The Desired After Group consists of participants who want to consult a neurologist shortly after DNA analysis regardless the outcome of the analysis and those who wish to see the neurologist only in case they are HDGEC (Figure 2). Eight participants did not want to visit a neurologist at all or in time when they or their relatives noticed symptoms and signs of HD.

The Desired Before Group and Desired After Group were compared to each other in order to evaluate the satisfaction of the participants with the provided care. The Desired Before Group consisted of a significantly higher number of participants who actually consulted a neurologist before predictive testing $(n=26)$ compared to the number of participants who actually consulted a neurologist after DNA-analysis in the Desired After Group $(n=11)$ $(p<0.001)$ (Table 2). The Desired After Group had a significantly higher number of HDGECs (repeat length >35) $(n=19)$ compared to the Desired Before Group ( $n=5)(p$ 0.003). In the retrospective group, the number of participants with a repeat expansion $(>35)(n=26)$ was not significantly higher compared to those without a repeat expansion $(<36)(n=33)(p=1.0)$. There were no significant differences in age between the Desired Before (mean 51.1; SD 14.5) and Desired After Group (mean 44.7; SD 14.1) (p 0.91).

Table 2. Actual versus desired visit to neurologist

\begin{tabular}{lccc}
\hline & \multicolumn{2}{c}{ Desired visit neurologist } & Total \\
\hline Actual visit neurologist & Before DNA & After DNA & 32 \\
Before DNA & 26 & 6 & 11 \\
After DNA & 0 & 15 & 16 \\
No consultation & 1 & 32 & 59 \\
Total & 27 & & \\
\hline
\end{tabular}

\section{Discussion}

The international guidelines of the Huntington Association and the World Federation of Neurology Research Group on Huntington's chorea of 1994 and the revised version of 2013 state that neurological examinations (if possible) are considered important to establish a baseline evaluation of each person. The guidelines state that the examination should be done before predictive testing.

We describe the experiences of persons at risk of HD with consulting a neurologist in the predictive testing phase. The main reasons to undergo DNA analysis in the Netherlands are comparable to the literature (3-8). The majority of the participants who visited a neurologist felt positive about their visit to a neurologist. The participants who consulted a neurologist before DNA-analysis were significantly more satisfied with the offered care compared to those who consulted a neurologist after DNA-analysis. 


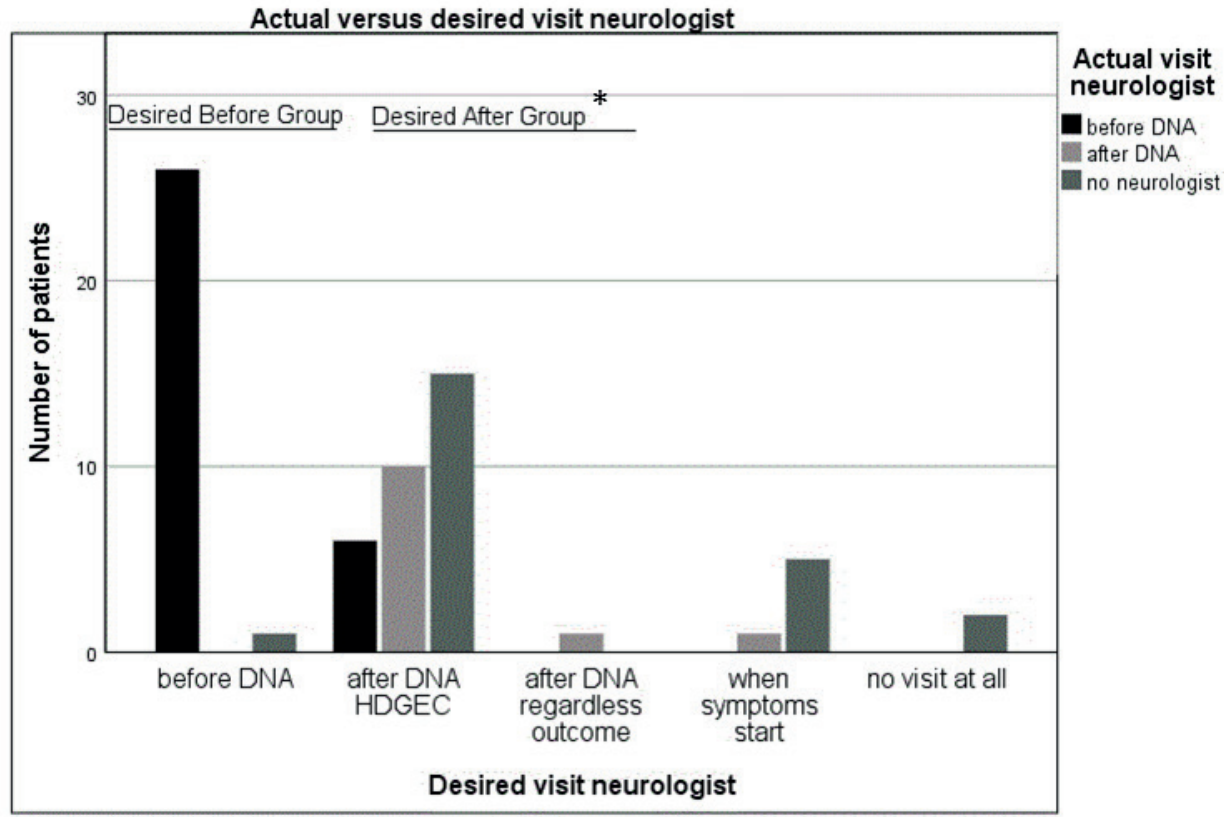

Figure 2. Time of desired visit neurologist versus actual visit

*The Desired After Group consists of participants who want to consult a neurologist shortly after DNA analysis regardless the outcome of the analysis and those who wish to see the neurologist only in case they are HDGEC.

Abbrevations: HDGEC = Huntington's Disease Gene Expansion Carrier

However, our results also show that HDGECs were more likely to prefer a consult after DNA-analysis, whereas participants without a repeat expansion were more likely to prefer a consult before analysis. On the one hand, those without a repeat expansion may wish to get the opportunity to ask questions about HD or get acquainted with an HD specialist. On the other hand, HDGECs might fear a consultation with a neurologist will reveal symptoms or signs of HD.

The majority of the subjects participated retrospectively and there were no significant differences between HDGECs and non HDGECs.

There are some limitations to this study. The number of participants is small, which might make statistical analysis less valid. There is also a chance of selection bias, meaning those who were not content with the offered care or would not wish to see a neurologist, did not participate. Most of the persons were included retrospectively, which might have induced recall bias.

Neurological examination is not a requirement for participation in predictive testing. Previous literature states that in case the applicant clearly does not wish to consider that he is possibly affected and that he might perhaps need a neurological consultation, we should appreciate such as a psychological defense (3). However, our results show that our 
participants who consulted a neurologist were positive about the consult. Participants felt it was even comforting to be acquainted with an HD specialist who will treat them (in the future). With numerous trials evaluating disease modifying therapies it becomes more and more important to define disease-onset as early as possible. However, it is even more important to keep HDGECs informed about these trials and offer them the possibility to participate in register studies such as Enroll-HD. In this way they have a higher and better chance to participate in future disease modifying therapy trials.

We conclude that most participants would like to consult a neurologist before or after DNA analysis. In our study persons without the gene expansion for HD clearly feel the need to have the opportunity to get in touch with a neurologist. As we are not able to distinguish premanifest HDGECs from non-expansion carriers in the beginning of the predictive testing procedure, offering a neurological consult in the premanifest testing procedure before DNA analysis might be beneficial for all. 


\section{Reference List}

1. A novel gene containing a trinucleotide repeat that is expanded and unstable on Huntington's disease chromosomes. The Huntington's Disease Collaborative Research Group. Cell. 1993;72(6):971-83.

2. Roos RA. Huntington's disease: a clinical review. Orphanet journal of rare diseases. 2010;5:40.

3. Tibben A. Predictive testing for Huntington's disease. Brain research bulletin. 2007;72(2-3):165-71.

4. Ramond F, Quadrio I, Le Vavasseur L, Chaumet H, Boyer F, Bost M, et al. Predictive testing for Huntington disease over 24 years: Evolution of the profile of the participants and analysis of symptoms. Mol Genet Genomic Med. 2019;7(10):e00881.

5. Dufrasne S, Roy M, Galvez M, Rosenblatt DS. Experience over fifteen years with a protocol for predictive testing for Huntington disease. Molecular genetics and metabolism. 2011;102(4):494-504.

6. Scuffham TM, MacMillan JC. Huntington disease: who seeks presymptomatic genetic testing, why and what are the outcomes? Journal of genetic counseling. 2014;23(5):754-61.

7. Mandich P, Lamp M, Gotta F, Gulli R, lacometti A, Marchese R, et al. 1993-2014: two decades of predictive testing for Huntington's disease at the Medical Genetics Unit of the University of Genoa. Mol Genet Genomic Med. 2017;5(5):473-80.

8. Holman MA, Quillin J, York TP, Testa CM, Rosen AR, Norris VW. The Changing Age of Individuals Seeking Presymptomatic Genetic Testing for Huntington Disease. Journal of genetic counseling. 2018;27(5):1157-66.

9. International Huntington Association and the World Federation of Neurology Research Group on Huntington's Chorea. Guidelines for the molecular genetics predictive test in Huntington's disease. Journal of medical genetics. 1994;31(7):555-9.

10. MacLeod R, Tibben A, Frontali M, Evers-Kiebooms G, Jones A, Martinez-Descales A, et al. Recommendations for the predictive genetic test in Huntington's disease. Clinical genetics. 2013;83(3):221-31.

11. McCusker E, Richards F, Sillence D, Wilson M, Trent RJ. Huntington's disease: neurological assessment of potential gene carriers presenting for predictive DNA testing. Journal of clinical neuroscience : official journal of the Neurosurgical Society of Australasia. 2000;7(1):38-41.

12. Kirkwood SC, Siemers E, Bond C, Conneally PM, Christian JC, Foroud T. Confirmation of subtle motor changes among presymptomatic carriers of the Huntington disease gene. Archives of neurology. 2000;57(7):1040-4. 
13. Tabrizi SJ, Langbehn DR, Leavitt BR, Roos RA, Durr A, Craufurd D, et al. Biological and clinical manifestations of Huntington's disease in the longitudinal TRACK-HD study: cross-sectional analysis of baseline data. Lancet neurology. 2009;8(9):791-801.

14. Tabrizi SJ, Scahill RI, Durr A, Roos RA, Leavitt BR, Jones R, et al. Biological and clinical changes in premanifest and early stage Huntington's disease in the TRACK-HD study: the 12-month longitudinal analysis. Lancet neurology. 2011;10(1):31-42.

15. Tabrizi SJ, Reilmann R, Roos RA, Durr A, Leavitt B, Owen G, et al. Potential endpoints for clinical trials in premanifest and early Huntington's disease in the TRACK-HD study: analysis of 24 month observational data. Lancet neurology. 2012;11(1):42-53.

16. Tabrizi SJ, Scahill RI, Owen G, Durr A, Leavitt BR, Roos RA, et al. Predictors of phenotypic progression and disease onset in premanifest and early-stage Huntington's disease in the TRACKHD study: analysis of 36-month observational data. Lancet neurology. 2013;12(7):637-49.

17. Paulsen JS, Langbehn DR, Stout JC, Aylward E, Ross CA, Nance M, et al. Detection of Huntington's disease decades before diagnosis: the Predict-HD study. Journal of neurology, neurosurgery, and psychiatry. 2008;79(8):874-80.

18. Biglan KM, Zhang $Y$, Long JD, Geschwind M, Kang GA, Killoran A, et al. Refining the diagnosis of Huntington disease: the PREDICT-HD study. Frontiers in aging neuroscience. 2013;5:12.

19. Paulsen JS, Long JD, Johnson HJ, Aylward EH, Ross CA, Williams JK, et al. Clinical and Biomarker Changes in Premanifest Huntington Disease Show Trial Feasibility: A Decade of the PREDICT-HD Study. Frontiers in aging neuroscience. 2014;6:78. 


\section{CHAPTER 6}




\section{Diagnosing juvenile Huntington's disease: an explorative study among caregivers of affected children}

Mayke Oosterloo, Emilia K Bijlsma, Christine EM de Die-Smulders, and Raymund AC Roos 


\section{Abstract}

Objective: To investigate the reasons for the diagnostic delay of juvenile Huntington's disease patients in the Netherlands.

Methods: This study uses interpretative phenomenological analysis. Eligible participants were parents and caregivers of juvenile Huntington's disease patients.

Results: Eight parents were interviewed, who consulted up to four health care professionals. The diagnostic process lasted three to ten years. Parents believe that careful listening and follow-up would have improved the diagnostic process. Although they believe an earlier diagnosis would have benefited their child's wellbeing, they felt they would not have been able to cope with more grief at that time.

Conclusion: The delay in diagnosis is caused by the lack of knowledge among health care professionals on the one hand, and the resistance of the parent on the other. For professionals, the advice is to personalize their advice in which a conscious doctor's delay is acceptable or even useful. 


\section{Introduction}

Huntington's disease (HD) is an autosomal dominant neurodegenerative disease characterized by unwanted movements, psychiatric disorders, and cognitive deterioration. $\mathrm{HD}$ results from an unstable and expanded Cytosine Adenine Guanine (CAG) trinucleotide repeat in the Huntingtin (HTT) gene on chromosome 4 (1). A CAG repeat size of 36 or more is invariably associated with HD. Most patients develop symptoms and signs in adulthood, with a mean onset of 40 years of age.

The juvenile form of Huntington's disease (JHD) is rare. It is defined as HD with an onset of $<21$ years of age (2). The Juvenile HD Working Group of the European Huntington's Disease Network (EHDN) recently redefined JHD as pediatric HD with an age of onset $\leq 18$ years ( 3 ). However, as our study was conducted before this redefinition, we still use the old definition. JHD contributes about $5.4 \%$ of all HD cases, with the percentage ranging from $1 \%-15 \%$ in several series $(4,5)$. There is an inverse correlation between the length of the CAG repeat and the age of onset. The longer the CAG repeat, the earlier the disease-associated symptoms start $(6,7)$.

The clinical presentation in children differs from that in adults. The most prevalent clinical features at the presentation of JHD are cognitive impairment and behavioral changes $(8,9)$. Common presenting motor features are rigidity, gait disorder, and oral motor dysfunction $(2,4,10,11)$. Chorea is uncommon in children with HD but becomes manifest in the second decade. Clinical features in the first decade are defined as two or more of the following features: declining school performance, seizures, oral motor dysfunction, rigidity and/or gait disorder in combination with a parent with (pre)symptomatic HD or a family history of HD (4). The clinical features of individuals in the second decade (adolescent) are less well defined in the literature but are more comparable to the adult manifestation. Disease progression in JHD is likely to be faster compared to normal onset (12). The variable and non-specific clinical presentation, such as declining school performances and behavioral disturbance, may be confused with disorders such as autism spectrum disorders or attention deficit hyperactivity disorder (ADHD) or with the effects of disrupted social and home environments in HD families. This significantly increases the chance of misdiagnosis and/or diagnostic delay. JHD is rare and probably less well recognized than usual-onset HD (30-50 years) by health professionals without specific knowledge of the disease. One study shows a mean delay of 9 years before diagnosis and another shows delays ranging from 0 to 6 years $(9,11)$.

The psychosocial impact and personal experience of parenting a child with JHD have been described in earlier studies (13-16). They describe the denial of parents at first, but also the awareness something is wrong with their child. Furthermore, these studies highlight the positive and negative experiences of the parents regarding the support they receive from family, friends, and professional caregivers.

Our aim is to investigate the diagnostic process of JHD patients in the Netherlands. We focus on the diagnostic timeline, the experiences of the parents or caregivers during the diagnostic process, and the role of the different health care providers. In this way, we hope 
to gain insight into the reason for the probable diagnostic delay and how to improve the diagnostic path.

\section{Methods}

This study employed in-depth semi-structured interviews and interpretative phenomenological analysis (IPA), a well-established experiential approach in health and clinical psychology (17). IPA's focus on the in-depth examination of the psychological process and descriptions of how individuals deal with life-transforming, or life-threatening events, conditions, or events.

\section{Participants}

Eligible participants were parents and/or caregivers of (living or already deceased) JHD patients in the Netherlands. Participants were recruited through a call published in the magazine of the Dutch Huntington's disease association and through HD specialists. The patients themselves were not interviewed.

In this study, JHD was defined as the onset of symptoms and signs of HD before the age of 21 years (4). Confirmation of the clinical diagnosis by molecular testing was not necessary for inclusion. If the patient was older than 20 years of age at the time of the interview, the caregivers could still participate.

All subjects gave their informed consent for inclusion before they participated in the study. The study was conducted in accordance with the Declaration of Helsinki, and the protocol was approved by the Ethics Committee of Leiden University Medical Center, The Netherlands (P17.025). Participants could also consent to a semi-structured interview with their child's general physician (GP). Information retrieved from the GP was used to complete the timeline of the diagnostic process.

\section{Data Collection}

The interviews took place at the participants' homes or the out-patient clinic and were conducted by the first author and audio-recorded. All interviews started with the opportunity for participants to ask questions about the aim of the study. The interviews were semistructured, covering general issues regarding JHD (age of onset, first symptoms), the recognition of JHD symptoms by parents and health professionals, the number of consulted health professionals, and their expertise in HD. Furthermore, questions about the quality and quantity of support from health care professionals and the process of diagnosis were included. The following two questions, directly referring to the process of diagnosis, were always asked:

- Which elements of the diagnostic process should be improved?

- Should the diagnosis of JHD have been made earlier, and if so, would you and your son/ daughter have benefited from it? 


\section{Analysis}

Consistent with standard qualitative research techniques, the interviews were based on a topic list, which evolved as the interviews progressed through an iterative process to ensure the questions captured all relevant emerging themes.

The interviews were transcribed ad verbatim and analyzed with IPA. First, several close readings of the transcripts were made, and points of interest and significance noted and coded. Second, these initial comments were used to document emerging themes, aiming at capturing the essential quality of the participants' experiences. Third, a list of themes was compiled and connections were made between the themes. The connected themes were grouped and labeled (superordinate theme). The superordinate themes for each interview were then compared, producing a table of comparative themes.

\section{Results}

Eight parents/caregivers gave informed consent for an interview. The interviews lasted approximately $60 \mathrm{~min}$ each. Two parents contacted the researcher after reading the announcement in the magazine of the Huntington's disease association. Five parents were approached by the treating HD specialist, and one parent was informed by another parent within the JHD community and contacted the researcher themselves. Six individual parents/ caregivers and two couples were interviewed. Four of them also gave informed consent for an interview with their child's GP. All identifying information has been changed to protect the privacy of the participating families. Table 1 presents the clinical characteristics of the children. The cultural backgrounds of the parents were alike. Seven participants had one affected child. One had two affected children. The mean age at diagnosis was 16 years, with a range of 9 to 24 (figure 1). The mean repeat size was 62, with a range from 49 to 83 . Individual repeat sizes cannot be provided since parents gave no informed consent for this. In six cases the father was the affected parent and, in three cases, the mother. All but one of the affected parents were deceased at the time of the interview. Six of the nine children were still alive. Six children had or still received HD expert care, three from an HD expert neurologist and three in an HD nursing home (table 2).

Six superordinate themes emerged from the analysis. They describe the parents' perceptions of the problems associated with the JHD diagnostic process. The six themes are (1) awareness ('something is wrong'), (2) the role of the different health care providers during the diagnostic process, (3) experiences after the diagnosis, (4) the need for support, (5) which elements of the diagnostic process should be improved, and (6) what if the diagnosis had been made earlier? These themes will be highlighted below by means of quotes from the interviewed parents/caregivers.

\section{Awareness: 'Something is Wrong'}

All parents noticed something was wrong with their child when, in retrospect, the first symptoms of the disease presented. The first symptoms varied from decreasing school performance, behavioral or motor symptoms, and sometimes a combination of these. Some 
initially thought the situation at home with the affected parent or the recent decease of a parent from HD was the cause of the behavior problems.

"My husband was still alive, but he was ill and I thought it's the situation at home. Because there was so much going on at home. I thought it was the stress because dad is at home and also has all these weird complaints." (Anna)

"By the end of elementary school, his grades were so poor. But at that time I thought it was because of the huge problems at home with my husband." (Clara)

These quotes highlight the disruption of the home environment with an ill parent as well as behavioral problems of this parent being seen as a cause of the behavioral changes in children from HD families. Also, puberty was mentioned as the initial presumed cause of the change in the behavior in older children.

"He was aggressive and angry. I thought it was some kind of macho behavior and wasn't quite sure if it had anything to do with HD. We thought it was puberty. But then I started reading about HD and I knew it was Huntington's." (Ellen)

Table 1. Clinical characteristics of juvenile Huntington's disease (JHD) patients.

\begin{tabular}{|c|c|c|c|c|c|c|c|c|c|}
\hline Parents & Affected Child & $\begin{array}{l}\text { Affected } \\
\text { Parent }\end{array}$ & $\begin{array}{l}\text { Age of First } \\
\text { Symptoms } \\
\text { (y) }\end{array}$ & $\begin{array}{l}\text { Present } \\
\text { age }(y)\end{array}$ & $\begin{array}{l}\text { Age of } \\
\text { Diagnosis } \\
\text { (y) }\end{array}$ & DNA & MDC & $\begin{array}{l}\text { HD } \\
\text { Expert } \\
\text { Care }\end{array}$ & Diagnosis \\
\hline Anna & daughter & $\mathrm{F}^{+}$ & $6-7$ & 14 & 10 & yes & yes & Yes & $\begin{array}{l}\text { HD expert } \\
\text { neurologist }\end{array}$ \\
\hline Beatrice & Son & $\mathrm{F}$ & 6 & $16+$ & 9 & no & yes & Yes & $\begin{array}{l}\text { HD expert } \\
\text { Neurologist }\end{array}$ \\
\hline Clara & Son & $\mathrm{F}^{\dagger}$ & $12-19$ & 38 & 28 & yes & no & Yes & $\begin{array}{l}\text { clinical } \\
\text { genetics }\end{array}$ \\
\hline Debby & Son & $\mathrm{F}^{\dagger}$ & 5 & 18 & 13 & yes & yes & No & $\begin{array}{l}\text { child } \\
\text { neurologist }\end{array}$ \\
\hline Eric \& Ellen & Son & $\mathrm{M}+$ & $14-15$ & $33+*$ & 24 & yes & no & Yes & $\begin{array}{l}\text { clinical } \\
\text { genetics }\end{array}$ \\
\hline Francine & stepdaughter & $\mathrm{M}+$ & 6 & 15 & 10 & yes & yes & Yes & $\begin{array}{l}\text { HD expert } \\
\text { Neurologist }\end{array}$ \\
\hline Geraldine A & daughter & $\mathrm{F}^{\dagger}$ & 10 & $28+*$ & 16 & yes & yes & Yes & $\begin{array}{l}\text { MD } \\
\text { neurologist }\end{array}$ \\
\hline Geraldine B & Son & $\mathrm{F}^{\dagger}$ & 12 & 28 & 19 & yes & no & No & $\begin{array}{l}\text { MD } \\
\text { neurologist }\end{array}$ \\
\hline Harry & Son & $\mathrm{M}+$ & 16 & $31^{\dagger}$ & 22 & yes & yes & No & $\begin{array}{l}\text { clinical } \\
\text { genetics }\end{array}$ \\
\hline
\end{tabular}

$\mathrm{F}=$ father; $\mathrm{M}=$ mother; + death; ${ }^{*}$ euthanasia; $\mathrm{MDC}=$ multidisciplinary care; $\mathrm{HD}=$ Huntington's disease; $M D=$ movement disorders. 
Ellen soon realized the behavioral changes were more likely to be caused by HD rather than puberty. Just like Francine, she is a stepmother. Their husbands both took a lot longer to realize something was wrong.

"It was the first thing I thought. I thought this isn't right. A normal student has the same grades throughout all their school years. Her father and grandmother thought it would be alright and that she was just emotional because her mother had just died." (Francine)

Just like the other parents, Francine's husband believed the death of his daughter's mother was the cause of emotional disruption rather than the start of JHD.

All parents indicated they thought the child's behavior was likely caused by the illness of the affected parent, regardless if they were still alive or already deceased. However, the stepmothers, Francine and Ellen, were convinced that it was symptoms and signs of HD.

Table 2. Diagnostic process by consult.

\begin{tabular}{|c|c|c|c|c|}
\hline Parent & 1st Consult & 2nd Consult & 3rd Consult & 4th Consult \\
\hline Anna & $\begin{array}{l}\text { Psychologist } \\
\text { neurological disorder }\end{array}$ & $\begin{array}{l}\text { Psychologist } \\
\text { ASD }\end{array}$ & $\begin{array}{l}\text { HD expert } \\
\text { HD }\end{array}$ & \\
\hline Beatrice & $\begin{array}{l}\text { physiotherapist/school } \\
\text { doctor } \\
\text { neurological disorder }\end{array}$ & $\begin{array}{l}\text { MHS } \\
\text { ASD }\end{array}$ & $\begin{array}{l}\text { neurologist/ } \\
\text { pediatrician } \\
\text { spasticity }\end{array}$ & $\begin{array}{l}\text { HD expert } \\
\text { HD }\end{array}$ \\
\hline Clara & $\begin{array}{l}\text { clinical genetics } \\
\text { HD }\end{array}$ & MHS & mental hospital & HD nursing home \\
\hline Debby & $\begin{array}{l}\text { psychologist } \\
\text { ADHD }\end{array}$ & $\begin{array}{l}\text { autism expert team } \\
\text { ASD }\end{array}$ & $\begin{array}{l}\text { Neurologist } \\
\text { HD }\end{array}$ & \\
\hline Eric & $\begin{array}{l}\text { clinical genetics } \\
\text { HD }\end{array}$ & neurologist & HD nursing home & \\
\hline Francine & $\begin{array}{l}\text { MHS } \\
\text { Unknown }\end{array}$ & $\begin{array}{l}\text { HD expert } \\
\text { HD }\end{array}$ & & \\
\hline Geraldine A & $\begin{array}{l}\text { Neurologist } \\
\text { HD }\end{array}$ & $\begin{array}{l}\text { HD expert } \\
\text { HD }\end{array}$ & & \\
\hline Geraldine B & $\begin{array}{l}\text { HD expert } \\
\text { ADD }\end{array}$ & $\begin{array}{l}\text { clinical genetics/ } \\
\text { neurologist HD }\end{array}$ & & \\
\hline Harry & $\begin{array}{l}\text { clinical genetics } \\
\text { unknown }\end{array}$ & assisted living & $\begin{array}{l}\text { HD nursing home } \\
\text { HD }\end{array}$ & \\
\hline
\end{tabular}

All referrals took place after a visit to the general practitioner. All HD experts are neurologists. Abbreviations: $\mathrm{HD}=$ Huntington's disease; $\mathrm{MHS}=$ mental health services; $\mathrm{ASD}=$ Autism Spectrum Disorder 


\section{The Role of the Different Health Care Professionals during the Diagnostic Process}

\section{Awareness of the Caregiver}

After the initial search for explanations, the parents gradually started realizing the signs were probably associated with HD. None of them formally knew about the juvenile onset of $\mathrm{HD}$ at the time. They usually consulted their GP for advice.

"Looking back, I think I knew she had Huntington's disease. I just didn't want to hear it, and when a GP tells you it isn't HD, that's simply what you want to hear. When the institute said it was autism, I thought that's just fine, even though I knew it wasn't. It's a very strange way to fool yourself, but you do it anyway." (Anna)

"We went to see our GP, who told us to buy some good shoes, start some therapies. So there was about 2 to 3 years between our first visit to the GP and the neurologist." (Geraldine)

When the thought of HD first crossed their minds, the parents felt anxious and unsure of what to do. They relied on the judgment of the health caregiver. Although most of the parents believed the physician misjudged the situation, they also admit they ignored their own suspicions that it could be JHD.

\section{Positive Support}

The parents did experience helpful support from health care professionals in their search for an answer to their child's problems. They mentioned health care professionals who took the problems seriously and/or who offered help and support, even though there was no diagnosis or a diagnosis other than JHD

"Even though they didn't make a diagnosis, that's different than the feeling of being supported. Sometimes doctors simply don't know what a patient is suffering from, but they do everything in their power to support you, psychologically as well as in other areas." (Anna)

"We started therapy for autism. I asked one of the physiotherapists if he knew what Huntington's disease was. He said he did, and he conducted several tests and put them on video to show a neurologist. After the summer holiday, he came back and said I was right, it was Huntington's disease." (Debby)

\section{Failure of Support}

Three children were first diagnosed as having autism or ADHD by several health care professionals, ranging from neurologists to psychologists.

"I remember that psychologist...Eventually, they had to make a diagnosis. She sat there with that green book on her lap, turning the pages back and forth. Finally, she said, well, we'll go with ADHD. I don't believe she was convinced at all." (Debby) 
"He started having behavioral problems and we went to see an HD expert neurologist. We already knew he had a 50\% chance of HD. But the neurologist ran some tests and said he thought it was a form of Attention Deficit Disorder. He really didn't see any signs of HD. We were told to come back if we started seeing any symptoms of HD." (Geraldine)

The children presented with behavioral changes, such as aggressive behavior, hyperactivity, or obsessive behavior. This led to misdiagnoses such as ADHD and autism. Professional help clearly failed in the period before diagnoses when parents were starting to experience problems with their child. The follow-up period was too short or was lacking entirely. In four cases, the health professionals denied there was anything wrong at all. The parents had a clear need for support from a health care professional on a regular basis.

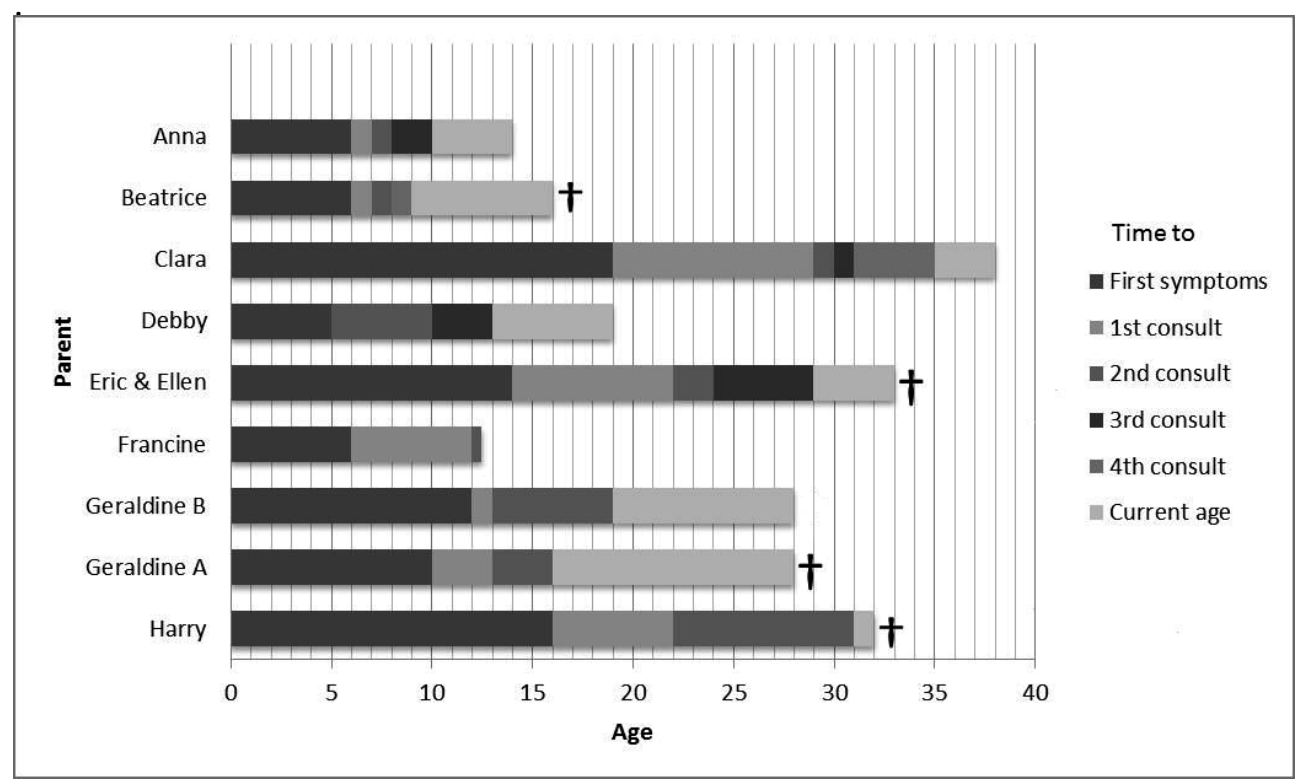

Figure 1. Diagnostic process timeline $\dagger=$ death.

\section{Experiences after the Diagnosis}

After the diagnosis had been made, most parents and their children received the support they needed. Three of the children received or are now receiving follow-up care from a neurologist with HD expertise. These children were 10 years or younger at the onset of HD. These parents are satisfied with the care provided.

Geraldine's two children received follow-up care from a neurologist with expertise in movement disorders, and she was very satisfied with the support they received. 
"We went there twice a year. Our son liked him because I liked him (the neurologist with HD expertise). And there was a special team just for him. That was fantastic. They did so much. Incredible, yes." (Beatrice)

Geraldine and Harry received long-term support from a social worker from one of the clinical genetic departments in the Netherlands. They were also very satisfied with the support from the social worker.

"I must say she was fantastic (social worker). She really took care of us. My daughter bonded with her. She guided us after the diagnosis. And she was the only one my son would speak to. She deserves a huge compliment." (Geraldine)

"She gave me advice. She gave me her mobile number. I once called her on a Sunday, and she rang me back within seconds. I could always tell her my story. Sometimes people complain about the care they get, but hats off for the care we got." (Harry)

It is comforting for parents to receive care from a caregiver who has knowledge of the disease. They feel their problems are taken seriously, and the caregiver is able to help with some of their issues. It is crucial for them that the caregiver knows the course of the disease and is able to support them in the long-term.

\section{The Need for Support}

It was clear to Clara, Eric, and Harry that their child suffered from JHD and they did not feel the need for a formal clinical diagnosis. Their past experiences with caregivers regarding HD were either somewhat negative or they felt caregivers were not able to do anything that would contribute to their child's well-being.

"It was so obvious for us that it was HD, we didn't do anything with it. We went to our GP once, and he had to look it up in a book. And even neurologists don't know what to do with it. They say they know what HD is, but they don't." (Ellen and Eric)

"Well, how shall I put this? I don't know if I'm allowed to say this, but there's nothing a neurologist can do for him." (Harry)

It was clear to Clara that something was wrong or that their child probably suffered from HD, but apart from visits to their GP, she did not feel the need for a referral. She assumed diagnosis was made by DNA testing and "as that is not allowed before the age of 18", there was no use in visiting a specialist.

"In that period, I was aware there was something going on, and then I thought, what am I going to do about it? Because we can't get him tested; he needs to be 18 for that. In fact, nobody made the diagnosis, but for us, it was clear." (Clara)

Anna and Debby felt the need for a diagnosis, but no need for extra support from health care professionals when their child became ill. They explained that the problems at home with an ill or deceased spouse were so huge that there was no place for any kind of support 
at that time. However, in a later stage, they felt somewhat better and reported they would have liked some support.

"I didn't feel the need. My husband had just died, so there was so much else to deal with at that moment. Looking back, l'd just had time to get back on my feet again when the next thing bombarded us." (Anna)

Clara and Geraldine felt the need for support, but their children did not want medical care or HD expert care.

"The problem was she didn't want HD expert care. They offered us a case manager who came a little too late after we'd already figured it out. We arranged 95\% of the care ourselves because she wouldn't let us involve anyone else." (Geraldine)

As described before, many HD patients do not feel the need for support from caregivers or expert centers. However, the family can feel abandoned as they generally do feel the need for support. In their opinion, they could have received support or help even if their child did not want it.

\section{Which Elements of the Diagnostic Process should be Improved?}

Most parents said they felt there was no-one to listen to them and take them seriously. They would have also liked the health professionals to be upfront with them. Four parents visited several health care professionals who offered no follow-up visits, which they clearly would have appreciated.

"I wanted to hear it was nonsense, and he (the GP) told me it was. On the one hand, I was glad, but on the other, I think he should have done something with it, he should have kept an eye on it. Asked us to come in for a check-up a few months later to see how things were going." (Anna)

Even after the diagnosis, some parents did not receive the right support until a later stage of the disease when their child had already been admitted to a nursing home. Clara's son did not want support. However, she believes the health care professionals should have provided more assistance and listened to the parents.

"Well, look at when things get out of hand, and there are no care providers there. It's clear they (patients) don't want them there. They don't want others to see what happens. Take the parents apart, ask how they experience things, how they see things. And then afterward decide how to move on." (Clara)

Parents with an adolescent child with JHD often say their child does not want support from caregivers. This makes it difficult for parents to find long-term care and support. Denial of the disease and problems resulting from the disease are a huge problem in patients with HD. It sometimes takes a lot of patience to persuade HD patients they need long-term care. 
Debby was offered support, but at that time, just after the diagnosis was made, it was too much for her as well.

"We contacted a social worker from an HD expertise nursing home, but because we had already figured things out for ourselves, she couldn't add much. However, it would have been good to have a case manager. And for you to be offered a case manager several times instead of once. If they offer this in a very hectic period, it might be too much." (Debby)

Again, parents said they would have appreciated follow-up in time, even though it was not initially wanted or needed.

\section{What if the Diagnosis of JHD had been Made Earlier?}

Parents whose children received a diagnosis other than JHD felt they would have been able to treat their children differently with an earlier correct diagnosis. They would have paid more attention and would have had more patience with their child if they had known what was going on.

"I think he would have benefited from it. My husband had just died. Things just kept piling up and I paid less attention and certainly had less patience." (Debby)

"When you know something's wrong with your child, you approach it in a different way. I sometimes thought she was just lazy or didn't feel like doing things. I think it would have made a difference in how I approached her. I wouldn't have been so strict." (Anna)

Furthermore, if the diagnosis had been made earlier, proper medication would have been provided in cases of aggression or other behavioral problems.

"I think that if he'd had medication to suppress the aggression. That would have made life easier for him." (Clara)

Francine believes her stepdaughter would not have been so alone. Before the diagnosis, she went to a regular school. However, because of her changing behavior, she did not have many friends and was isolated.

"Maybe she wouldn't have been so alone and isolated from other children. She was so alone, that was incredibly sad. Of course, I don't know how she experienced it." (Francine)

All the interviewed parents believed an earlier diagnosis would have benefited their children. Especially in the different way they, as parents, would have approached their children. However, as mentioned before, some of the parents had difficulty acknowledging their child might have JHD. 


\begin{abstract}
"On the one side, it would have been better if the GP had taken the suspicions of the psychotherapist seriously. He could have sent her to a neurologist. That would have been a more logical decision than telling me not to worry. I suppose it's difficult for doctors to say or... it's logical really, in case of such a terrible disease and knowing a child has a 50\% chance, you would think they'd do something if there's any kind of neurological issue. On the other side, I don't know if I would have been able to handle it at the time." (Anna)
\end{abstract}

An earlier diagnosis may not always have contributed to their well-being as parents. They felt they would not have been able to cope with any more grief or problems than they already had at that time.

\title{
Discussion
}

Our study describes the experiences of parents who have cared for or are still caring for a child with JHD, in particular, in regard to the diagnostic process of JHD.

The parents described denial and, afterwards, being aware something was wrong with their child. This denial and awareness are clear phenomena mentioned in previous studies on JHD (13-16). The most commonly perceived reasons for delayed diagnosis reported in an Australian survey among parents of children living with rare diseases was the lack of knowledge among health professionals (18). In line with this, we found that the unawareness or lack of knowledge of this serious neurological disease among health care professionals led to a delay in diagnosis. Parents believe that careful listening, attention, and clinical follow up would have improved the diagnostic process.

However, we are the first to report that, for some parents, a period of denial was helpful. They indicated that if the diagnosis JHD had been made shortly after the presentation of the first symptoms, this would have been too much for them. In a way, growing slowly towards the realization of their child being affected by JHD was helpful.

The fact that some of them were recently confronted with a sick or recently deceased spouse contributed to the denial. They would not have been able to manage an earlier diagnosis. In fact, the delay gave them the opportunity to process and face the problems with ill family members consecutively. Some parents visited a neurologist with expertise in $\mathrm{HD}$ and would have had the opportunity to discuss their suspicions with the neurologist. They chose not to do so.

So, it seems that shortening the diagnostic delay will not be helpful for every parent. For some children, the mixed feelings of their parents had probably added to a delay in diagnosis. The parents believed their child probably would have benefited from an earlier diagnosis as personalized care and pharmaceutical treatment could have been started earlier, and they would have been more patient with their child. 
All children with JHD either received or were offered multidisciplinary care after the diagnosis. However, some parents turned down the offer of help because they either had so many problems that any form of support would have been too much, or their past experience with their affected spouse led them to believe this support would not be of much value.

It seems difficult for clinicians with little or no experience with HD to diagnose JHD. However, HD specialists are still faced with the dilemma if non-specific signs symptoms are caused by JHD or a number of other explanations for the behavioral problems. Therefore, informing the HD community about the existence of JHD could help make parents more aware of the possible signs of JHD. This gives parents the opportunity to gain information if they wish to have it. Better information would also improve their understanding of the condition and of what to expect in the future, and it would probably help them better manage the challenges they face (15).

For clinicians specialized in HD, we recommend a careful follow-up if children from HD families present with non-specific symptoms such as decreased school performance, hyperactivity, and/or behavioral changes [4]. Children from HD families who present with such symptoms should be evaluated longitudinally, at least on an annual basis. Furthermore, we recommend being upfront about whether symptoms and signs might be due to JHD or not. On the other hand, we believe it is important to judge whether parents are able to cope with the diagnosis. Also, it is good to be aware that parents appreciate it when help and support are offered more than once, as the need for support can change during the course of follow-up.

We conclude that the delay in diagnosis is caused by the lack of knowledge among health care professionals on the one hand and the resistance of the parent on the other. In our opinion, this is a new and important finding that has not been described before. For health care professionals, diagnosing JHD is walking a tightrope. As for some parents, an earlier diagnosis would be too distressing; it is important to check whether parents are ready for the information. If not, keep in contact and try again at a later appointment. We hope these findings will be helpful for clinicians, caregivers, and the HD community in contributing to the well-being of these children and their parents. For professionals, our advice is to personalize their advice, in which a conscious doctor's delay is acceptable or even useful. 


\section{Reference List}

1. The Huntington's Disease Collaborative Research Group. A novel gene containing a trinucleotide repeat that is expanded and unstable on Huntington's disease chromosomes. Cell 1993, 72, 971-983.

2. van Dijk, J.G.; van der Velde, E.A.; Roos, R.A.; Bruyn, G.W. Juvenile Huntington disease. Hum. Genet. 1986, 73, 235-239.

3. Quarrell, O.W.J.; Nance, M.A.; Nopoulos, P.; Reilmann, R.; Oosterloo, M.; Tabrizi, S.J.; Furby, H.; Saft, C.; Roos, R.A.C.; Squitieri, F.; et al. Defining pediatric huntington disease: Time to abandon the term Juvenile Huntington Disease? Mov. Disord. Off. J. Mov. Disord. Soc. 2019, doi:10.1002/ mds.27640.

4. Nance, M.A. Genetic testing of children at risk for Huntington's disease. US Huntington Disease Genetic Testing Group. Neurology 1997, 49, 1048-1053.

5. Quarrell, O.; O'Donovan, K.L.; Bandmann, O.; Strong, M. The Prevalence of Juvenile Huntington's Disease: A Review of the Literature and Meta-Analysis. PLoS Curr. 2012, 4, doi:10.1371/4f8606b742ef3.

6. Andrew, S.E.; Goldberg, Y.P.; Kremer, B.; Telenius, H.; Theilmann, J.; Adam, S.; Starr, E.; Squitieri, F.; Lin, B.; Kalchman, M.A.; et al. The relationship between trinucleotide (CAG) repeat length and clinical features of Huntington's disease. Nat. Genet. 1993, 4, 398-403, doi:10.1038/ng0893-398.

7. Telenius, H.; Kremer, H.P.; Theilmann, J.; Andrew, S.E.; Almqvist, E.; Anvret, M.; Greenberg, C.; Greenberg, J.; Lucotte, G.; Squitieri, F.; et al. Molecular analysis of juvenile Huntington disease: The major influence on (CAG)n repeat length is the sex of the affected parent. Hum. Mol. Genet. 1993, 2, 1535-1540.

8. Koutsis, G.; Karadima, G.; Kladi, A.; Panas, M. The challenge of juvenile Huntington disease: To test or not to test. Neurology 2013, 80, 990-996, doi:10.1212/WNL.0b013e31828727fa.

9. Ribai, P.; Nguyen, K.; Hahn-Barma, V.; Gourfinkel-An, I.; Vidailhet, M.; Legout, A.; Dode, C.; Brice, A.; Durr, A. Psychiatric and cognitive difficulties as indicators of juvenile huntington disease onset in 29 patients. Arch. Neurol. 2007, 64, 813-819, doi:10.1001/archneur.64.6.813.

10. Nance, M.A.; Myers, R.H. Juvenile onset Huntington's disease--clinical and research perspectives. Ment. Retard. Dev. Disabil. Res. Rev. 2001, 7, 153-157, doi:10.1002/mrdd.1022.

11. Gonzalez-Alegre, P.; Afifi, A.K. Clinical characteristics of childhood-onset (juvenile) Huntington disease: Report of 12 patients and review of the literature. J. Child Neurol. 2006, 21, 223-229.

12. Quarrell, O.W.; Nance, M.A.; Nopoulos, P.; Paulsen, J.S.; Smith, J.A.; Squitieri, F. Managing juvenile Huntington's disease. Neurodegener. Dis. Manag. 2013, 3, doi:10.2217/nmt.13.18. 
13. Smith, J.A.; Brewer, H.M.; Eatough, V.; Stanley, C.A.; Glendinning, N.W.; Quarrell, O.W. The personal experience of juvenile Huntington's disease: An interpretative phenomenological analysis of parents' accounts of the primary features of a rare genetic condition. Clin. Genet. 2006, 69, 486496, doi:10.1111/j.1399-0004.2006.00624.x.

14. Brewer, H.M.; Smith, J.A.; Eatough, V.; Stanley, C.A.; Glendinning, N.W.; Quarrell, O.W. Caring for a child with Juvenile Huntington's Disease: Helpful and unhelpful support. J. Child. Health Care 2007, 11, 40-52, doi:10.1177/1367493507073060.

15. Brewer, H.M.; Eatough, V.; Smith, J.A.; Stanley, C.A.; Glendinning, N.W.; Quarrell, O.W. The impact of Juvenile Huntington's Disease on the family: The case of a rare childhood condition. J. Health Psychol. 2008, 13, 5-16, doi:10.1177/1359105307084307.

16. Eatough, V.; Santini, H.; Eiser, C.; Goller, M.L.; Krysa, W.; de, N.; Paduanello, M.; Petrollini, M.; Rakowicz, M.; Squitieri, F.; et al. The personal experience of parenting a child with juvenile Huntington's disease: Perceptions across Europe. Eur. J. Hum. Genet. 2013, 21, 1042-1048, doi:10.1038/ejhg.2013.15.

17. Smith, J.A. Qualitive Psychology; Sage: London, UK, 2003.

18. Zurynski, Y.; Deverell, M.; Dalkeith, T.; Johnson, S.; Christodoulou, J.; Leonard, H.; Elliott, E.J.; APSU Rare Diseases Impacts on Families Study group. Australian children living with rare diseases: Experiences of diagnosis and perceived consequences of diagnostic delays. Orphanet J. Rare Dis. 2017, 12, 68, doi:10.1186/s13023-017-0622-4. 



\section{CHAPTER 7}

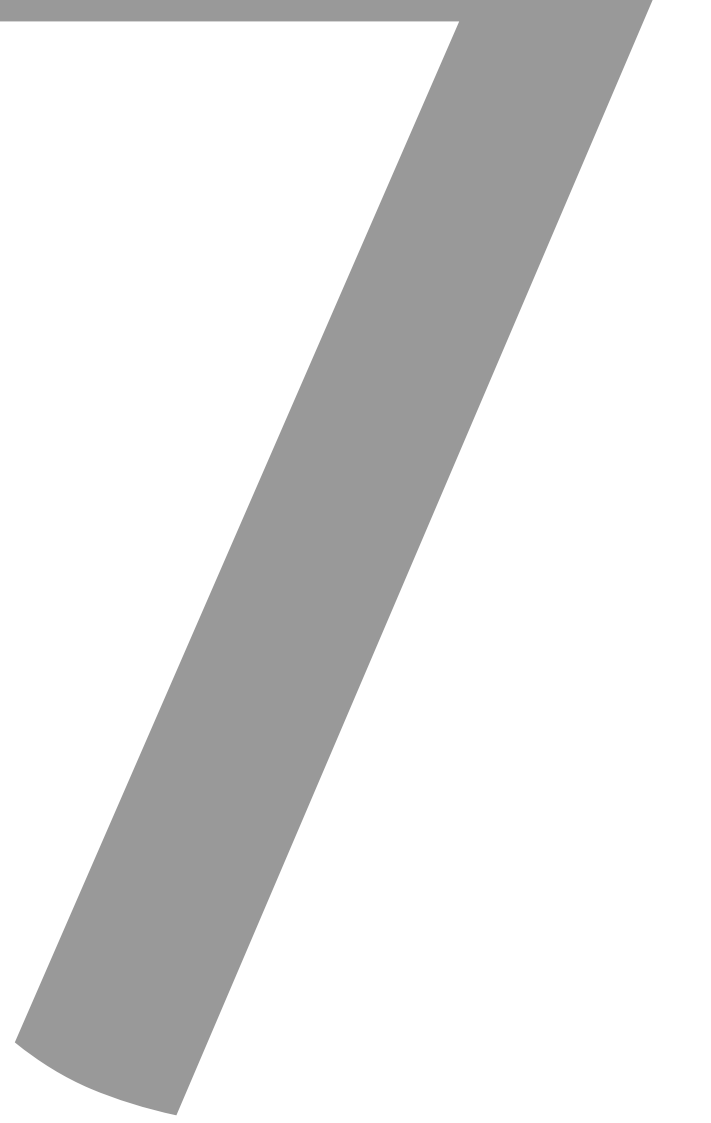




\section{General discussion}



The general aim of this thesis was to investigate the controversies and pitfalls in diagnosing Huntington's Disease (HD). Diagnosing HD in general and in several sub-groups in particular may be difficult and asks a lot of clinical experience. Decades have passed since molecular testing became possible for HD (1). Although the length of the CAG repeat determines maximal $70 \%$ of the variance in age at onset, the clinical diagnosis, i.e. the clinical onset of the disease is still challenging. An untimely diagnosis or misdiagnosis is not without harm and may cause a lot of distress in patients and families. Providing more and better insight in diagnosing and the diagnostic process in HD, might thus benefit the HD population in general.

In the previous chapters, several important pitfalls in diagnosing HD were addressed. In the following discussion, results are summarized and placed into perspective. Furthermore, opportunities for improvements and directives for further research are suggested.

\section{How adequate are current used rating scales to determine disease onset?}

$\mathrm{HD}$ is an adult-onset progressive neurodegenerative disorder. Premanifest Huntington's Disease Gene Expansion Carriers (HDGECs) do not become manifest over a short period of time. The conversion from premanifest to manifest is rather a gradual process. Previous studies showed that subtle motor, cognitive and behavioral changes are already present in premanifest HDGECs up to more than 10 years before estimated HD diagnosis (2-6). Therefore, estimation of disease-onset in HD is challenging. At what point do we decide a person to be manifest?

The diagnosis of HD in clinical practice and in research is made on the bases of the Diagnostic Confidence Level (DCL) of the motor score of the Unified Huntington's Disease Rating Scale (UHDRS) (7). The UHDRS comprises motor function, cognitive function, behavioral abnormalities, and functional capacity. The $D C L$ is a question regarding the certainty about the clinical diagnosis based on motor symptoms. Only a person with a DCL of 4 receives the formal diagnosis of manifest HD. This means he or she shows clinical motor signs not otherwise explained. The Movement Disorder Society Task Force on Huntington's Disease diagnostic categories suggested to redefine the diagnostic criteria of genetically confirmed HD into presymptomatic (no significant motor signs; DCL of 0 or 1 and no cognitive change); prodromal (DCL of 2 plus clear cognitive changes) and manifest HD (DCL of 3 plus minor neurocognitive disorder or DCL of 4). This also includes cognitive and behavioral changes and adds a prodromal stage. However, currently there are no clear cut-off points for the used motor, behavioral and cognitive scales. However, an UHDRS total motor score (TMS) $>5$ has been used as cut-off for disease onset in common practice and the TRACK-HD study.

Our data showed that $50 \%$ of the premanifest participants who converted to manifest already had a mean TMS $>5$ at baseline, but a DCL $<4$ (chapter 2). This means that they already had motor abnormalities not otherwise interpreted, but were still rated as premanifest. Furthermore, during longitudinally follow up converters received a DCL of 2 or 3 all the preceding years before conversion. This means the clinician had a $50-89 \%$ or $90-98 \%$ confidence the participant had signs of HD. However, they did not diagnose the participant 
with HD yet. If well trained HD specialists around the world are not able to adequately determine disease onset, the $D C L$ is not an accurate nor a reliable instrument to determine HD disease onset. We believe that clear cut-off scores for the currently used motor scale are necessary to determine disease onset. Furthermore, our data showed that the clinical diagnosis of HD in clinical practice and research is still merely made on the basis of motor signs (chapter 2). Behavioral and/or cognitive changes are known to frequently precede motor signs and symptoms of the disease. Behavioral changes may be non-specific and may be attributed to many other life event causing problems. However, cognitive changes, whether or not confirmed with neuropsychological examination, in otherwise healthy HDGECs are hard to explain other than caused by onset of disease. This means that cut-off scores for behavioral and cognitive scales are just as important as the UHDRS motor scale.

With clear cut-off scores for the different subscales, we would be able to define the premanifest, prodromal and manifest stage. In my opinion the DCL could still be used in the following way: $\mathrm{DCL} 0=$ normal $(\mathrm{TMS}=0), \mathrm{DCL} 1=$ prodromal $(\mathrm{TMS} \leq 5), \mathrm{DCL} 2=$ manifest $(\mathrm{TMS}$ $>5$ ). In this way the DCL would give an operational definition that guides the clinician which motor abnormalities are unequivocal signs of HD.

Although there is no cure for HD, determining accurate disease onset is very important, as currently several trials with disease modifying treatments have started. In order to ameliorate the outcome measures of these and future trials, a precise and accurate diseaseonset definition in patients is desirable. Furthermore, this will help to determine when to start these treatments.

\section{Diagnosing Huntington's disease}

Diagnosing HD, determining the clinical manifestation, the development of signs belonging to the spectrum of Huntington's disease in general is already problematic, and becomes even more difficult in the very young and the elderly. In order to determine if and when they develop symptoms and signs of the disease, we need to know more about these groups of patients.

\section{Huntington's disease and Intermediate Repeats}

CAG repeat elongation sizes between 27 and 35 are called intermediate. They are believed not to cause symptoms and signs of HD. However, case reports in the literature claim otherwise. A review of symptomatic case reported in the literature and intermediate allele (IA) carrier cases from the Dutch HD database resulted in the identification of four individuals with an intermediate repeat size and symptoms and signs comparable with those seen in HD (chapter 3). A recent study in a large European cohort of HD patients (REGISTRY) showed no significant differences between IA carriers and controls for total motor, behavioral and cognitive functioning. However, older participants with IAs had significant higher chorea scores compared to controls (8). There is also some evidence that carriers of an intermediate allele are at risk to develop behavioral problems (9). Taken together, there seems to be some clinical evidence that intermediate repeat sizes might cause symptoms and signs resembling HD. However, these individuals have only been followed over a short period of time. It is 
known that there is a significant inverse correlation between the size of the CAG repeat and the age of onset. We already know that persons with a reduced penetrance allele (repeat 36-39) are likely to have disease onset later in life. In our study we confirm that the number of persons with a CAG repeat in the reduced penetrance range is significantly higher in lateonset $\mathrm{HD}$ ( $\geq 60$ years) compared to those with an onset between 30 and 50 years (chapter 4 ).

If intermediate repeats can cause symptoms and signs of HD, they are likely to start at relatively old age, even later than in the persons with reduced penetrance repeat sizes. Therefore, thorough follow up of IA carriers for decades would be necessary to be able to answer the question if intermediate repeats can cause HD. This must be done, but is time consuming and will not give answers to our questions on the short term.

Concluding that intermediate alleles can cause HD, would have tremendous consequences. First of all, IAs are relatively common in the general population, with frequency estimates between 1 and $7 \%$ (10-14). Other reasons to be cautious with this conclusion, is the scarcity of convincing cases as there is no substantial follow up of patients and over generations, the lack of convincing biological evidence and many genes still to be discovered causing an HD like phenotype (chapter $\mathbf{3}$ ).

\section{Late-onset Huntington's Disease}

In general the common onset of HD is between 30 and 50 years age. For a substantial part of HDGECs symptoms and signs start after 60 years of age, so called late-onset HD. Lateonset HD is believed to be uncommon. HD in elderly people might easily be misjudged as senile chorea, especially without a clear family history of HD. However, late-onset HD is not so rare, as it appeared in more than $10 \%$ of a large database (Registry) population. Frequencies in literature vary between $4.4 \%$ and $25 \%$ in small cohorts (15-23) (chapter 4 ). To distinguish late-onset HD from other causes of late-onset chorea, it is important to have more information about the clinical course of the disease in elderly. Is the clinical course corresponding with that of patients with disease onset between 30 and 50 years (common onset)? In contrast to what has been suggested in precious studies, we found that disease progression is not milder in late-onset HD, although motor progression tends to be slower (chapter 4). Furthermore, late-onset HD patients present more frequently with motor symptoms and less frequently with behavioral problems compared to common-onset HD patients (chapter 4). Also, they have significantly more balance and gait problems as first symptom compared to common-onset patients (chapter 4). Sometimes the family history is seemingly negative, which might increase the chance of misdiagnosis in this group (chapter 4). Therefore, physicians should not hesitate to perform molecular testing in elderly with probable symptoms and or signs of HD who have no family history of HD. This might save a lot of time and costs in the work up of late-onset chorea. Especially balance and gait problems as first symptom combined with chorea or other movement disorder symptoms should arise their suspicion. 


\section{Juvenile Huntington's Disease}

A small group of patients develop HD in their childhood or adolescence. This so called juvenile form of Huntington's Disease (JHD) is defined as HD with an onset $<21$ years of age. However, the Working Group of the European Huntington's Disease Network proposed to use the term pediatric HD (PHD) for patients with symptoms and signs of HD of 18 years and younger (24). PHD may be confused with other disorders, often leading to a lengthy diagnostic process (25-28). The delay in diagnosis is caused by lack of knowledge among health care professionals on the one hand and resistance of the parents on the other hand (chapter 5) (29-32). Because PHD is rare and has different clinical manifestations compared to adult-onset HD (33), it is easily missed by health care professionals, especially if they have little or no experience with HD. Parents do not always recognize the symptoms and signs of the disease or they deny them (chapter 5). The available instruments (UHDRS) to assess symptoms of HD are not developed for children. Rasch Measurement Theory provides a way to assess multi-item latent scales, to ensure that it is valid to add the individual items together to form an overall total score. Rasch analysis showed that the Total Motor Score (TMS) of the UHRDS is not suitable for children (34). A new, more valid or adapted TMS for PHD would help clinicians to determine disease-onset in children. Another obstacle in timely diagnosis is that predictive testing in children from HD families is strongly discouraged (35). DNA analysis is only recommended in case there is clinical evidence of disease onset in children. The diagnosis of HD is a clinical one, and DNA analysis can only confirm the diagnosis. However, if there is no complete confidence that the symptoms and signs a child from an HD family shows are caused by HD, DNA analysis will not be helpful. In fact, it may be contra productive and the child may have unintentionally had predictive testing for a yet incurable disease. The reason we have to be cautious is, that we have to respect a person's right to decide if he or she wants to know or not if he or she will develop an incurable and deadly disease. In case clinical trials with disease modifying therapies will show to be effective on disease progression, predictive testing in children might become justified. In this way, we might be able to be more supportive in the guidance of children with pediatric onset $\mathrm{HD}$ and their caregivers.

\section{Personal wishes and patient experiences in the diagnostic process of Huntington's Disease}

As health care professionals we strive to avoid doctors delay and believe that a diagnosis in an early stage will benefit the patient. However, in case of Huntington's Disease this might be different. Till now it is still an incurable disease. Shared decision making is an upcoming trend in the treatment and guidance of patients. If we want to meet the needs of HD patients or those who are at risk, it is very important to know what those needs are. We can learn from the experiences of patients in the predictive and diagnostic trajectory.

\section{Lessons from the predictive testing trajectory}

In the predictive testing trajectory persons at risk for HD are counseled for presymptomatic DNA analysis. According to the international guidelines of the Huntington Association and the World Federation of Neurology Research Group on Huntington's Disease, it is important to differentiate whether a person at risk or already shows signs and symptoms of HD (36, 
37). However, neurological examination is not a requirement for participation in predictive testing. Previous literature states that in case the applicant clearly does not wish to consider that he is possibly affected and that he might perhaps need a neurological consultation, we should appreciate such as a psychological defense (38). Investigation of patients show most patients are positive about their visit to a neurologist in the predictive testing trajectory and would like to consult a neurologist before or after DNA analysis (chapter 6). In this retrospective study, HDGECs were more likely to prefer a consultation after DNA-analysis, whereas participants without a repeat expansion were more likely to prefer a consultation before DNA-analysis (chapter 6). As by definition we are not able to distinguish premanifest HDGECs from non-expansion carriers before predictive DNA-testing, offering a neurological consult in the premanifest testing procedure before DNA analysis might be beneficial for all (chapter 6).

To get acquainted with the future treating neurologist is one of the main reasons for at-risk persons and HDGECs to consult a neurologist (chapter 6). Consultation and follow-up by a neurologist with HD expertise may help to trace behavioral and cognitive changes in an early stage and treat them if possible. Furthermore, adequate and specialized care and assistance can be offered to patients and their families in this prodromal or early manifest stage of the disease. Patients reported mixed feelings about the neurological consultation. On the one hand they found it very stressful because they were afraid the neurological examination might show signs of HD. On the other hand they were relieved if the examination showed no signs of HD (chapter 6).

\section{Lessons from the diagnostic trajectory in PHD}

In PHD the diagnostic trajectory is difficult and often lengthy. Some parents report that a period of denial was helpful. They had to deal with too many life events at the same time and were not able to cope with their child being diagnosed with HD simultaneously (chapter 5). In a way, growing slowly towards realizing their child being affected with PHD was helpful. In fact, the delay gave them the opportunity to process and face the problems with ill family members consecutively. It seems that shortening the diagnostic delay in PHD will not always be helpful for every parent. For some children, the mixed feelings of their parents have probably added to a delay in diagnosis. Diagnosing PHD is walking a tightrope. One can easily assume that everyone wants a diagnosis as quickly as possible. It seems however that this is not a fact for everyone, and one should check whether parents are ready for the diagnosis. Furthermore, parents indicate that healthcare professionals should offer regularly follow up of their child when the diagnosis is still on hold/when postponing the diagnosis (chapter 5).

The results of our study may give healthcare professionals a better insight in the wishes of patients and caregivers in the diagnostic and follow-up trajectory of adult-onset and pediatric onset patients. 


\section{Future perspectives and opportunities for further research}

\section{Estimation of clinical disease onset}

As mentioned above, precise and accurate estimation of clinical disease onset in HD is very important to evaluate the effect of new interventions of possible disease modifying drugs. The development of new rating scales or adjustments to the already existing rating scales with clear cut-off points are important in this process.

Furthermore, with better and more objective research tools for motor symptoms we would probably be able to estimate clinical disease onset more accurately. Although the motor score of the UHDRS shows good interrater reliability it remains a subjective measurement tool (40). Also, Winder et al. showed that the dystonia items of the TMS have a very low interrater reliability and advise to remove these items from the TMS (39). TRACK-HD already uses a quantitative motor battery consisting of ambulatory- applied force-transducer-based assessments of variability in tapping with the index finger, grip force in a grasping and lifting task, force in a tongue protrusion force-matching task, and three-dimensional measures of involuntary choreatic movements $(4,40)$. These are a few examples of tools that are helpful in recording motor changes more objectively. However, these tools are not standard in clinical out-patient practice. Further research in collaboration with movement scientists would be a step towards better and more objective measurement of motor changes in HD. Developing three-dimensional measurements of involuntary and voluntary movements could be one example. Also, a Rasch analysis of the total UHDRS would help to find out which parts of the rating scale are useful and where adjustments are needed. The Rasch model is a unidimensional measurement model that provides a measurement template against which scales can be tested. The assumption that all items contribute independently to the total score is formally tested against the Rasch model, and any measurement anomalies within the item set are highlighted. The application of Rasch Measurement Theory provides a unified framework for several aspects of internal construct validity to be assessed (41). This has already been done for PHD and showed adjustments need to be made (42).

At this moment we still consider motor onset of HD the most reliable symptom to define age of onset. However, as we know, non-motor symptoms may precede motor onset many years and can be very invalidating for patients as well as their families. Neuropsychiatric symptoms in HDGECs are significantly higher in HDGECs compared to mutation-negative controls (40). However, we are still reluctant to define HDGECs with neuropsychiatric symptoms as having manifest HD. Therefore, cut-off points for behavioral (Problem Behavior Assessment) and cognitive assessment tools are just as important as motor assessment.

\section{The use of biomarkers in estimating disease onset}

Apart from defining clinical disease onset, it is just as important to define disease onset itself. After all, disease onset in HD starts long before the first clinical symptoms. Van der Plas et al. recently showed that asymptomatic children and adolescents carrying mutant HTT already have abnormal brain development (43).

The use of biomarkers is another way to help to define disease onset as early as possible. In this way we would be able to estimate disease onset before clinical signs arise. Biomarkers may 
already be present or show abnormalities long before the first clinical signs and symptoms of the disease. Previous studies already showed that not only subtle clinical changes, but also brain atrophy on 1,5 and 3 Tesla(T) MRI were present in premanifest HDGECs, up to more than 10 years from estimated HD diagnosis (2-6). Ultra-high field imaging of the brain in premanifest and manifest HD with 7T MRI has been performed in two small cohorts (9, 10). Doan et al. performed 7T and 3T MRI in seven premanifest, eight manifest HD patients and five healthy controls. Future research with ultra-high field MRI in a large cohort of premanifest and manifest patients might be able to help us define preclinical disease-onset even more precisely than with 1,5 or 3T. It may also be helpful in the evaluation of persons with an intermediate repeat.

Also the quantification of disease-associated proteins in cerebrospinal fluid (CSF) may be valuable as a diagnostic tool in HD. It has already been shown that it is possible to determine mutant Huntingtin ( $\mathrm{mHTT}$ ) in CSF. Furthermore, the $\mathrm{mHTT}$ concentration is higher in manifest than in premanifest HD participants (44). Also, neurofilament light protein in blood is shown to predict regional atrophy in HD (45). The HD Clarity study is a multi-site CSF collection initiative to facilitate therapeutic development for HD and will hopefully give more and better insight in which of these wet biomarkers are suitable for estimation of disease onset (http://hdclarity.net).

\section{Factors influencing onset of disease}

It is important to gain more and better insight in factors that in some way influence disease onset or age of onset. Are there ways to predict or determine if or when persons will develop HD? Especially for persons with an intermediate repeat size this is an important question. It still had not been determined whether intermediate alleles are able to cause HD. Postmortem neuropathological evaluation of IA carriers is scarce, but may be very useful. It is the golden standard to confirm cellular evidence of HD. Postmortem neuropathological evaluation of IA carriers with and without symptoms and signs resembling HD might be valuable to verify the diagnosis. Furthermore, it also gives the opportunity to search for somatic mosaicism. There is evidence the CAG repeat size in brain is longer than in blood $(46,47)$. However, this literature describes very small cohorts and shows conflicting results. Also, the investigated patients had a repeat expansion of 40 or more in blood. It might be that some of the persons with an intermediate repeat size in blood show repeat sizes of 40 or more in some brain regions, such as the basal ganglia. Unfortunately, the availability of HD brain tissue is scarce. A recent study demonstrates that HD blood exhibits dysregulation of the immune response and the gene expression of spinocerebellar ataxias that is similar to brain at a functional level, but not necessarily at the level of individual genes (48). Having a blood measure to monitor brain pathology might be an alternative way to gain more insight if intermediate repeats are pathogenic.

The CAG repeat length for late-onset HD is significantly lower than for common-onset HD. This is not a surprise, as we already know that CAG repeat length negatively correlates with age of onset and accounts for maximal $70 \%$ of the variation in age of onset (49). The length of the expanded CAG repeat explains much, but not all, of the variation in age at motor onset and there is emerging evidence that other genetic factors influence the age of onset either positively or negatively (50). A chromosome 15 locus displays two independent effects that 
accelerate or delay onset by 6.1 years and 1.4 years, respectively, whereas a chromosome 8 locus accelerates onset by 1.6 years. Further research on these genetic factors would be interesting, not only for future disease modifying treatments, but also as a future predictive clinical model in predictive counseling. If these influencing genetic factors become available in clinical practice, we will hopefully be able to develop a risk table for age of onset. If we would be able to define whether HDGECs are more likely to be affected in their 60 s than in their 40s, this would have tremendous consequences for their lives.

\section{Conclusions}

The aim of this thesis is to address diagnostic issues that HD specialists as well as other physicians face with HD diagnosis in their daily practice.

There is no operational definition that guides the clinician which motor abnormalities are unequivocal signs of HD. The DCL does not state what are "unequivocal" signs of HD. Hopefully, this thesis will encourage HD researchers to design clear cut-off scores for the different subscales and abandon the use of the $\mathrm{DCL}$ as this will ultimately improve defining premanifest, prodromal and manifest stages.

Furthermore, this thesis helps neurologists and movement disorder specialists to recognize late-onset HD. Patients in this subgroup have more gait and balance problems as first symptom and are more likely to have a negative family history. Also, it may help to guide clinicians how to approach a patient with a movement disorder and an intermediate repeat size.

Last, but not least it draws attention to the personal needs of patients and caregivers in the diagnostic as well as predictive process. After all, the main goal of being a clinician is to help a patient. Patients and caregivers may not always share our opinion on what we think is positive support. Caregivers of PHD patients teach us that doctors delay is accepted, sometimes even desirable or necessary. And it teaches us not only HDGECs are willing to consult a neurologist in the predictive trajectory, but also genotype negative persons feel the need to consult a neurologist. 


\section{Reference List}

1. A novel gene containing a trinucleotide repeat that is expanded and unstable on Huntington's disease chromosomes. The Huntington's Disease Collaborative Research Group. Cell. 1993;72(6):971-83.

2. Paulsen JS, Langbehn DR, Stout JC, Aylward E, Ross CA, Nance M, et al. Detection of Huntington's disease decades before diagnosis: the Predict-HD study. Journal of neurology, neurosurgery, and psychiatry. 2008;79(8):874-80.

3. Paulsen JS, Long JD, Ross CA, Harrington DL, Erwin CJ, Williams JK, et al. Prediction of manifest Huntington's disease with clinical and imaging measures: a prospective observational study. Lancet neurology. 2014;13(12):1193-201.

4. Tabrizi SJ, Langbehn DR, Leavitt BR, Roos RA, Durr A, Craufurd D, et al. Biological and clinical manifestations of Huntington's disease in the longitudinal TRACK-HD study: cross-sectional analysis of baseline data. Lancet Neurol. 2009;8(9):791-801.

5. Tabrizi SJ, Scahill RI, Durr A, Roos RA, Leavitt BR, Jones R, et al. Biological and clinical changes in premanifest and early stage Huntington's disease in the TRACK-HD study: the 12-month longitudinal analysis. Lancet Neurol. 2011;10(1):31-42.

6. Tabrizi SJ, Scahill RI, Owen G, Durr A, Leavitt BR, Roos RA, et al. Predictors of phenotypic progression and disease onset in premanifest and early-stage Huntington's disease in the TRACKHD study: analysis of 36-month observational data. Lancet Neurol. 2013;12(7):637-49.

7. Unified Huntington's Disease Rating Scale: reliability and consistency. Huntington Study Group. Movement disorders : official journal of the Movement Disorder Society. 1996;11(2):136-42.

8. Cubo E, Ramos-Arroyo MA, Martinez-Horta S, Martinez-Descalls A, Calvo S, Gil-Polo C, et al. Clinical manifestations of intermediate allele carriers in Huntington disease. Neurology. 2016;87(6):571-8.

9. Killoran A, Biglan KM, Jankovic J, Eberly S, Kayson E, Oakes D, et al. Characterization of the Huntington intermediate CAG repeat expansion phenotype in PHAROS. Neurology. 2013;80(22):2022-7.

10. Semaka A, Kay C, Doty CN, Collins JA, Tam N, Hayden MR. High frequency of intermediate alleles on Huntington disease-associated haplotypes in British Columbia's general population. Am J Med Genet B Neuropsychiatr Genet. 2013;162B(8):864-71.

11. Semaka A, Creighton S, Warby S, Hayden MR. Predictive testing for Huntington disease: interpretation and significance of intermediate alleles. Clinical genetics. 2006;70(4):283-94.

12. Ha AD, Jankovic J. Exploring the correlates of intermediate CAG repeats in Huntington disease. Postgraduate medicine. 2011;123(5):116-21. 
13. Maat-Kievit A, Losekoot $M$, Van Den Boer-Van Den Berg $H$, Van Ommen GJ, Niermeijer M, Breuning $M$, et al. New problems in testing for Huntington's disease: the issue of intermediate and reduced penetrance alleles. J Med Genet. 2001;38(4):E12.

14. Sequeiros J, Ramos EM, Cerqueira J, Costa MC, Sousa A, Pinto-Basto J, et al. Large normal and reduced penetrance alleles in Huntington disease: instability in families and frequency at the laboratory, at the clinic and in the population. Clinical genetics. 2010;78(4):381-7.

15. Cornejo-Olivas MR, Inca-Martinez MA, Espinoza-Huertas K, Veliz-Otani D, Velit-Salazar MR, Marca $\mathrm{V}$, et al. Clinical and Molecular Features of Late Onset Huntington Disease in a Peruvian Cohort. Journal of Huntington's disease. 2015;4(1):99-105.

16. Sipila JOT, Kauko T, Paivarinta M, Majamaa K. Comparison of mid-age-onset and late-onset Huntington's disease in Finnish patients. J Neurol. 2017;264(10):2095-100.

17. Chaganti SS, McCusker EA, Loy CT. What do we know about Late Onset Huntington's Disease? Journal of Huntington's disease. 2017;6(2):95-103.

18. Koutsis G, Karadima G, Kladi A, Panas M. Late-onset Huntington's disease: diagnostic and prognostic considerations. Parkinsonism \& related disorders. 2014;20(7):726-30.

19. Alonso ME, Ochoa A, Boll MC, Sosa AL, Yescas P, Lopez M, et al. Clinical and genetic characteristics of Mexican Huntington's disease patients. Movement disorders : official journal of the Movement Disorder Society. 2009;24(13):2012-5.

20. Roos RA, Vegter-van der Vlis M, Hermans J, Elshove HM, Moll AC, van de Kamp JJ, et al. Age at onset in Huntington's disease: effect of line of inheritance and patient's sex. J Med Genet. 1991;28(8):515-9.

21. James CM, Houlihan GD, Snell RG, Cheadle JP, Harper PS. Late-onset Huntington's disease: a clinical and molecular study. Age and ageing. 1994;23(6):445-8.

22. Roos RA, Hermans J, Vegter-van der Vlis M, van Ommen GJ, Bruyn GW. Duration of illness in Huntington's disease is not related to age at onset. Journal of neurology, neurosurgery, and psychiatry. 1993;56(1):98-100.

23. Lipe $H$, Bird T. Late onset Huntington Disease: clinical and genetic characteristics of 34 cases. J Neurol Sci. 2009;276(1-2):159-62.

24. Quarrell OWJ, Nance MA, Nopoulos P, Reilmann R, Oosterloo M, Tabrizi SJ, et al. Defining pediatric huntington disease: Time to abandon the term Juvenile Huntington Disease? Movement disorders : official journal of the Movement Disorder Society. 2019.

25. Nance MA, Myers RH. Juvenile onset Huntington's disease--clinical and research perspectives. Mental retardation and developmental disabilities research reviews. 2001;7(3):153-7. 
26. Gonzalez-Alegre P, Afifi AK. Clinical characteristics of childhood-onset (juvenile) Huntington disease: report of 12 patients and review of the literature. Journal of child neurology. 2006;21(3):223-9.

27. Ribai P, Nguyen K, Hahn-Barma V, Gourfinkel-An I, Vidailhet M, Legout A, et al. Psychiatric and cognitive difficulties as indicators of juvenile huntington disease onset in 29 patients. Arch Neurol. 2007;64(6):813-9.

28. Koutsis $G$, Karadima G, Kladi A, Panas M. The challenge of juvenile Huntington disease: to test or not to test. Neurology. 2013;80(11):990-6.

29. Brewer HM, Eatough V, Smith JA, Stanley CA, Glendinning NW, Quarrell OW. The impact of Juvenile Huntington's Disease on the family: the case of a rare childhood condition. Journal of health psychology. 2008;13(1):5-16.

30. Brewer HM, Smith JA, Eatough V, Stanley CA, Glendinning NW, Quarrell OW. Caring for a child with Juvenile Huntington's Disease: helpful and unhelpful support. Journal of child health care : for professionals working with children in the hospital and community. 2007;11(1):40-52.

31. Smith JA, Brewer HM, Eatough V, Stanley CA, Glendinning NW, Quarrell OW. The personal experience of juvenile Huntington's disease: an interpretative phenomenological analysis of parents' accounts of the primary features of a rare genetic condition. Clinical genetics. 2006;69(6):486-96.

32. Eatough V, Santini H, Eiser C, Goller ML, Krysa W, de N, et al. The personal experience of parenting a child with juvenile Huntington's disease: perceptions across Europe. European journal of human genetics : EJHG. 2013;21(10):1042-8.

33. Fusilli C, Migliore S, Mazza T, Consoli F, De Luca A, Barbagallo G, et al. Biological and clinical manifestations of juvenile Huntington's disease: a retrospective analysis. Lancet neurology. 2018;17(11):986-93.

34. Horton MC, Nopoulos P, Nance M, Landwehrmyer GB, Barker RA, Squitieri F, et al. Assessment of the Performance of a Modified Motor Scale as Applied to Juvenile Onset Huntington's Disease. Journal of Huntington's disease. 2019.

35. Nance MA. Genetic testing of children at risk for Huntington's disease. US Huntington Disease Genetic Testing Group. Neurology. 1997;49(4):1048-53.

36. Guidelines for the molecular genetics predictive test in Huntington's disease. International Huntington Association (IHA) and the World Federation of Neurology (WFN) Research Group on Huntington's Chorea. Neurology. 1994;44(8):1533-6.

37. MacLeod R, Tibben A, Frontali M, Evers-Kiebooms G, Jones A, Martinez-Descales A, et al. Recommendations for the predictive genetic test in Huntington's disease. Clin Genet. 2013;83(3):221-31. 
38. Tibben A. Predictive testing for Huntington's disease. Brain research bulletin. 2007;72(2-3):165-71.

39. Winder JY, Roos RAC, Burgunder JM, Marinus J, Reilmann R. Interrater Reliability of the Unified Huntington's Disease Rating Scale-Total Motor Score Certification. Mov Disord Clin Pract. 2018;5(3):290-5.

40. Reilmann R, Kirsten F, Quinn L, Henningsen H, Marder K, Gordon AM. Objective assessment of progression in Huntington's disease: a 3-year follow-up study. Neurology. 2001;57(5):920-4.

41. Vanhoutte EK, Hermans MC, Faber CG, Gorson KC, Merkies IS, Thonnard JL, et al. Rasch-ionale for neurologists. J Peripher Nerv Syst. 2015;20(3):260-8.

42. Horton MC, Nopoulos P, Nance M, Landwehrmyer GB, Barker RA, Squitieri F, et al. Assessment of the Performance of a Modified Motor Scale as Applied to Juvenile Onset Huntington's Disease. Journal of Huntington's disease. 2019;8(2):181-93.

43. van der Plas E, Langbehn DR, Conrad AL, Koscik TR, Tereshchenko A, Epping EA, et al. Abnormal brain development in child and adolescent carriers of mutant huntingtin. Neurology. 2019.

44. Wild EJ, Boggio R, Langbehn D, Robertson N, Haider S, Miller JR, et al. Quantification of mutant huntingtin protein in cerebrospinal fluid from Huntington's disease patients. The Journal of clinical investigation. 2015;125(5):1979-86.

45. Johnson EB, Byrne LM, Gregory S, Rodrigues FB, Blennow K, Durr A, et al. Neurofilament light protein in blood predicts regional atrophy in Huntington disease. Neurology. 2018;90(8):e717-e23.

46. De Rooij KE, De Koning Gans PA, Roos RA, Van Ommen GJ, Den Dunnen JT. Somatic expansion of the (CAG)n repeat in Huntington disease brains. Human genetics. 1995;95(3):270-4.

47. Swami M, Hendricks AE, Gillis T, Massood T, Mysore J, Myers RH, et al. Somatic expansion of the Huntington's disease CAG repeat in the brain is associated with an earlier age of disease onset. Human molecular genetics. 2009;18(16):3039-47.

48. Mina E, van Roon-Mom W, Hettne K, van Zwet E, Goeman J, Neri C, et al. Common disease signatures from gene expression analysis in Huntington's disease human blood and brain. Orphanet journal of rare diseases. 2016;11(1):97.

49. Andrew SE, Goldberg YP, Kremer B, Telenius H, Theilmann J, Adam S, et al. The relationship between trinucleotide (CAG) repeat length and clinical features of Huntington's disease. Nat Genet. 1993;4(4):398-403.

50. Genetic Modifiers of Huntington's Disease C. Identification of Genetic Factors that Modify Clinical Onset of Huntington's Disease. Cell. 2015;162(3):516-26. 


Summary 

Huntington's disease (HD) is an autosomal dominant inherited disease characterized by unwanted movements, psychiatric disorders, and cognitive deterioration. It is a rare disorder with a prevalence of 5-10 per 100,000 in the Caucasian population. The clinical diagnosis of HD is generally based on the appearance of unequivocal motor signs with or without psychiatric or cognitive changes, a positive family history and/or DNA confirmation.

The mean age at onset is between 30 and 50 years. A small group of patients develop HD in their childhood or adolescence. This so called Pediatric Huntington's Disease (PHD) is extremely rare. Yet another group displays symptoms and signs after 60 years of age, the so called late-onset HD (LoHD).

The repeat length plays an important role in de age of onset. Persons with a repeat length of $<36$ will not develop the disease. In families with 'intermediate' repeat size (27-35) the repeat size has the potential to expand into the disease range within one or more generations. A CAG repeat of 36 to 39 might give reduced penetrance which means that the clinical symptoms are milder and/or symptoms start later in life or not at all. A CAG repeat size of 40 or more is invariably associated with HD.

In this thesis the pitfalls and controversies in diagnosing HD are appraised. The aim is to address the problems determining disease onset in HD (chapter 2), discuss the probability intermediate repeat carriers will develop HD signs (chapter 3 ), diagnosing pediatric and LoHD (chapter $\mathbf{4}$ and $\mathbf{6}$ ) and to evaluate the wishes of persons at risk regarding the diagnostic process in the genetic counseling phase (chapter 5 ).

In the first chapter (chapter 1) the clinical and genetic manifestations of HD, the history, etiology and pathology, differential diagnosis, treatment and future perspectives are described. In the final paragraph the aims of this thesis are presented.

In chapter 2 the accuracy of the estimation of disease onset according to the Diagnostic Confidence Level (DCL) is discussed. The clinical diagnosis of HD is predominantly made on characteristic motor signs, often with a positive family history and/or confirmed by DNA analysis. For clinical follow-up and research purposes the Unified Huntington's Disease Rating Scale (UHDRS) was designed. The UHDRS contains a motor (Total Motor Score, TMS), psychiatric, psychological, and functional part. Based on the motor signs a four-item assessment regarding the certainty about the clinical diagnosis was added: the Diagnostic Confidence Level ( $D C L)$. By definition in this scale only a person with a $D C L$ of 4 receives the formal diagnosis of manifest HD, meaning that the age of onset was determined. A DCL of 4 means that the motor abnormalities are unequivocal signs of HD ( $\geq 99 \%$ confidence of the rater) and not otherwise explained by another extrapyramidal movement disorder. However, several remarks can be made: the DCL 1) does not state which motor abnormalities are unequivocal signs of $\mathrm{HD}$ and 2) does not mention how many motor signs must be present. The diagnosis is made by clinical experience, currently there is no operational definition that guides the clinician. In other words there is no cut-off point for the TMS of the UHDRS. The TMS rates extrapyramidal motor abnormalities. This suggests that healthy persons, including premanifest persons, are supposed to have a TMS of 0 . Otherwise, this person should have a movement disorder other than HD. In the TRACK-HD study a defined cut-off TMS of 5 or less 
in the of the UHDRS, was chosen, indicating no substantial motor signs in premanifest gene carriers. This allows Huntington's Disease Gene Expansion Carriers (HDGECs) to have some motor abnormalities without being called manifest yet. However, this cut-off is not used in the current diagnostic criteria.

Data were obtained from the Enroll-HD Periodic Dataset 4 (PDS4). Premanifest participants who converted to manifest (converters) and non-converters were compared for baseline clinical symptoms, disease burden and DCL. Clinical symptoms and DCL were longitudinally displayed in converters. Of 3,731 eligible participants, 455 were converters and 3,276 non-converters. Baseline DCLs were significantly higher in converters compared to nonconverters. Also, the data revealed that $50 \%$ of the converters had a mean TMS $>5$ at baseline. Although, longitudinally the TMS fluctuates, it still remained $>5$ before disease onset. This means that at that point patients already have clear extrapyramidal motor abnormalities. Furthermore, converters had significantly more baseline clinical symptoms, and higher disease burden compared to non-converters.

In converters the $\mathrm{DCL}$ in the years previous to disease-onset did not score 0 , but remained between 2 and 3 . A DCL of 2 or 3 already gives a $50-98 \%$ confidence that abnormalities are likely signs of HD. This means the raters had $50-98 \%$ confidence the participant had signs and symptoms of HD up to 12 years before he rated the participant to be manifest. It is very unlikely that all participants remained premanifest for such a long time.

We conclude that estimating disease onset in HD remains very difficult even in premanifest patients who are followed annually by trained and skilled HD physicians. We conclude the $D C L$ is not an accurate and reliable instrument to determine HD disease onset. With numerous trials evaluating disease modifying therapies it is extremely important to develop more adequate diagnostic criteria, including non-motor symptoms. We believe it is time to define motor and non-motor disease onset more clearly. In order to do so, we need to use cut-off scores for the TMS, cognitive and behavioral tests of the UHDRS.

Chapter 3 presents a review of published case reports on HTT intermediate repeat sizes. Furthermore, it provides an overview of all cases with an intermediate sized CAG repeat (27-35 repeats) from persons who had undergone diagnostic DNA analysis for HD between January 2001 and December 2012 in the Laboratory for Diagnostic Genome Analysis (LDGA), department of Clinical Genetics (Leiden Medical University Center, the Netherlands). The literature review included patients with hyperkinesia in combination with cognitive decline that might point to HD and could not be explained by other known factors. Cases with a non-progressive chorea, structural basal ganglia lesions on MRI other than atrophy, a persistent focal or hemi chorea, and cases without cognitive deterioration as well as all cases using drugs known to induce chorea were excluded. The literature search identified six articles containing case reports of 10 patients with a clinical performance presuming Huntington's disease. Four of these patients had a clinical presentation of Huntington's disease and an intermediate allele according to our in- and exclusion criteria. Between 2001 and 2012, 1,690 patients were tested for HD in the Netherlands. One case out of 60 with an intermediate allele had a phenotype resembling HD, but had already been published in a case report of the reviewed literature. We are reluctant to conclude to a causal relationship 
between intermediate alleles and signs and symptoms resembling HD as there are several factors, such as recently discovered genetic causes for HD like phenotypes, that have to be taken into account before a definite conclusion can be reached. Therefore, further research is needed.

Chapter 4 provides an overview of clinical and genetic manifestations in LoHD compared to common-onset HD patients (30-50 years of age). Data were obtained from patients enrolled in the European Huntington's Disease Registry Database of the European Huntington's Disease Network (EHDN-Registry) between 2004 to 2016. The onset of disease was estimated by the clinician, family members and participants themselves. LoHD participants were compared to common-onset on first motor, cognitive, and behavioral symptoms, as well as disease progression and total function score. 9,970 participants were included in the EHDN Registry. Of 6,007 eligible participants, 687 patients have an estimated age of onset $>59$ years (11.4\%). Furthermore, the results showed that LoHD patients present more frequently with gait and balance problems as first symptom compared to common-onset patients. Disease progression is not milder compared to common-onset HD patients, apart from motor progression. Repeat size in the LoHD group is significantly lower than in the common-onset group and contained significant more repeat sizes in the reduced penetrance range (36-39). The family history is likely to be negative, which might make diagnosing HD more difficult in this population.

Chapter 5 provides an overview of the experiences of Dutch at risk persons for HD, opting for predictive testing, in consulting a neurologist before or after DNA-analysis. The international guidelines on Huntington's Disease recommend a neurological examination in the predictive testing trajectory. However, the experiences and personal wishes of persons at risk of Huntington's Disease regarding this topic have never been evaluated. Persons at risk of $H D$ in the Netherlands are usually seen by a clinical geneticist and are offered consultation by a neurologist before or after DNA-analysis. We investigated if and when the judgment of a neurologist is desirable. Persons who were counseled for predictive testing in four clinical genetics clinics in the Netherlands between 2017 and 2019 were retrospectively or prospectively asked to complete an online questionnaire. The questionnaire listed emerging topics like experiences with consultation by a neurologist and personal wishes. From 71 participants, 44 (62\%) participants visited a neurologist before or after DNA-analysis and $27(38 \%)$ did not visit a neurologist. The majority of the participants indicated their visit to a neurologist as positive. Thirty-two responders indicated consultation shortly after DNA-analysis (Desired After Group) and twenty-seven before DNA-analysis (Desired Before Group) as personal wish. The Desired Before group contained a significantly higher number of participants who actually consulted a neurologist before DNA-analysis compared to the Desired After Group. The Desired After Group contained a significantly higher number of HDGECs (repeat length >35) compared to the Desired Before Group. We conclude that participants are content with consultation before as well as after DNA-analysis. However, in hindsight, persons without the gene expansion still feel the need to get in touch with an HD specialist. Therefore, offering a consultation with a neurologist before DNA-analysis might be beneficial for all. 
In Chapter 6 the personal experiences of parents of a child with pediatric onset of HD (PHD) regarding the diagnostic process is described. In this study we used qualitative research methods, in-depth semi-structured interviews and interpretative phenomenological analysis (IPA). Eligible participants were parents and/or caregivers of (living or already deceased) PHD patients in the Netherlands. In this study PHD was defined according the former definitions of Juvenile HD: the onset of symptoms and signs of HD before the age of 21 years. Eight parents of nine patients were interviewed. They consulted up to 4 different health care professionals before the diagnosis was made. The mean age at diagnosis was 16 years with a range of 9 to 24 . In six cases ( 1 sib pair), the father was the affected parent and in three cases the mother. All but one of the affected parents were deceased at the time of the interview. Six of the nine children were still alive. Six children had or still received HD expert care, three from an HD expert neurologist and three in an HD nursing home. Six of the nine children were still alive. The diagnostic process lasted three to ten years. The parents described denial and with hindsight being aware something was wrong with their child. Parents believe that careful listening of the health care professional and follow up of their child would have improved the diagnostic process. Although they believe an earlier diagnosis would have benefited to their child's well-being, it may not always have contributed to their well-being as parents. They indicated that if the diagnosis JHD had been made shortly after presentation of the first symptoms, this would have been too stressful. In a way, a prolonged diagnostic process, growing slowly towards the realization of their child being affected with JHD, was helpful.

A reflection of all study results is provided in chapter 7 . Outcome data are placed into perspective and additional opportunities for future research are discussed. 
Samenvatting 

De ziekte van Huntington (HD) is een autosomale dominante aandoening die gekarakteriseerd wordt door ongewilde bewegingen, psychiatrische en cognitieve stoornissen. Het is een zeldzame ziekte met een prevalentie van 5-10 per 100.000 in de Kaukasische bevolking. De klinische diagnose wordt in het algemeen gesteld op basis van eenduidige motorische kenmerken passend bij de ziekte van Huntington, met of zonder psychiatrische of cognitieve veranderingen, een positieve familie anamnese al dan niet met DNA-onderzoek bevestigd. De meeste patiënten ontwikkelen symptomen tussen hun $30^{\mathrm{e}}$ en $50^{\mathrm{e}}$ levensjaar. Een kleine groep krijgt de ziekte op de kinderleeftijd of tijdens de adolescentie. Deze Pediatrische Huntington (PHD) is extreem zeldzaam. Nog een andere groep wordt juist op oudere leeftijd ziek, boven het $60^{\mathrm{e}}$ levensjaar: de zogenaamde late-onset ziekte van Huntington (LoHD).

De repeatlengte speelt een belangrijke rol in de leeftijd waarop de ziekte ontstaat. Zo worden mensen met een repeatlengte $<36$ in principe niet ziek. Binnen families met een intermediaire repeat (27-35) kan in een volgende generatie de repeat wel verlengen en binnen de range vallen die de ziekte veroorzaakt. Een CAG-repeat van 36 tot 39 kan een gereduceerde penetrantie geven, wat betekent dat de klinische symptomen milder zijn en/ of symptomen later in het leven optreden of zelfs helemaal niet optreden. Een repeatlengte van 40 of meer is onomstotelijk geassocieerd met de ziekte van Huntington.

In dit proefschrift worden de valkuilen en controverses in het diagnosticeren van de ziekte van Huntington beschreven en onderzocht. Het doel van dit proefschrift is te onderzoeken welke problemen bij het vaststellen van het begin van HD optreden (hoofdstuk 2), de mogelijkheid te bediscussiëren dat dragers van een intermediaire repeat tekenen van HD ontwikkelen (hoofdstuk 3), het diagnosticeren van PHD en LoHD (hoofdstuk 4 en 6) en de wensen van risicodragers ten aanzien van het diagnostisch proces in de genetische counselingsfase (hoofdstuk 5).

In het eerste hoofdstuk (hoofdstuk 1) worden de klinische en genetische manifestaties van $\mathrm{HD}$, de geschiedenis, etiologie en pathologie, differentiële diagnose, behandeling en toekomstperspectieven beschreven. In de laatste paragraaf worden de doelen van dit proefschrift gepresenteerd.

In hoofdstuk 2 wordt bediscussieerd hoe precies het schatten van het begin van de ziekte is als de Diagnostic Confidence Level (DCL) wordt gebruikt. De klinische diagnose van HD wordt voornamelijk bepaald op grond van karakteristieke motorische kenmerken vaak samen met een positieve familie- anamnese en/of bevestiging middels DNA-diagnostiek. Voor klinische follow up en onderzoeksdoeleinden werd de Unified Huntington's Disease Rating Scale (UHDRS) ontworpen. De UHDRS bevat een motorisch (Total Motor Score (TMS)), psychiatrisch, psychologisch en functioneel deel. Gebaseerd op de motorische kenmerken is nog een beoordeling bestaande uit 4 onderdelen toegevoegd om de zekerheid van de klinische diagnose aan te kunnen geven: de Diagnostic Confidence Level (DCL). Volgens de definitie van deze schaal kan alleen een persoon met een $\mathrm{DCL}$ van 4 de formele diagnose van manifeste HD krijgen. Dit betekent dat de leeftijd waarop de ziekte ontstond, kan worden vastgesteld. Een $\mathrm{DCL}$ van 4 betekent dat de motorische afwijkingen bij deze persoon onomstotelijk tekenen van HD zijn ( $\geq 99 \%$ zekerheid van de beoordelaar) en niet door een andere bewegingsstoornis bepaald worden. Echter, hier 
kunnen enkele kanttekeningen bij geplaatst worden. Ten eerste beschrijft de DCL niet welke motorische afwijkingen onomstotelijke tekenen van HD zijn. Ten tweede benoemt het ook niet hoeveel van de afwijkingen aanwezig moeten zijn. De diagnose wordt gesteld op klinische gronden en ervaring, maar er is op dit moment geen duidelijke leidraad voor de clinicus. Met andere woorden, er is geen afkapwaarde voor de TMS van de UHDRS. De TMS beoordeelt extrapyramidale bewegingsstoornissen. Daarmee wordt gesuggereerd dat gezonde personen, waaronder premanifeste personen, geacht worden een TMS van 0 te hebben. In het TRACK-HD onderzoek werd gekozen voor een TMS afkapwaarde van 5 of minder. Beneden deze afkapwaarde werden motorische kenmerken in premanifeste gendragers niet als bijdragend geduid. Op deze manier kunnen personen met de aanleg voor HD (HDGECs) toch enkele motorische afwijkingen op de TMS hebben zonder dat zij manifest worden genoemd. Deze afkapwaarde is echter geen onderdeel van de huidige diagnostische criteria.

Data uit de Enroll-HD Periodic Dataset (PSD4) werden gebruikt voor de analyse. Premanifeste deelnemers die manifest werden tijdens deelname (converters) en non-converters werden met elkaar vergeleken op basis van klinische symptomen op baseline, ziekte ernst en DCL. Klinische symptomen en DCL werden longitudinaal weergegeven. Van 3731 geschikte deelnemers, waren 455 converters en 3276 non-converters. De baseline DCL's waren significant hoger in de converters vergeleken met de non-converters. Daarnaast had $50 \%$ van de converters een gemiddelde TMS boven de 5 voor het begin van de ziekte. Ook al fluctueerde de TMS longitudinaal, hij bleef steeds gemiddeld $>5$ op baseline. Dit betekent dat zij op dat moment duidelijke extrapyramidale motorische afwijkingen hadden. Verder hadden converters significant meer klinische symptomen op baseline en een hogere ziektelast score vergeleken met non-converters.

De DCL was in de jaren voorafgaand aan het begin van de ziekte altijd tussen de 2 en 3 in converters. Een DCL van 2 of 3 geeft aan dat de beoordelaar $50-98 \%$ zeker is dat de motorische afwijkingen tekenen van HD zijn. Dit betekent dat de beoordelaars al zelfs 12 jaar voordat ze de deelnemer als manifest diagnosticeerden, 50-98\% zeker waren dat de deelnemers tekenen van de ziekte van Huntington had. Het is erg onwaarschijnlijk dat alle deelnemers zo lang premanifest zijn gebleven.

Wij concluderen dat het erg moeilijk blijft om in te schatten wanneer premanifeste personen, die jaarlijks vervolgd worden door ervaren en getrainde HD artsen, daadwerkelijk ziek worden. We concluderen dat de DCL geen nauwkeurig en betrouwbaar instrument is om het begin van de ziekte mee vast te stellen. Met in het achterhoofd dat er meerdere studies zijn die het effect van ziekte modificerende therapieën testen, is het ontzettend belangrijk om adequate diagnostische criteria te ontwikkelen, vooral voor niet-motorische symptomen. Wij geloven dat het tijd is om de motorische en niet motorische start van de ziekte beter en duidelijker te definiëren. Daarvoor is het noodzakelijk om afkap waarden voor de TMS, cognitieve en gedragsmatige testen van de UHDRS te gebruiken.

Hoofdstuk 3 geeft een overzicht van alle gepubliceerde casuïstiek over patiënten met een intermediaire repeat lengte van het HTT gen. Daarnaast geeft het ook een overzicht van alle cases met een intermediaire CAG repeat (27-35 repeats) middels diagnostische DNA-analyse 
tussen januari 2001 en december 2012 uitgevoerd in het Laboratorium voor Diagnostische Genoom Analyse (LDGA) (afdeling Klinische Genetica van het Leids Universitair Medische Centrum). In het overzicht van de literatuur zijn patiënten geïncludeerd die hyperkinesie hadden in combinatie met cognitieve stoornissen die zouden kunnen passen bij HD en niet verklaard konden worden door andere bekende factoren. Cases met niet progressieve chorea, structurele letsels in de basale ganglia op MRI, persisterende focale of hemi-chorea, cases zonder cognitieve achteruitgang en alle cases die drugs gebruikten die chorea kunnen veroorzaken, werden geëxcludeerd. Er werden zes artikelen gevonden waarin 10 cases met een klinische presentatie gelijkend op Huntington beschreven zijn. Vier van deze patiënten hadden een klinische presentatie van HD én een intermediaire repeat lengte op basis van onze in- en exclusiecriteria. Tussen 2001 en 2012 werden 1690 patiënten getest op HD in Nederland. Eén casus van alle 60 patiënten met een intermediaire repeat lengte had een fenotype gelijkend op HD. Deze casus was ook al eerder gepubliceerd in de literatuur en beschreven in het literatuur overzicht. We zijn terughoudend om te concluderen dat er een relatie is tussen intermediaire repeats en symptomen die overeenkomen met die van HD. Er zijn meerdere factoren die daar een rol in spelen, zoals recent gevonden genetische oorzaken voor fenotypes van HD. Deze factoren moeten in acht worden genomen voordat definitief wordt geconcludeerd dat intermediaire repeats HD kunnen veroorzaken. Hier is uitgebreider onderzoek voor noodzakelijk.

Hoofdstuk 4 geeft een overzicht van klinische en genetische manifestaties van late-onset HD (LoHD) vergeleken met de gebruikelijke leeftijd waarop de ziekte begint (30-50 jaar). De data zijn verkregen van patiënten die deel hebben genomen aan de European Huntington's Disease Registry Database van het European Huntington's Disease Network (EHDN-Registry) tussen 2004 en 2016. Het begin van de ziekte werd geschat door de arts, familieleden en deelnemers zelf. LoHD patiënten werden vergeleken met patiënten die tussen de 30 en 50 jaar ziek zijn geworden, op het gebied van eerste motorische, cognitieve en gedragsmatige symptomen, ziekteprogressie en totale functie score. 9.970 deelnemers werden in de EHDN Registry geïncludeerd. Van 6.007 geschikte deelnemers hadden 687 patiënten een geschatte beginleeftijd > 59 jaar (11.4\%). Verder toonden de resultaten dat LoHD patiënten zich vaker presenteren met balansstoornissen als eerste symptoom van de ziekte in vergelijking met patiënten met een beginleeftijd van 30-50 jaar. De ziekteprogressie is niet milder vergeleken met de groep met een beginleeftijd van 30-50 jaar, behoudens op het gebied van motorische achteruitgang. De repeat lengte in de LoHD groep is significant lager dan die in de groep met beginleeftijd van 30-50 jaar en bevat significant meer repeat lengtes in de gereduceerde penetrantie categorie (36-39). De familiegeschiedenis is vaker negatief, wat het lastiger kan maken om HD in deze populatie te diagnosticeren.

Hoofdstuk 5 beschrijft de ervaringen van Nederlandse personen met een risico op HD naar aanleiding van het consulteren van een neuroloog voor of na DNA-analyse tijdens de counselingsfase van een eventuele voorspellende test. De internationale richtlijnen voor de ziekte van Huntington adviseren een neurologisch onderzoek in het traject van het voorspellend onderzoek. De ervaringen en persoonlijke wensen van mensen die een risico hebben op HD aangaande dit onderwerp zijn echter nooit onderzocht. Personen met een risico op HD worden in Nederland meestal gezien door een klinisch geneticus en krijgen het aanbod om een neuroloog te zien voor of na DNA-analyse. We onderzochten of en wanneer 
de beoordeling door een neuroloog gewenst is. Personen die in Nederland op 4 verschillende Klinische Genetica poliklinieken werden gecounseld voor voorspellende testonderzoek tussen 2017 en 2019 werden retrospectief of prospectief benaderd om een online vragenlijst in te vullen. Deze vragenlijst bevatte vragen over de ervaringen en persoonlijke wensen aangaande de consultatie door een neuroloog. Van 71 deelnemers bezochten 41 (62\%) een neuroloog voor of na DNA-analyse en 27 (38\%) bezocht geen neuroloog. De meerderheid van de deelnemers gaf aan dat zij het bezoek aan de neuroloog als positief had ervaren. Twee-en-dertig deelnemers gaven aan het liefst kort na de DNA-analyse een neuroloog te willen bezoeken (Desired After Groep). Zeven-en-twintig deelnemers hadden de wens om voor de DNA-analyse een neuroloog te bezoeken (Desired Before Groep). De Desired Before Groep bevatte een significant hoger aantal deelnemers die daadwerkelijk voor de DNA-analyse door een neuroloog waren gezien vergeleken met de Desired After Groep. De Desired After Groep bevatte een significant hoger aantal mensen die drager zijn van een verlengde repeat (repeat lengte $>35$ ) vergeleken met de Desired Before Groep. Wij concluderen dat deelnemers tevreden zijn met de consultatie zowel voor als na DNAanalyse. Echter, deelnemers zonder repeatverlenging gaven aan toch de behoefte te hebben aan contact met een in Huntington gespecialiseerde neuroloog. Daarom is het wellicht voor iedereen gunstig om de consultatie voor DNA-analyse aan te bieden.

In Hoofdstuk 6 worden de persoonlijke ervaringen van ouders met een kind met pediatrische onset van HD (PHD) ten aanzien van het diagnostisch proces beschreven. In deze studie wordt gebruik gemaakt van kwalitatieve onderzoeksmethoden, diepte semigestructureerde interviews en interpretatieve fenomenologische analyse (IPA). Deelnemers die in aanmerking kwamen waren ouders en/of zorgverleners van een (nog levende of overleden) patiënt met PHD in Nederland. In deze studie wordt PHD gedefinieerd volgens de voormalige definitie van juveniele HD: het begin van de symptomen van HD start voor het $21^{\mathrm{e}}$ levensjaar. Acht ouders van negen patiënten werden geïnterviewd. Zij consulteerden maximaal 4 zorgverleners voordat de diagnose werd gesteld. De gemiddelde leeftijd waarop de diagnose werd gesteld was 16 jaar met een spreiding van 9-24 jaar. In zes cases (1 broer en zus) was de vader de aangedane ouder en in drie cases de moeder. Alle aangedane ouders, behalve één, waren reeds overleden op het moment van het interview. Zes van de negen kinderen waren nog in leven. Het diagnostische proces duurde drie tot tien jaar. Zes kinderen ontvingen of hadden zorg van HD experts ontvangen, drie van een neuroloog met HD expertise en drie in een verpleeghuis met HD expertise. De ouders beschreven ontkenning en gaven aan dat achteraf ze er zich wel van bewust waren dat er iets mis was met hun kind. De ouders geloven dat zorgvuldig luisteren en het opvolgen van hun kind door een zorgprofessional het diagnostisch proces had verbeterd. Zij geloven dat ondanks dat een eerdere diagnose bij had gedragen aan het welzijn van hun kind, het voor hun eigen welzijn als ouders niet altijd bijdragend zou zijn geweest. Ze gaven aan dat als de diagnose kort na de uiting van de eerste symptomen had plaatsgevonden, dit te stressvol voor hen was geweest. Op een bepaalde manier was het langdurige diagnostische proces zinvol, waarbij zij langzaam naar het idee konden groeien dat hun kind PHD heeft.

Een reflectie op alle studieresultaten wordt in hoofdstuk 7 verschaft. De uitkomst gegevens worden daar in perspectief geplaatst en aanvullende mogelijkheden voor toekomstig onderzoek worden hier bediscussieerd. 


\section{Valorisation}

"Valorisation is the process of creating value from knowledge, by making this knowledge available and suitable for economic and social exploitation and to translate this knowledge into products, services, processes and new business" (1). With other words, a way in which one can express the importance of research by translating it into social, economic and financial value.

\section{Introduction}

Huntington's disease (HD) is a progressive, neurodegenerative disorder characterized by unwanted movements, psychiatric disorders, and cognitive deterioration. The disease is associated with a CAG repeat expansion in the Huntingtin (HTT) gene. Patients die in end stage disease approximately 20 years after the first onset of symptoms.

It is a rare disease with approximately 1,700 patients in the Netherlands. Because of the $50 \%$ chance of inheriting the disease if a parent has the disease, the estimation of persons at risk to develop HD is 6,000-9,000. Persons at risk can apply for predictive DNA testing to confirm or exclude if one is a Huntington's Disease Gene Expansion Carrier (HDGEC). HDGECs with 40 or more CAG repeats will develop disease nevertheless, 35 and below will not. Until now there is no cure or disease progression stabilising treatment.

The progressive and long-term nature of HD puts a substantial financial burden on patients, spouses and healthcare providers. Especially nursing home costs and job disqualification result in major financial burden. As would be expected with a degenerative condition, costs increase with disease severity. This thesis mainly focuses on the pitfalls in diagnosing HD for several groups of patients. For every group the final goal of the investigation was to undermine the pitfalls in diagnosis.

HD patients score statistically lower on health related Quality of Life (HrQoL) than mutationnegative controls across physical, emotional and social life domains (2). Reducing disease and psychological burden of patients and caregivers will eventually reduce healthcare costs as well. With disease progression the need for specialised care increases dramatically.

\section{Societal impact of this thesis}

In this thesis we investigated HD subgroups such as juvenile HD, late-onset, premanifest (carrier without symptoms) and carriers of an intermediate repeat. Furthermore the onset of disease was investigated.

The actual age of onset remains unclear in many patients. With numerous novel approaches for treatments in HD in development and several clinical trials that have been conducted 
and further trials under way, it is very important to have accurate diagnostic criteria for age of onset. If disease modifying treatments become available, accurate defining onset of disease will not only contribute to earlier treatment possibilities, but also to more precise monitoring of treatment effects.

The aim of this thesis is to undermine the pitfalls in diagnosing HD subgroups such as late-onset and pediatric HD, and persons with an intermediate repeat size. In this way we hope to diminish the psychological burden for patients and their caregivers, the chance of misdiagnosis and/or delay of diagnosis.

Carriers with an intermediate allele (IA) are expected not to develop HD, although some case reports claim otherwise. Concluding that IAs are able to cause HD would have tremendous consequences in diagnosing and pre-symptomatic counselling HD. Not only would diagnostic protocols in HD counselling have to be adapted, it would also put an enormous psychological burden for carriers of an IA. As we were not able to confirm this with our investigation, we suppose this prevents unnecessary psychological burden for the group of IA carriers.

Defining the characteristics of groups such as late-onset and pediatric-onset will help physicians specialised in HD to give customised care and provide individualised information. This might also prevent health care professionals from unnecessary costly investigations and/or treatments.

It is yet unknown if persons at risk feel relieved when examination by a neurologist shows no signs of disease in that stage. Psychological burden of not knowing and the anxiety of having symptoms might be reduced by visiting a neurologist in the premanifest stage and therefore have a positive impact on optimising care as well as effectiveness in care for HD patients.

\section{Conclusion}

Fulfilling the needs of HD patients regardless the disease stage reduces burden as well as consumption of care. This thesis can help neurologists, genetics and psychiatrists to understand the needs of different groups of HD patients. If this is accomplished, quality of life of HD patients and their caregivers and family members will increase and health related costs will likely decline.

All HD patients will need extensive care at some time during their disease. However, if we want care to be provided efficiently, it is necessary to customise care regarding the stage of disease and group of patients (juvenile, late onset, intermediate). In this way patients and caregivers will get the best individual care and the total healthcare costs will be reduced as much as possible.

Furthermore, accurately defining onset of disease will contribute to start treatment possibilities as early as possible. Treatment costs will rise, but care costs will be postponed. 


\section{Reference List}

1. Center MV. Available from: https://www.maastrichtuniversity.nl/about-um/units/maastrichtvalorisation-centre. cited 2017.

2. Read J, Jones R, Owen G, Leavitt BR, Coleman A, Roos RA, et al. Quality of life in Huntington's disease: a comparative study investigating the impact for those with pre-manifest and early manifest disease, and their partners. Journal of Huntington's disease. 2013;2(2):159-75. 


\section{Publications}

\section{This thesis}

-Oosterloo M, van Belzen MJ, Bijlsma EK, Roos RA. Is there convincing evidence that intermediate repeats in the HTT gene cause Huntington's Disease? J Huntingtons Dis. 2015;4(2):141-8

- Oosterloo M, Bijlsma EK, van Kuijk SM, Minkels F, de Die-Smulders CE, Roos RA et al. Clinical and genetic characteristics of late-onset Huntington's disease. Parkinsonism Relat Disord. 2019 apr; 16; 101-105.

- Oosterloo M, Bijlsma EK, de Die-Smulders C, Roos RA. Diagnosing juvenile Huntington's Disease: an explorative study among caregivers of affected children. Brain Sci 2020 Mar 7; 10(3)

- Oosterloo M, Bijlsma EK, Verschuuren-Bemelmans CC, Schouten MI, de Die-Smulders C, Roos RA. Predictive genetic testing in Huntington's disease: should a neurologist be involved? Eur J Hum Genet. 2020 May 13 doi: 10.1038/s41431-020-0633-9.

\section{Other publications}

- Oosterloo M, Lammers GJ, Overeem S, de Noord I, Kooij JJ. Possible confusion between primary hypersomnia and adult attention-deficit/hyperactivity disorder. Psychiatry Res. 2006 Aug 30;143(2-3):293-7.

- Burgel ND van, Oosterloo M, Kroon FP, van Dam AP. Severe course of Lyme neuroborreliosis in an HIV-1 positive patient; case report and review of the literature. BMC Neurol. 2010 Nov 30;10:117.

- Vlamings R, Zeef DH, Janssen ML, Oosterloo M, Schaper F, Jahanshahi A, Temel Y. - Lessons learned from the transgenic Huntington's disease rats. Neural Plast. 2012;2012:682712.

- Temel Y, Hescham SA, Jahanshahi A, Janssen ML, Tan SK, van Overbeeke JJ, Ackermans L, Oosterloo M, Duits A, Leentjens AF, Lim L. Neuromodulation in psychiatric disorders. Int Rev Neurobiol. 2012;107:283-314.

- Zeef DH, Jahanshahi A, Vlamings R, Casaca-Carreira J, Santegoeds RG, Janssen ML, Oosterloo M, Temel Y. An experimental model for Huntington's chorea? Behav Brain Res. 2014 Apr 1;262:31-4. 
- van Hooren MR, Baijens LW, Voskuilen S, Oosterloo M, Kremer B. Treatment effects for dysphagia in Parkinson's disease: a systematic review. Parkinsonism Relat Disord. 2014 Aug;20(8):800-7.

- Janssen ML, Duits AA, Turaihi AH, Ackermans L, Leentjens AF, Leentjes AF, van KranenMastenbroek V, Oosterloo M, Visser-Vandewalle V, Temel Y. Subthalamic nucleus highfrequency stimulation for advanced Parkinson's disease: motor and neuropsychological outcome after 10 years. Stereotact Funct Neurosurg. 2014;92(6):381-7.

- Semaka A, Kay C, Belfroid RD, Bijlsma EK, Losekoot M, van Langen IM, van Maarle MC, Oosterloo M, Hayden MR, van Belzen MJ. A new mutation for Huntington's disease following maternal transmission of an intermediate allele. Eur J Med Genet. 2015 Jan;58(1):28-30.

- Smeets AY, Ackermans L, Oosterloo M, Kuijf ML, van Overbeeke JJ, Visser-Vandewalle V, Temel Y. Modified cement-based fixation of the deep brain stimulation electrode. Stereotact Funct Neurosurg. 2015;93(1):67.

- Tonge M, Ackermans L, Kocabicak E, van Kranen-Mastenbroek V, Kuijf M, Oosterloo M, Kubben $\mathrm{P}$, Temel Y. A detailed analysis of intracerebral hemorrhages in DBS surgeries. Clin Neurol Neurosurg. 2015 Dec;139:183-7.

- Smeets AYJM, Duits AA, Plantinga BR, Leentjens AFG, Oosterloo M, Visser-Vandewalle V, Temel Y, Ackermans L. Deep brain stimulation of the internal globus pallidus in refractory Tourette syndrome. Clin Neurol Neurosurg. 2016 Mar;142:54-59.

- Oosterloo M, Van Belzen MJ, Bijlsma EK, Roos RA. Reply: Late-onset Huntington's disease with 29 CAG repeat expansion. J Neurol Sci. 2016 Sep 15;368:343.

- Gubler FS, Ackermans L, Kubben PL, Damci A, Kuijf ML, Oosterloo M, Vermeulen RJ, Hescham S, Kocabicak E, Kurt E, Temel Y. Infections in deep brain stimulation: shaving versus not shaving. Surg Neurol Int. 2017 Oct 10;8:249.

- Traschütz A, van Gaalen J, Oosterloo M, Vreeburg M, Kamsteeg EJ, Deininger N, Rieß O, Reimold M, Haack T, Schöls L, van de Warrenburg BP, Synofzik M. The movement disorder spectrum of SCA21 (ATX-TMEM240): 3 novel families and systematic review of the literature. Parkinsonism Relat Disord. 2019 May; 62; 215-220

- Oosterloo M, Craufurd D, Nijsten H, van Duijn EJ. Obsessive-compulsive and perseverative behaviors in Huntington's Disease. Huntingtons Dis. 2019; 8(1): 1-7

- Quarrell OWJ, Nance MA, Nopoulos P, Reilmann R, Oosterloo M, Tabrizi SJ, Furby H, Saft C, Roos RAC, Squitieri F, Landwehrmeyer GB, Burgunder JM, Juvenile Huntington Disease Working Group of the European Huntington Disease Network. Defining pediatric Huntington disease: time to abandon the term juvenile Huntington Disease? Mov. Disord. 2019 Apr; 34(4); 584-585 
- Geraerds VJ, Kuijf ML, van Hilten JJ, Marinus J, Oosterloo M, Contarino MF. Selecting candidates for Deep Brain Stimulation in Parkinson's disease: the role of patients' expectations. Parkinsonism Relat Disord. 2019 Sep; 66; 207-211

- Heffels JCF, Everink IHJ, Oosterloo M, Roos RAC, Schols JMGA. Measuring the quality of care in nursing home residents with early-onset neurodegenerative diseases: a scoping review. BMC Palliat Care. 2020 Feb 27;19(1):25.

- Wijnen IGM, Veenstra-Knol HE, Vansenne F, Gerkes EH, de Koning T, Vos YJ, Tijssen MAJ, Sival D, Darin N, Vanhoutte EK, Oosterloo M, Pennings M, van de Warrenburg BP, Kamsteeg EJ. De novo variants in CAMTA1 cause a syndrome variably associated with spasticity, ataxia, and intellectual disability. Eur J Hum Gen. 2020 Mar 


\section{Dankwoord}

Mijn grote dank gaat uit naar alle patiënten die hebben deelgenomen aan de verschillende onderzoeken, waaronder Registry en Enroll-HD. Mijn bijzondere dank gaat uit naar de ouders van kinderen met de pediatrische vorm van de ziekte van Huntington. Jullie verhalen hebben mij diep geraakt.

Professor Roos, beste Raymund, wij hebben inmiddels al in veel hoedanigheden samen gewerkt. Van secretaresse tot AIOS en nu als promovenda. Een lange weg waarin we elkaar steeds beter hebben leren kennen. Ik wil je ontzettend bedanken voor de vele kansen die je me hebt geboden om me te ontwikkelen binnen de Huntington. Maar bovenal stond je voor me klaar in zwaar weer en heb ik op je mogen vertrouwen op moeilijke momenten in mijn leven. Bedankt voor alles wat je me hebt geleerd, maar bovenal de goede band die we hebben.

Professor De Die-Smulders, beste Christine, bedankt voor de fijne begeleiding tijdens het schrijven van dit proefschrift. Als ik het even niet meer wist, was er altijd een plekje vrij in jouw agenda om me weer op weg te helpen. Jij vond dat ik nog best wat vaker hulp mocht zoeken, maar voor mij waren onze gesprekken net datgene wat ik nodig had om weer verder te kunnen. Daarnaast heb je me enorm geholpen en gesteund hebt bij het opzetten van ons Huntington Expertisecentrum. Bedankt voor alles en de superfijne samenwerking die we hopelijk voort kunnen blijven zetten!

Dr. Bijlsma, beste Emilia, bedankt voor jouw altijd kritische en positieve instelling tijdens het tot stand komen van mijn proefschrift. Jij zette altijd de puntjes op de i en hebt mij laten zien hoe een mooi artikel tot stand komt. Daarnaast heb je me de vrijheid geboden om mijn eigen onderzoeks-ideeën uit te werken en dat waardeer ik enorm!

Ik wil de beoordelingscommissie bestaande uit Prof. Dr. J. Schols, Prof. Dr. R. van Oostenbrugge, Prof. F. Verhey, Mw. Dr. J. Kievit en Dr. R. Reilmann hartelijk danken voor hun tijd en kritische beoordeling van mijn proefschrift.

Er zijn een aantal mensen zonder wie dit boekje er nu niet zou liggen. Floor Minkels, Sander van Kuijk en Bianca de Greef, bedankt voor alles wat jullie voor mij hebben gedaan. Floor, bedankt voor al het monnikenwerk in de database en het uittypen van enkele interviews. Wat hebben we gelachen toen jij erachter kwam dat je een cassettebandje toch echt kan omdraaien! Sander en Bianca, jullie zijn mijn statische steun en toeverlaat en ik ben jullie extreem dankbaar voor jullie geduld en vermogen die enorme database te doorgronden.

Werken aan dit proefschrift viel samen met mijn start als neuroloog die met ups en downs is verlopen. Ik wil dan ook al mijn collega neurologen heel erg bedanken voor het opvangen van taken tijdens deze afgelopen jaren. 
Professor van Oostenbrugge, beste Robert, mijn speciale dank aan jou dat je me de ruimte hebt gegeven dit proefschrift te voltooien. Ik ben blij dat ik van jou de mogelijkheid heb gekregen om in het MUMC Huntington zorg en onderzoek op te zetten.

Professor Temel, allerbeste Yasin, samen stonden wij aan de basis van een nieuw DBS team dat tot iets prachtigs is uitgegroeid. Toen ik de stap naar Huntington zette, heb jij mij gesteund en aangemoedigd. Ontzettend bedankt daarvoor!

Alle neurologen uit het LUMC, Rijnland ziekenhuis en Spaarne Ziekenhuis wil ik ontzettend bedanken voor de leuke, leerzame en vooral gedegen opleiding die ik van jullie heb gehad. Jullie hebben mij tot een kritische en pragmatische neuroloog gevormd.

Een expertise centrum en netwerk komen niet tot stand zonder de input en bereidwilligheid van vele anderen:

Rachel en Vivian, ontzettend bedankt voor wat jullie allemaal voor mij regelen. Maar bovenal bedankt voor het luisterend oor! Zonder jullie ben ik nergens.

Joëlle, Marijn, Christianne en Daisy bedankt voor jullie onmetelijk input aan Enroll-HD, het plannen en te woord staan van alle Huntington patiënten. Jullie zijn een top team!

Jolanda, ik ken niemand die zoveel boeken in korte tijd over Huntington heeft gelezen! Je hebt mij enorm geholpen bij het opstarten met Enroll-HD en bent nog steeds mijn rots in de branding op de poli!

Mirella, je hebt mij niet alleen geholpen met het opzetten van Huntington onderzoek, maar was ook degene die mij wegwijs maakte in het MUMC! Bedankt voor alle gezellige momenten als metgezel op congres!

Daisy, je verdient een ere plek in dit dankwoord. Soms vind je een collega met wie je kan lezen en schrijven. Two people, one mind. Ik ben onmetelijk blij met jou als coördinator van ons Huntington onderzoek en je niet aflatende enthousiasme! Op naar nog vele jaren!

Verder gaat mijn dank uit naar de fijne samenwerking met de Huntington Vereniging Nederland, Huntington Netwerk Nederland en the Dutch Huntington's Disease Research Network.

Lieve Maurits, ontzettend bedankt voor de prachtige artwork van dit boekje. Ik ben enorm trots op het resultaat! Geen "SNOC rulez" graffiti of voor mij onnavolgbare 'erwt' stripjes, maar next level art! Het feit dat we al sinds de middelbare school vrienden zijn, maakt het des te bijzonderder.

Lieve San, je bent al sinds dat we drie waren mijn vriendinnetje. Daar is in al die jaren niks aan veranderd. Bedankt voor al je steun in mooie en moeilijke tijden! Je bent er altijd voor mij. 
Janneke en Martijn, wat fantastisch dat jullie mij willen bijstaan op deze bijzondere dag. Bedankt voor jullie luisterend oor, aanmoedigingen als ik het even niet zag zitten, humor en gezellige avonden buiten werk, maar bovenal vriendschap.

Lieve Martijn, Broenie, wie had kunnen denken dat jij: de eerste AIOS die ik superviseerde, mijn collega en kamergenoot zou worden? Over de lamellen zijn we het helaas niet eens geworden, maar gelukkig is dat maar bijzaak in het leven! Ik weet dat ik altijd op je kan bouwen en vertrouwen.

Lieve Janneke en Peter, bedankt dat ik iedere zaterdag jullie 'gezinslid' mocht zijn tijdens de toch wat eenzame tijd van de corona crisis. Onze gezellige avonden bij de Brandweer, concerten en jaarlijkse afsluiter op Werchter waren goede momenten van afleiding van de eeuwigdurende gedachte aan dit proefschrift. Bedankt voor jullie steun en vriendschap!

Lieve mama, jij hebt me geleerd dat niets in het leven vanzelfsprekend is en als je iets wilt bereiken de drijfveer vanuit jezelf moet komen. Zonder jouw steun, wijze woorden en kritische noot was ik zover niet gekomen. Bedankt dat je er altijd voor mij bent.

Lieve papa, wat zou het mooi geweest zijn als je deze dag had kunnen meemaken. Ik had dit moment en vele anderen nog graag met je willen delen. Ik weet zeker dat je enorm trots zou zijn geweest. 


\section{Curriculum Vitae}

Mayke Oosterloo was born on July 31th 1980 in Leeuwarden, The Netherlands. She graduated for secondary school at the Stedelijk Gymnasium Leeuwarden in 1998. In that same year she started her medical training at the University of Leiden and consecutively obtained her "doctoraal" in 2002. Awaiting her internships, she worked as a secretary for the department of Neurology of the Leiden University Medical Center (LUMC) during several months. In 2004 she obtained her medical degree. That same year she started working as a resident neurology in the department of Neurology of the LUMC (head: Prof. Dr. R.A.C. Roos). During her training she worked at the department of neurology, Rijnland Hospital in Leiderdorp (head: Dr. J. Haan) for one year, at the department of Clinical Neurophysiology, LUMC and at the department of neurology, Spaarne Hospital, Hoofddorp (head: Prof. dr. I.S.J. Merkies). After finishing her residency in 2011, she started working as a neurologist, specialized in movement disorders, at the Maastricht University Medical Center (MUMC+) in Maastricht. Parallel to her clinical duties she worked on her PhD thesis. Currently she is specialized in Huntington's disease. In 2017 she attended a clinical fellowship psychiatry in Huntington's disease at Saint Mary Hospital (Central Manchester University Hospitals) in Manchester, United Kingdom under supervision of Dr. D. Craufurd.

Mayke Oosterloo werd op 31 juli 1980 geboren te Leeuwarden. In 1998 slaagde zij voor haar VWO diploma aan het Stedelijk Gymnasium te Leeuwarden. In datzelfde jaar startte zij met de studie geneeskunde aan de Universiteit Leiden waar zij in 2002 haar doctoraal examen behaalde. In afwachting van haar co-schappen werkte zij enkele maanden als secretaresse voor de afdeling Neurologie van het Leids Universitair Medisch Centrum (LUMC). In 2004 behaalde ze haar arts diploma en startte datzelfde jaar als arts assistent op de afdeling neurologie van het LUMC (Hoofd/ opleider: Prof. dr. R.A.C. Roos). Tijdens haar opleiding tot neuroloog werkte zij een jaar op de afdeling neurologie van het Rijnland ziekenhuis te Leiderdorp (opleider: Dr. J. Haan), een jaar op de afdeling klinische neurofysiologie van het LUMC (opleider: Prof. dr. J.G. van Dijk) en een half jaar op de afdeling neurologie van het Spaarne ziekenhuis te Hoofddorp (Opleider: Prof. dr. I.S.J. Merkies). Na het afronden van haar opleiding startte zij in 2011 als neuroloog in het Maastricht Universitair Medisch Centrum (MUMC+) met aandachtsgebied bewegingsstoornissen, waar zij naast de klinische taken haar promotieonderzoek verrichtte. Momenteel is zij gespecialiseerd in de ziekte van Huntington, waarvoor zij in 2017 een klinisch fellowship psychiatrie bij de ziekte van Huntington volgde aan Saint Mary Hospital (Central Manchester University Hospitals) te Manchester, Verenigd Koninkrijk onder begeleiding van Dr. D. Craufurd. 
